๑1999 Centro Internacional para Pesquisa Florestal (Cifor)

Elaborado por AFTERHOURS +62 218306819

Fotografia

Um orangotando jovem (Pongo pigmaeus), por um anônimo

Floresta de Eucalyptus paliformis, por John Turnbull

Uma aldeã em seu jardim, Tanah Merah, Indonésia, por Alain Compost

Árvore tropical em floração, Peru, por Andre Bartschi (WWF)

Tradução

Glaucia Barreto

Revisão

Tatiana Corrêa

Diagramação da versão em português

Israel Gutemberg

Os autores agradecem a contribuição do sr. Rahayu Koesnadi pelo controle de qualidade deste manual.

ISBN: 979-8764-25-0

\section{Publicado por}

Centro Internacional de Pesquisa Florestal (Cifor)

Caixa Postal: PO Box 6596 JKPWB, Jakarta 10065, Indonésia

Tel: +62-251-622 622 Fax: +62-251-622 100

Endereço eletrônico: cifor@cgiar.org

WWW: http://www.cgiar.org/cifor

Com o apoio da

Comissão Européia

Sob linha orçamentária B7-6201 relativa a "Florestas Tropicais"

Bruxelas, Bélgica

Deutsche Gesellschaft für Technische Zusammenarbeit (GTZ) GmbH

Eschborn, Alemanha

Agência Americana para o Desenvolvimento Internacional (USAID)

Washington D.C., USA 


\section{Guia de Pontuação e Análise para Avaliar o Bem-Estar Humano}

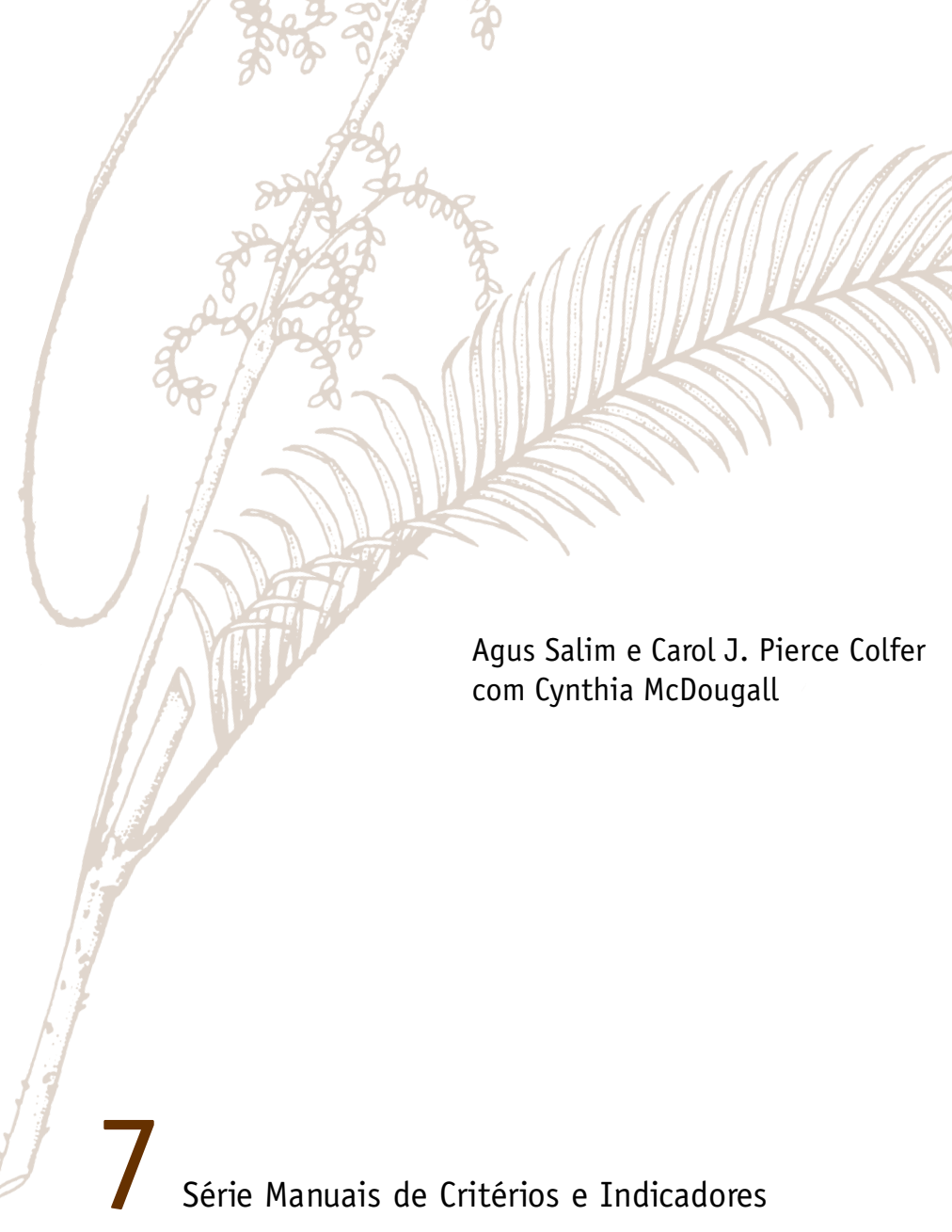




\section{Índice}

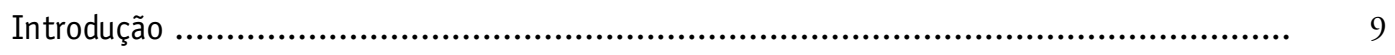

I - 0 Guia de Pontuação ........................................................................... 14

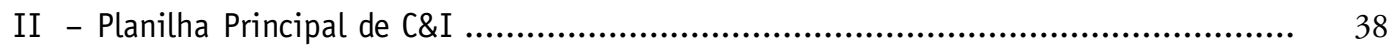

III - Guia de Análises Quantitativas ............................................................ 56

A - Análise dos resultados de um método de identificação de atores (CatPac) ................ 56

B - Análise dos métodos de avaliação da segurança de acesso aos recursos entre gerações . 59

$\mathrm{C}$ - Análise dos métodos de avaliação dos direitos e meios para manejar ......................... 77

$\mathrm{D}$ - Conclusão ............................................................................................. 87

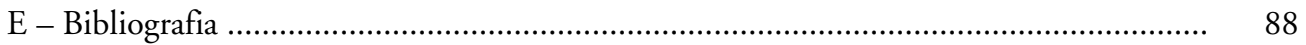

Apêndice A: Verificando os pressupostos da análise de regressão ....................................... 89

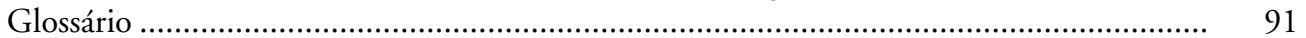

\section{Lista de Figuras}

Figura 1. Tela do computador mostrando parte de uma planilha principal de C\&I ................ 40

CatPac

Figura 2. Mapa cognitivo para as mulheres baka (Reserva Dja, República dos Camarões) .......

Matriz Histo-Ecológica

Figura 3. Formato da planilha para os dados histo-ecológicos

Figura 4. Escolhendo o submenu add-ins (dados histo-ecológicos)

60

Figura 5. Escolhendo o módulo suplementos (add-ins) especificado (dados histo-ecológicos) ...

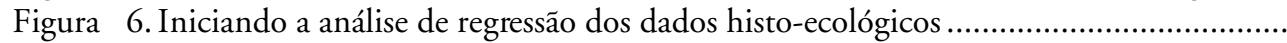

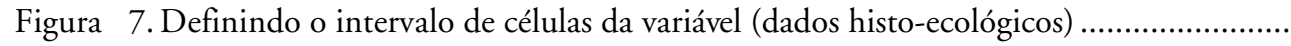

Figura 8. Produto da análise de regressão dos dados histo-ecológicos ........................................ 61

Acesso aos recursos por geração

Figura 9. Formato da planilha para os dados intergeracionais

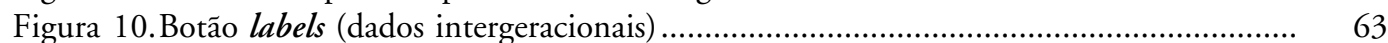

Figura 11.Definindo os rótulos (labels) por gênero nos dados intergeracionais ........................ 63

Figura 12.Escolhendo o tipo de diagrama de distribuição dos dados (boxplot) intergeracionais 64

Figura 13. Escolhendo as variáveis dos dados intergeracionais (para verificar a distribuição dos dados)

Figura 14.Diagrama de distribuição dos dados (boxplot) intergeracionais

Figura 15. Selecionando as variáveis intergeracionais ............................................................... 65

Figura 16. Tabela do programa SPSS descrevendo a distribuição do acesso aos recursos ao longo das geraçôes de acordo com todos os respondentes.

Figura 17.Assistente da tabela dinâmica (pivot table wizard) (dados intergeracionais) ............ 65

Figura 18. Construindo uma tabela dinâmica (pivot table) para a análise simples dos dados 
intergeracionais ( $1^{\mathrm{a}}$ etapa)

Figura 19. Construindo uma tabela dinâmica (pivot table) para análise simples dos dados intergeracionais $\left(2^{\mathrm{a}}\right.$ etapa)

Figura 20. Mudando a estatística predefinida nos dados intergeracionais

Figura 21. Tabela do Excel descrevendo o acesso aos recursos ao longo das gerações, de acordo com todos os respondentes

Figura 22.Selecionando as variáveis entre geraçôes (para resumir)

Figura 23. Selecionando a variável demogrática nos dados intergeracionais

Figura 24. Tabela do programa SPSS descrevendo a comparação da distribuição do acesso aos recursos ao longo das gerações com base na etnia

Figura 25.Selecionando o teste estatístico para verificar se há acordo nos dados intergeracionais

Figura 26.Selecionando as variáveis de teste (test variables) e a variável de agrupamento (grouping variable) (dados intergeracionais)

Figura 27.Definindo o intervalo para a variável de agrupamento (grouping variable) (demográfico) (dados intergeracionais)

Figura 28. Produto do teste estatístico para cada geração (dados intergeracionais)

Figura 29. Construindo uma tabela dinâmica (pivot table) para análise avançada dos dados intergeracionais

Figura 30. Tabela do Excel descrevendo a comparação da distribuição do acesso aos recursos ao longo das gerações com base na etnia

Divisão dos benefícios entre os atores

Figura 31. Formato das planilhas para os dados sobre divisão dos benefícios

Figura 32. Botão label (dados sobre benefícios florestais) ...

Figura 33. Definindo os rótulos (labels) para nível educacional nos dados referentes aos benefícios florestais

Figura 34.Escolhendo o tipo de diagrama de distribuição dos dados (boxplot) sobre benefícios florestais

Figura 35. Escolhendo as variáveis dos dados sobre benefícios florestais (para verificar a distribuição dos dados)

Figura 36.Diagrama de distribuição dos dados (boxplot) sobre benefícios florestais

Figura 37. Primeira etapa da seleção das variáveis dos dados sobre benefícios florestais (para resumir)

Figura 38. Segunda etapa da seleção das variáveis dos dados sobre benefícios florestais (para resumir)

Figura 39. Tabela do SPSS descrevendo a distribuição dos benefícios florestais de acordo com todos os respondentes

Figura 40. Assistente da tabela dinâmica (pivot table wizard) (dados sobre benefícios florestais) ...

Figura 41. Construindo uma tabela dinâmica (pivot table) para análise simples dos dados sobre benefícios florestais ( $1^{\text {a }}$ etapa)

Figura 42. Construındo uma tabela dınâmıca (pivot table) para análıse sımples dos dados sobre 
benefícios florestais ( $2^{\mathrm{a}}$ etapa)

Figura 43.Mudando a estatística predefinida nos dados sobre benefícios florestais

Figura 44. Tabela do Excel descrevendo a distribuição dos benefícios florestais de acordo com todos os respondentes

Figura 45. Selecionando os casos para o subgrupo específico nos dados sobre benefícios florestais

Figura 46. Filtrando os respondentes com nível educacional inferior nos dados sobre benefícios florestais

Figura 47. Resultado da seleção de casos (dados sobre benefícios florestais)

Figura 48. Distribuição dos benefícios entre os atores de acordo com os respondentes com nível educacional inferior

Figura 49. Comparação da distribuição dos benefícios florestais entre os atores com base no nível educacional

Figura 50. Filtrando os dados para o grupo kenyah e selecionando o teste estatístico (dados sobre benefícios florestais)

Figura 51.Selecionando as variáveis de teste (test variables) e a variável de agrupamento (grouping variable) (dados sobre benefícios florestais)

Figura 52. Definindo o intervalo para a variável de agrupamento (dados sobre benefícios florestais)

Figura 53.Produto do teste estatístico para o grupo kenyah com base no nível educacional (dados sobre benefícios florestais)

Figura 54. Construindo uma tabela dinâmica (pivot table) para análise avançada dos dados sobre benefícios florestais

Figura 55. Tabela do Excel descrevendo a comparação da distribuição dos benefícios florestais com base no nível educacional

Direitos para manejar entre os atores

Figura 56. Formato das planilhas para os dados sobre direitos para manejar.....

Figura 57. Botão labels (dados sobre direitos para manejar).

Figura 58. Definindo os rótulos para os dados sobre nível educacional (dados sobre direitos para manejar)

Figura 59. Escolhendo o tipo de diagrama de distribuição dos dados (boxplot) sobre direitos para manejar

Figura 60. Escolhendo as variáveis dos dados sobre direitos para manejar (para verificar a distribuição dos dados)

Figura 61.Diagrama de distribuição dos dados (boxplot) sobre direitos para manejar.....

Figura 62. Primeira etapa da seleção das variáveis dos dados sobre direitos para manejar (para resumir)

Figura 63. Segunda etapa da seleção das variáveis dos dados sobre direitos para manejar (para resumir)

Figura 64. Tabela do SPSS descrevendo a distribuição dos direitos para manejar entre os atores 
de acordo com todos os respondentes .

Figura 65. Assistente da tabela dinâmica (pivot table wizard) (dados sobre direitos para manejar)

Figura 66. Construindo uma tabela dinâmica (pivot table) para análise simples dos dados sobre direitos para manejar ( $1^{\text {a }}$ etapa)

Figura 67. Construindo uma tabela dinâmica (pivot table) para análise simples dos dados sobre direitos para maneịar ( $2^{\mathrm{a}}$ etapa)

Figura 68. Mudando a estatística predefinida nos dados sobre direitos para manejar.....

Figura 69. Tabela do Excel descrevendo a distribuição dos direitos para manejar entre os atores de acordo com todos os respondentes

Figura 70. Selecionando os casos para o subgrupo específico (dados sobre direitos para manejar)

Figura 71. Filtrando os respondentes com nível educacional inferior nos dados sobre direitos para manejar

Figura 72. Resultado da seleção de casos (dados sobre direitos para manejar)

Figura 73. Distribuição dos direitos para manejar entre os atores de acordo com os respondentes com nível educacional inferior....

Figura 74. Comparação da distribuição dos direitos para manejar entre os atores com base no nível educacional

Figura 75. Filtrando os dados para o grupo Punan (dados sobre direitos para manejar)...

Figura 76. Selecionando o teste estatístico para examinar se há acordo nos dados sobre direitos para maneiar

Figura 77.Selecionando as variáveis de teste (test variables) e a variável de agrupamento (grouping variable) (dados sobre direitos para manejar)

Figura 78. Definindo o intervalo para a variável de agrupamento (grouping variable) dados sobre direitos para manejar)

Figura 79.Produto do teste estatístico para o grupo punan com base no nível educacional (dados sobre direitos para manejar).....

Figura 80. Construindo uma tabela dinâmica (pivot table) para análise avançada dos dados sobre direitos para manejar

Figura 81. Tabela do Excel descrevendo a comparação da distribuição dos direitos para manejar com base no nível educacional

Verificando a análise de regressão

Figura 82. Alguns padrões de variâncias dos resíduos

Figura 83.Diagrama de probabilidade normal (normal probabilitv plot) do resíduo ............... 89

Figura 84.Diagramas mostram resíduos autocorrelacionados

\section{Lista de Tabelas}

Tabela 1. Listagem de casos de amostra, com pontuação associada, da Reserva de Vida Silvestre Danau Sentarum, 1996 ................................................................................... 40

Tabela 2. Pontuação dos C\&I sobre segurança de acesso aos recursos entre gerações .............. 53 


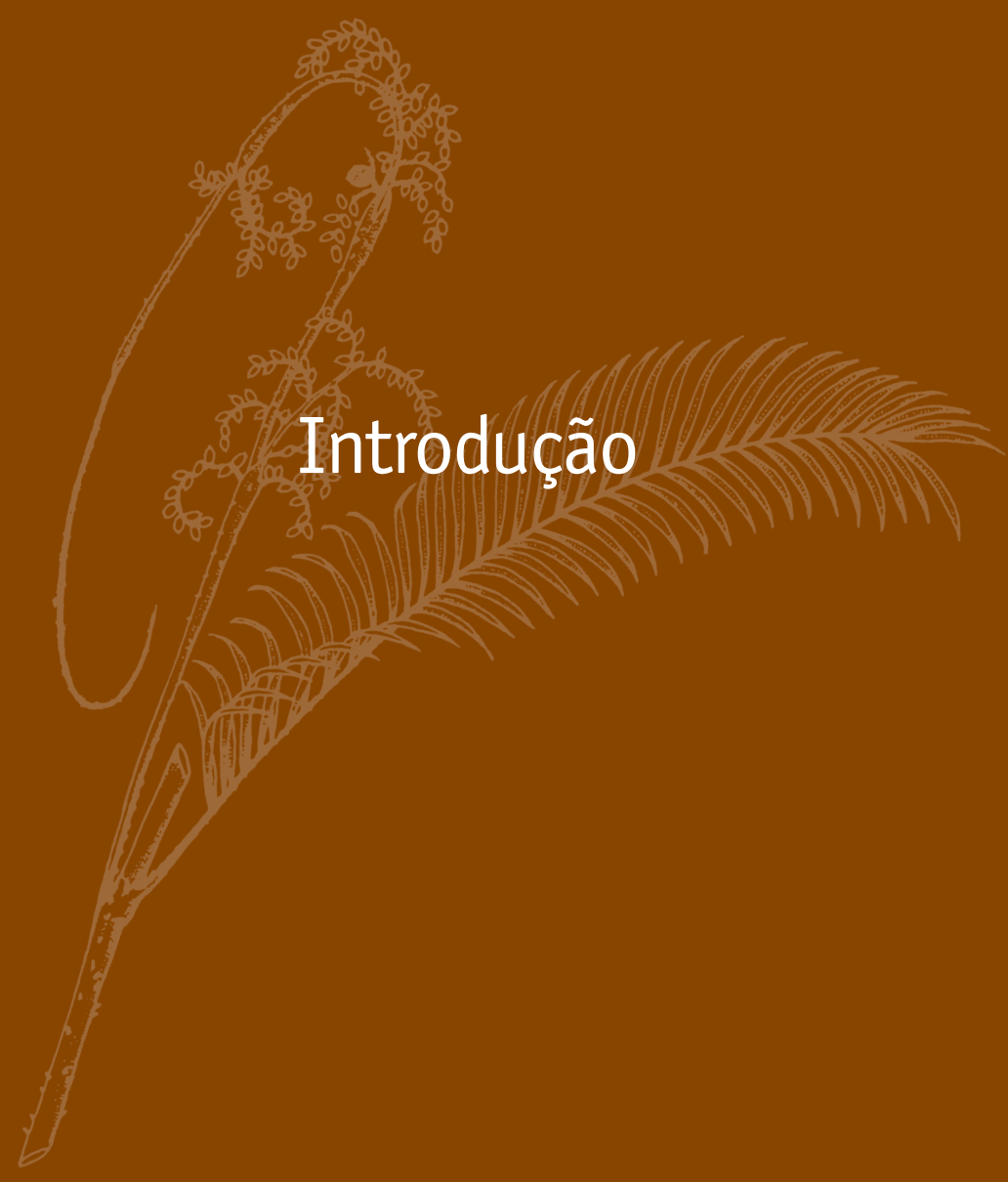


habilidade para avaliar o bem-estar humano tem sido recentemente reconhecida de modo crescente como um elemento importante na avaliação do manejo florestal sustentável em diversas partes do mundo. As dez ferramentas apresentadas na Série Manuais de C\&I do Cifor incluem um conjunto genérico de princípios, critérios e indicadores, bem como métodos relacionados. Esses métodos são elaborados para ajudar as pessoas na avaliação do manejo florestal, particularmente em florestas sob exploração ou ao seu redor onde pessoas vivem e trabalham. As avaliações incluem aspectos relativos ao manejo, meio ambiente e bem-estar humano. Os potenciais avaliadores podem ser gerentes de projetos, certificadores, agências financiadoras, órgãos do governo, pesquisadores, ONGs e comunidades.

Esta ferramenta, o Guia de Pontuação e Análise, ajuda o usuário do manual Modelo Genérico de CひrI e dos métodos oferecidos no manual Os Acessórios na pontuação do bem-estar humano das pessoas em uma dada floresta. Os critérios e indicadores para o bem-estar humano são classificados sob três princípios, com os seguintes pesos:

P1

0 manejo florestal mantém ou melhora o acesso eqüitativo aos recursos e benefícios econômicos entre gerações. Peso $1=40 \%$

Os direitos e meios dos atores interessados para manejar florestas de forma cooperativa e eqüitativa são reconhecidos. Peso $2=30 \%$

A saúde dos atores florestais e da floresta, bem como a integridade cultural são aceitáveis por todos os atores. Peso $3=30 \%$

Bem-estar humano $=[\mathrm{P} 1($ pontuação $) \times$ Peso 1 $]+[$ P2 (pontuação $) \times$ Peso 2] $+[$ P3 (pontuação $) \times$ Peso 3] 
A seção I é o guia que orienta o usuário na pontuação dos critérios e indicadores utilizados na avaliação do bem-estar humano. O sistema de pontuação é simples, com 1 representando as condições mais insustentáveis, e 10, as mais sustentáveis. Para ajudar os usuários a avaliarem as condições com as quais se defrontam, apresentamos exemplos e casos de situaçôes refletindo condiçôes de insustentabilidade $(1-3)$, níveis médios de sustentabilidade $(4-6)$ e níveis razoavelmente bons de sustentabilidade $(7-10)$.

A seção II orienta o usuário no processo de montagem das planilhas e no desenvolvimento da "planilha principal" de C\&I descritos nos manuais GBA e Os Acessórios. Em seguida, o usuário é guiado por uma série de etapas envolvendo:

1. Julgamento (muitas vezes qualitativo) da sustentabilidade de exemplos e material do caso;

2. Designação de pontuações para cada caso/exemplo (como evidências a respeito de um indicador particular);

3. Cálculo da média das pontuaçôes para todos os casos que fornecem evidências relativas aos indicadores para um critério particular;

4. Multiplicação dessas pontuações médias por um peso dentro dos critérios e indicadores sociais; e

5. Cálculo da média desses valores, determinados para cada critério, a fim de fornecer um valor para o princípio e, em última análise, para todo o conjunto de C\&I sociais.

Esse procedimento é simplesmente uma forma de sistematizar e registrar suas observações e julgamentos. Ele ajuda você a lembrar de suas observações, a concentrar-se nos C\&I de interesse e a identificar falhas em seu entendimento durante o processo de avaliação. Os valores que você confere ou as médias que você calcula não são "sagrados". Eles simplesmente refletem seu 
julgamento qualitativo, o qual tem como base a observação sistemática das condições humanas na área. Eles são valores relativos e não absolutos.

A seção III orienta os usuários na análise de dados dos métodos quantitativos propostos nos manuais GBA e Os Acessórios. Essa seção ajuda o avaliador a usar o computador e estatísticas, bem como facilita o desenvolvimento de tabelas e figuras descritivas simples. O manual focaliza a análise dos resultados dos seguintes métodos: CatPac, Matriz Histo-Ecológica, Acesso aos Recursos entre Gerações, Divisão dos Benefícios entre os Atores e Direitos para Manejar Florestas. Essa seção inclui desde instruções muito básicas para pessoas sem qualquer experiência com planilhas até análises estatísticas mais complexas que podem ser conduzidas se houver habilidade, tempo e interesse. 
CONJUNTO DOS “MELHORES PALPITES" DO CIFOR SOBRE PRINCÍPIOS, CRITÉRIOS E INDICADORES PARA 0 BEM-ESTAR HUMANO (BASEADO EM CINCO ANOS DE TESTES DE CAMPO EM DIVERSAS PARTES DO MUNDO)

\section{P1 0 manejo florestal mantém ou melhora 0 acesso equiitativo aos recursos e beneficios} econômicos entre gerações.

\section{C1.1 0 manejo local é efetivo no controle da manutenção e acesso aos recursos. ${ }^{1}$}

I1.1.1 A propriedade e os direitos de uso dos recursos (entre e intragerações) são claros e respeitam os direitos preexistentes.

I1.1.2 As regras e padrões de uso dos recursos são monitorados e efetivamente aplicados.

I1.1.3 Os meios para resolução de conflitos funcionam sem violência.

I1.1.4 0 acesso aos recursos florestais é considerado justo localmente.

I1.1.5 As pessoas locais se sentem seguras em relação ao acesso aos recursos.

C1.2 Os atores florestais possuem uma parte justa dos benefícios econômicos derivados do uso da floresta.

I1.2.1 Os mecanismos para a divisão dos benefícios são considerados justos pelas comunidades locais.

I1.2.2 As empresas madeireiras oferecem oportunidades de emprego e treinamento para as pessoas locais e aquelas que dependem da floresta.

I1.2.3 Os salários e outros benefícios seguem os padrões da Organização Nacional e ou Internacional do Trabalho (OIT).

I1.2.4 Os danos são compensados de forma justa.

I1.2.5 Os vários produtos florestais são usados de forma ótima e eqüitativa.

\section{C1.3 As pessoas associam o seu futuro e o de seus filhos ao manejo dos recursos florestais.}

I1.3.1 As pessoas investem em seu meio ambiente circundante (isto é, tempo, esforço, dinheiro).

I1.3.2 Os níveis de migração externa são baixos. ${ }^{2}$

I1.3.3 As pessoas reconhecem a necessidade de equilibrar o número de indivíduos com o uso dos recursos naturais.

I1.3.4 As crianças são educadas (formal e informalmente) para o manejo dos recursos naturais.

I1.3.5 A destruição dos recursos naturais pelas comunidades locais é rara.

I1.3.6 As pessoas mantêm vínculos espirituais ou emocionais com a terra.

1 Este critério está obviamente muito relacionado aos critérios que partem da perspectiva ecológica e formal do "manejo florestal".

2 Os indicadores 1.3 .2 e 3.1 .2 contêm uma contradição potencial. Os baixos níveis de migração externa (I1.3.2) indicam que as pessoas relacionam o seu futuro e o de seus filhos à manutenção da floresta; contudo, o reconhecimento da necessidade de equilibrar o número de pessoas com o uso dos recursos naturais (I3.1.2) pode levá-los a favorecer a migração externa. Essa contradição provavelmente ocorrerá quando as condições locais estiverem se deteriorando. 


\section{P2 Os direitos e meios dos atores interessados para manejar florestas de forma cooperativa e} eqüitativa são reconhecidos.

C2.1 Existem mecanismos efetivos para comunicação entre os atores no que diz respeito ao manejo florestal.

I2.1.1 > 50\% dos funcionários das empresas madeireiras e funcionários públicos do setor florestal falam um ou mais idiomas locais, ou $>50 \%$ das mulheres locais falam o idioma nacional.

I2.1.2 Os atores locais reúnem-se com freqüência satisfatória, representação da diversidade local e boa qualidade de interação.

I2.1.3 As contribuições de todos os atores são mutuamente respeitadas e valorizadas em um nível de satisfação geral.

C2.2 0s atores locais possuem conhecimento detalhado e recíproco sobre o uso dos recursos florestais (incluindo grupos de usuários e o papel dos gêneros), bem como sobre os planos de manejo florestal anteriores a sua implementação.

I2.2.1 Existem planos/mapas demonstrando a integração de usos pelos diferentes atores.

I2.2.2 Planos atualizados, estudos de diagnóstico e mapas estão amplamente disponíveis. Esses documentos descrevem os detalhes da exploração, tal como as áreas de extração e a construção de estradas, além de incluir aspectos temporais.

I2.2.3 Estudos de diagnóstico sobre os sistemas humanos locais estão disponíveis e são consultados.

I2.2.4 A equipe de manejo reconhece a legitimidade dos interesses e direitos dos outros atores.

I2.2.5 0 manejo dos Produtos Florestais Não-Madeireiros (PFNMs) reflete os interesses e os direitos dos atores locais.

C2.3 Existe acordo sobre os direitos e responsabilidades dos atores relevantes.

I2.3.1 0 nível de conflito é aceitável para os atores. 


\section{P3 A saúde dos atores florestais e da floresta, bem como a integridade cultural são aceitáveis por todos os atores.}

C3.1 Há um equilíbrio evidente entre as atividades humanas e as condições ambientais.

I3.1.1 As condições ambientais afetadas pelas atividades humanas estão estáveis ou melhorando.

I3.1.2 0 aumento da migração interna e ou da população natural está em harmonia com a manutenção da floresta.

\section{C3.2 A relação entre o manejo florestal e a saúde humana é reconhecida.}

I3.2.1 0s gerentes florestais cooperam com as autoridades de saúde pública no que diz respeito às doenças relacionadas ao manejo florestal.

I3.2.2 0 estado nutricional é adequado entre as populações locais (por exemplo, o crescimento infantil segue os padrões internacionais de altura e peso; os níveis de mortalidade infantil de crianças menores que 5 anos são baixos. ${ }^{3}$

I3.2.3 Empregadores nas áreas florestais seguem os padrões de trabalho e condições de segurança da Organização Internacional do Trabalho - OIT e responsabilizam-se pelos riscos florestais à saúde dos trabalhadores.

\section{C3.3 A relação entre a manutenção da floresta e a cultura humana é reconhecida como importante.}

I3.3.1 Os gerentes florestais compreendem as relações entre as culturas humanas relevantes e a floresta local.

I3.3.2 Os planos de manejo florestal consideram as questões culturais.

I3.3.3 Não há aumento significativo dos sinais de desintegração cultural.

30 fato de esse indicador não estar necessariamente relacionado ao seu critério é um exemplo das falhas neste terceiro princípio (ao contrário dos dois primeiros princípios) resultantes da falta de teste sistemático de campo. 


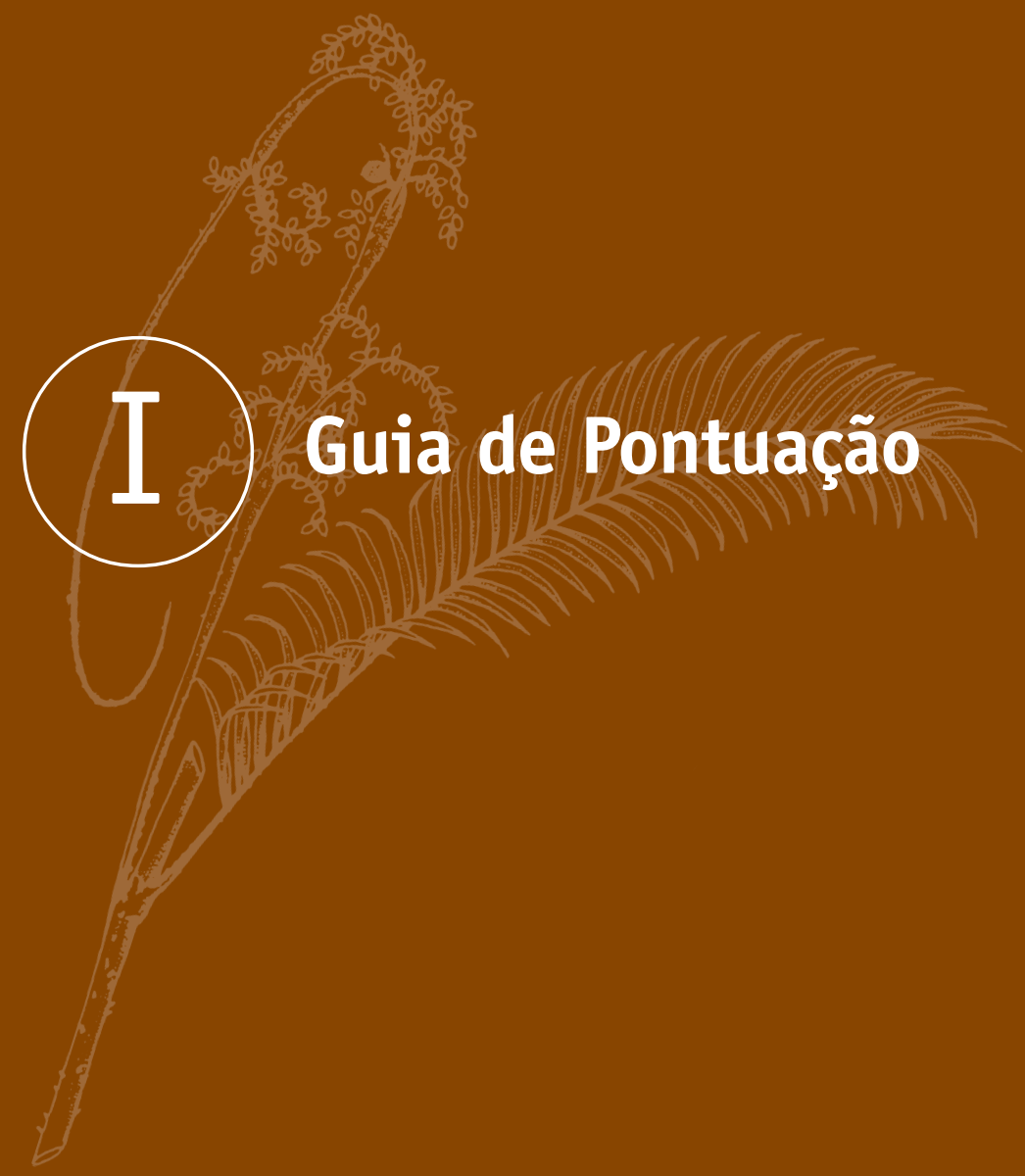


$\mathrm{N}_{2}$

as páginas a seguir inicialmente apresentamos a pontuação dos princípios, critérios e indicadores que compõem o modelo de C\&I do Cifor relacionados às questôes sociais. Supomos que as questôes sociais possuem o mesmo peso que os aspectos ecológicos e de produção das avaliações de sustentabilidade. Nos C\&I sociais, definimos pesos (percentagens) para cada princípio e dividimos a percentagem de cada princípio em pesos para os critérios. Esses pesos estão especificados entre parênteses após cada princípio (total) e cada critério (proporção do total do princípio). Eles são baseados na estimativa qualitativa dos pesos feita por nossa equipe. Essa estimativa, por sua vez, tem como base nossa experiência de campo, em vários países, com testes de critérios e indicadores e de métodos para avaliá-los. Pode ser necessário ajustar os pesos com base nos diferentes contextos no campo. Pedimos aos usuários deste manual que em nenhum aspecto considerem "sagradas" estas pontuações e pesos. Embora eles representem nossas melhores estimativas (naquele momento) sobre como avaliar as questóes de sustentabilidade, reconhecemos facilmente suas imperfeiçôes (mantenha isso em mente).

Subseqüentemente à seção que orienta na pontuação de conclusões qualitativas, temos uma breve seção (II) que ensina a montar uma planilha principal de C\&I - um dispositivo para manter-se atualizado de seu material do caso, assegurar-se de ter tratado cada indicador e obter uma pontuação final para sua avaliação. Além disso, oferecemos exemplos de evidências ou casos já pontuados. 


\section{P1 0 manejo florestal mantém ou melhora 0 acesso eqüitativo aos recursos e benefícios econômicos entre gerações. (Valor total $=\mathbf{4 0 \%}$ )}

\section{C1.1 O manejo local é efetivo no controle da manutenção e acesso aos recursos. ${ }^{4} \quad$ (Peso $\left.=15 \%\right)$}

\section{I1.1.1 A propriedade e os direitos de uso dos recursos (entre e intragerações) são claros e respeitam os direitos preexistentes.}

Pontuação de 1 - 3

Diferentes atores consistentemente apresentam diferentes opiniões sobre os regulamentos de propriedade (por exemplo, o governo e as empresas madeireiras afirmam que a floresta thes pertence, enquanto as pessoas locais consideram a floresta sua propriedade).

\section{Pontuação de 4 - 6}

Embora haja alguma discordância sobre situações específicas (determinadas espécies ou algumas áreas especiais podem ser objeto de conflito), vários atores têm a mesma interpretação sobre os direitos de propriedade e de uso. Pode haver uma diferenciação dos direitos de propriedade/uso por área, estação, ou produto.

Pontuação de 7 - 10

Parece haver virtualmente pleno acordo, preferivelmente de alguma maneira legalizado, sobre os direitos de propriedade e uso dos recursos locais dos vários atores. A propriedade privada da terra e ou das plantas, a propriedade comum e os vários sistemas de direitos de uso estão entre as opções para tal acordo que certamente ocorrerá.

11.1.2 As regras e padrões de uso dos recursos são monitorados e efetivamente aplicados.

\section{Pontuação de 1 - 3}

As regras e normas de uso dos recursos podem não funcionar. Pode-se observar muitos exemplos de pessoas desobedecendo as leis locais (por exemplo, pessoas que vêm de outras comunidades e extraem junco em uma comunidade onde a exploração dos recursos exige permissão; ou caçadores intrusos nas áreas onde as pessoas locais têm direitos, de acordo com relatos, exclusivos). Parece não haver nenhum mecanismo efetivo para monitorar ou aplicar os regulamentos locais.

Pontuação de 4 - 6

Há regras e regulamentos locais, mas esses podem divergir das regras e regulamentos de outros grupos (por exemplo, comunidade local vs. governo nacional, ou mesmo confusões relativas a regulamentos para conservação vs. componentes da exploração do Ministério da Silvicultura). Os avaliadores observam um número maior de pessoas obedecendo as leis locais e apenas exemplos ocasionais de pessoas desobedecendo-as. Portanto, sentem que o sistema está funcionando. Há algumas evidências de mecanismos para monitoração, embora eles não funcionem perfeitamente. Pelo menos algumas vezes penalidades são aplicadas (observam-se incidentes de transgressores sendo capturados, multados, presos etc.).

\footnotetext{
4 Este critério está, obviamente, muito relacionado aos critérios que partem da perspectiva ecológica e formal do "manejo florestal".
} 
Pontuação de 7 - 10

As regras e regulamentos locais são claramente definidos e consistentemente aplicados. Casualmente os avaliadores encontram não mais que um exemplo recente de pessoas desobedecendo as leis prevalecentes sem punição. Os atores sentem que o manejo dos recursos é aprovado e está sob controle.

\section{I1.1.3 0s meios para resolução de conflitos funcionam sem violência.}

Pontuação de 1 - 3

Registram-se muitos exemplos de conflitos, incluindo violência física recorrente (queima de acampamentos de exploração madeireira, brigas entre diferentes atores, ameaças); é provável que os avaliadores presenciem alguns desses conflitos. Não parece haver mecanismos para lidar efetivamente com conflitos (os tribunais não funcionam; suborno é comum; ninguém pode servir como juiz independente).

\section{Pontuação de 4 - 6}

Embora ocorram conflitos, incluindo ocasionalmente alguma violência, eles não prevalecem. 0s mecanismos para resolução de conflitos, embora imperfeitos, funcionam. Muitos casos podem ser resolvidos satisfatoriamente nos tribunais, por meios convencionais ou através de negociações entre os atores.

Pontuação de 7 - 10

Os conflitos são raros e, quando ocorrem, são resolvidos satisfatoriamente. Os mecanismos para resolução de conflitos são claros e funcionam sem transtornos.

\section{I1.1.4 0 acesso aos recursos florestais é considerado justo localmente.}

\section{Pontuação de 1 - 3}

Todos ou alguns atores (especialmente atores florestais) queixam-se continuamente sobre o acesso injusto aos recursos. Também pode haver grupos que sofrem injustiças evidentes silenciosamente. A injustiça quanto ao acesso aos recursos para os forasteiros também é evidente.

\section{Pontuação de 4 - 6}

Embora haja certa injustiça na distribuição dos recursos, a maioria dos atores considera a situação de marginalmente a razoavelmente aceitável. A situação dos trabalhadores e das pessoas locais, por exemplo, pode ser considerada melhor do que se eles estivessem sem a empresa madeireira.

Pontuação de 7 - 10

Quase todas as pessoas entrevistadas concordam que o acesso aos recursos é aceito como justo. Vários atores podem explicar por que o acesso aos recursos funciona daquela maneira e por que concordam que essa distribuição é razoavelmente boa e até mesmo excelente. 
I1.1.5 As pessoas locais se sentem seguras em relação ao acesso aos recursos.

\section{Pontuação de 1 - 3}

As pessoas expressam regularmente suas preocupações em relação ao seu acesso e o de seus filhos aos recursos. Possivelmente elas consideram sua posse da terra ou direitos aos produtos florestais "muito instáveis". Pode haver planos do governo nacional ou regional para a conversão de algumas áreas em outros usos da terra (plantações, transmigração e mineração), dos quais seus proprietários receiam receber pouco ou nenhum benefício. As pessoas locais podem sentir que a quantidade dos recursos está declinando tão rápido que sobrará pouco recurso no futuro.

Pontuação de 4 - 6

Embora as pessoas expressem algumas preocupações em relação ao futuro, elas sentem-se razoavelmente seguras no momento. É possível que haja alguma ameaça, no entanto, ou nenhuma parece terrivelmente amedrontadora, ou as pessoas não estão certas das implicações dessas ameaças. Ainda há um sentimento de otimismo, geralmente sobre 0 acesso presente e futuro aos recursos.

Pontuação de 7 - 10

As pessoas livremente expressam segurança quando são questionadas sobre o acesso presente e futuro aos recursos. Elas habitualmente planejam o futuro naquela localidade, incluindo, por exemplo, atividades como o plantio de árvores de crescimento lento. As pessoas também podem demonstrar generosidade ao emprestar terras ou proporcionar acesso periódico aos seus outros recursos. Raramente há expressões de preocupação em relação a essa questão.

\section{C1.2 Os atores florestais possuem uma parte justa dos benefícios econômicos derivados do uso da floresta. (Peso $=15 \%)$}

I1.2.1 Os mecanismos para divisão de benefícios são considerados justos pelas comunidades locais.

Pontuação de 1 - 3

Aparentemente não há nenhum mecanismo para divisão dos benefícios, a não ser uma possibilidade muito pequena de emprego para as pessoas locais. Os atores locais consideram que os recursos florestais estão disponíveis exclusivamente para alguns, usualmente para atores poderosos/ricos. É provável que as comunidades locais tenham acesso severamente restrito ou nenhum acesso a esses recursos. Os avaliadores ouvem queixas constantes de vários atores sobre a deslealdade da situação atual e injustiças evidentes (por exemplo, uma empresa se estabelece com o apoio do governo e proíbe os usos florestais tradicionais locais).

Pontuação de 4 - 6

Há alguns mecanismos para divisão dos benefícios, tais como a contribuição da empresa para a construção da comunidade, atividades de desenvolvimento comunitário e acesso à assistência médica na base de campo. Apesar de a empresa madeireira receber grande parte dos benefícios florestais (particularmente benefícios monetários), as pessoas locais também recebem alguns desses benefícios. Elas podem continuar suas atividades agrícolas tradicionais (ainda que com alguma incerteza e falta de poder nas negociações relacionadas), coleta de PFNMs e outros usos florestais, de tal maneira que não são seriamente enfraquecidas pelas atividades da empresa madeireira. 
Pontuação de 7 - 10

A questão da divisão dos benefícios é considerada por todos os atores locais, e a divisão satisfatória dos benefícios evolui ou tem sido negociada. Os mecanismos para essa divisão podem incluir direitos entre gerações formalmente reconhecidos a determinadas áreas de terra ou espécies, pagamentos de royalties pela empresa, reconhecimento dos direitos de propriedade intelectual, "ações afirmativas" ${ }^{\text {NT }}$ para as comunidades locais no que se refere a emprego etc.

I1.2.2 As empresas madeireiras oferecem oportunidades de emprego e treinamento para as pessoas locais e aquelas que dependem da floresta ${ }^{5}$.

\section{Pontuação de 1 - 3}

Virtualmente todos os empregados das empresas madeireiras vêm de outros lugares; o acesso a empregos é regularmente negado às pessoas locais. 0 s poucos que conseguem emprego são designados para tarefas "sem oportunidade de promoção".

\section{Pontuação de 4 - 6}

Embora alguns empregados da empresa madeireira sejam trazidos de outros lugares, uma porcentagem considerável de pessoas locais têm oportunidade de trabalho na empresa. Observa-se possibilidade de promoção de pessoas locais para cargos mais elevados. Algumas pessoas locais expressam interesse em trabalhar na empresa.

Pontuação de 7 - 10

A empresa prioriza as pessoas locais no que se refere à oportunidade de emprego. A empresa procura atrair pessoas locais (por exemplo, podem existir acordos para suprir as necessidades de mão-de-obra periódica da agrosilvicultura local).

\section{I1.2.3 Os salários e outros benefícios seguem os padrões da Organização Nacional e ou Internacional} do Trabalho (OIT).

Pontuação de 1 - 3

Os salários são baixos comparando com os salários de trabalhos similares em outros setores na área e com os dos padrões legais. Seguros de vida e saúde não são nem mesmo considerados. Tampouco são consideradas férias, licença para tratamento de saúde, ou pagamentos por produtividade. Os contratos de trabalho podem ser apenas acordos verbais. Pode haver trapaças recorrentes ou deficiência por parte da empresa para aceitar e executar esses contratos e acordos informais.

Pontuação de 4 - 6

A empresa de exploração possui regras especificando padrões salariais e benefícios, sendo que algumas são aplicadas. Todavia, a atenção dada a esses detalhes pode ser inadequada, ou raramente eles são seguidos estritamente. É provável que os empregados desconheçam a extensão de seus direitos e benefícios, tanto na empresa quanto legalmente. Se a remuneração é determinada por metros cúbicos de madeira cortada, por exemplo, os trabalhadores podem não saber como fazer esse cálculo para definir o que thes é devido. 0s trabalhadores terceirizados podem ter salários e benefícios significativamente menores do que aqueles que trabalham diretamente para a empresa.

NT Este termo refere-se a ações que beneficiam grupos em desvantagem. Um exemplo de ação afirmativa no Brasil é a determinação de que pelo menos $20 \%$ dos componentes de cada partido político sejam mulheres.

5 Há um conflito potencial entre esse indicador e a preocupação em manter a relação floresta-cultura ou diversidade cultural. Algumas vezes, o fato de as pessoas se envolverem em trabalhos assalariados como os oferecidos pelas empresas madeireiras conduz à alienação de suas tradições, sem que estas sejam substituídas por algo melhor. 
Pontuação de 7 - 10

Os padrões nacionais ou os da Organização Internacional do Trabalho (OIT) são uma parte explícita da política da empresa e, para prosseguir em sua implementação, realizam-se esforços significativos. Os salários e benefícios são iguais ou melhores do que aqueles pagos a trabalhos semelhantes por outros empregadores na área. Os empregados da empresa habitualmente recebem seguro de vida e saúde, licença para tratamento de saúde e férias. Os empregados novos são informados sobre seus direitos de uma maneira transparente. Existem mecanismos para assegurar que outros trabalhadores (os terceirizados, por exemplo) também recebam salários e benefícios adequados.

\section{I1.2.4 Os danos são compensados de forma justa.}

\section{Pontuação de 1 - 3}

É comum a empresa madeireira causar danos à propriedade local ou prejudicar as pessoas locais sem oferecer qualquer compensação. Entre esses danos estão morte ou ferimentos nas pessoas locais, com caminhões ou lanchas; morte de árvores durante a exploração florestal ou construção de estradas; construção de estradas dentro de sítios sagrados; passagem de balsas transportando toras sobre redes de pesca; produtos químicos jogados no suprimento de água local. As empresas podem desmataráreas que as pessoas locais têm usado tradicionalmente para a agricultura e replantar outras espécies comerciais de propriedade da empresa, sem oferecer em troca qualquer indenização.

Pontuação de 4 - 6

Embora ocasionalmente a empresa madeireira danifique algum bem de propriedade das pessoas locais, há mecanismoclaros para compensar os proprietários. Esses mecanismos são temas de debates, no entanto, exemplos de compensação justa não são muito comuns. Pode haver desacordos que não foram resolvidos satisfatoriamente.

Pontuação de 7 - 10

A empresa madeireira conhece os direitos locais de propriedade e uso, e raramente danifica a propriedade local. Quando inadvertidamente ocorrem danos, há mecanismos transparentes para avaliá-los e compensá-los. Há também mecanismos para resolução de conflitos no caso de desacordo sobre a compensação justa.

\section{C1.3 As pessoas associam o seu futuro e o de seus filhos ao manejo dos recursos florestais. $($ Peso $=10 \%)$}

I1.3.1 As pessoas investem em seu meio ambiente circundante (isto é, tempo, esforço, dinheiro).

Pontuação de 1 - 3

Não há virtualmente nenhuma cooperação comunitária visível (por exemplo, construção de igrejas/mesquitas, limpeza de ruas e execução de projetos da vila). As pessoas não estão cuidando bem de sua própria vila, de seus próprios lares, de seus próprios bens, ou dos recursos naturais locais. Há a sensação de que elas podem partir a qualquer momento, sem muito arrependimento. 
Pontuação de 4 - 6

Há alguma atividade organizada na comunidade, apesar de ser frustrada pelos conflitos internos e de um certo grau de comodismo. As pessoas investem em seus próprios lares e, em menor proporção, na comunidade como um todo. Elas plantam árvores e outras culturas de longo prazo, indicando sua intenção de permanecer na área.

Pontuação de 7 - 10

As comunidades locais são bem-organizadas e regularmente estão engajadas em projetos comunitários. As pessoas têm orgulho de seus ambientes e esforçam-se para melhorá-los. Há uma quantidade considerável de construções, ornamentações e outros melhoramentos na comunidade. Os jovens são educados para melhorar seus próprios ambientes.

\section{I1.3.2 Os níveis de migração externa são baixos. ${ }^{6}$}

\section{Pontuação de 1 - 3}

Há um êxodo de pessoas da área. A população está diminuindo dramaticamente, principalmente por causa da migração externa. Além disso, as pessoas encorajam seus filhos a procurarem melhores oportunidades em outro lugar.

Pontuação de 4 - 6

As pessoas sentem-se atraídas pelas "luzes da cidade" por razões financeiras ou outras. Algumas desejam fugir das dificuldades da vida na floresta, mas a maioria permanece no local. Embora os pais percebam algumas vantagens da vida urbana, eles tendem a criar seus filhos com a expectativa de que permanecerão na área e levarão uma vida relacionada à floresta.

\section{Pontuação de 7 - 10}

Muito poucas pessoas deixam a área por necessidade ou insatisfação com a vida no local. As crianças são educadas para valorizarem seus modos de vida, além de serem treinadas em atividades localmente relevantes.

\section{I1.3.3 As pessoas reconhecem a necessidade de equilibrar o número de indivíduos com o uso dos recursos naturais.}

\section{Pontuação de 1 - 3}

0 índice de aumento da população é alto, criando um problema para seu meio ambiente. É comum haver grandes famílias, com a maioria dos filhos permanecendo na área e tendo um estilo de vida dependente dos recursos naturais locais. As pessoas não reconhecem qualquer relação entre o número de indivíduos e a base dos recursos.

\section{Pontuação de 4 - 6}

A população está crescendo um pouco, e há certa pressão sobre os recursos naturais, mas a situação não é grave. As pessoas estão cientes de uma relação entre o número de indivíduos e o uso dos recursos, no entanto, existem poucos mecanismos para garantir um equilíbrio. Pode haver poucas alternativas.

6 0s indicadores 1.3.2 e 3.1.2 contêm uma contradição potencial. Os baixos níveis de migração externa (I1.3.2) indicam que as pessoas relacionam o seu futuro e o de seus filhos à manutenção da floresta: contudo, o reconhecimento da necessidade de equilibrar o número de indivíduos com o uso dos recursos naturais (I3.1.2) pode levá-los a favorecer a migração externa. Essa contradição provavelmente ocorrerá quando as condições locais estiverem se deteriorando. 
Pontuação de 7 - 10

As pessoas expressam explicitamente a importância de equilibrar os recursos naturais com a população humana e 0 uso da terra. Há mecanismos efetivos para intensificar o uso da terra e ou estabilizar os níveis populacionais (por exemplo, programa eficaz de planejamento familiar; migração externa significativa; desenvolvimento de alternativas locais para dependência ou uso mais eficiente dos recursos naturais).

\section{I1.3.4 As crianças são educadas (formal e informalmente) para o manejo dos recursos naturais.}

\section{Pontuação de 1 - 3}

Os adultos não possuem nenhum conhecimento relevante (incluindo conhecimento tradicional) sobre o manejo dos recursos naturais locais, ou não transmitem tais conhecimentos a seus filhos. Em alguns casos, o conhecimento tradicional tem sido subvalorizado por décadas, resultando em sua perda ou "silenciamento". Além disso, nenhum processo educacional formal está disponivel.

\section{Pontuação de 4 - 6}

0 nível de conhecimento (tradicional, formal, ou a combinação dos dois) é aceitável. Embora haja alguns mecanismos para a transmissão do conhecimento, os problemas persistem. É provável que o conhecimento tradicional útil não seja reconhecido pelas pessoas educadas formalmente; o conhecimento informal inadequado pode ter maior poder e, assim, ser aplicado de maneira prejudicial; o tempo gasto em educação formal pode afastar importantes mecanismos informais para transmissão do conhecimento tradicional.

Pontuação de 7 - 10

Os adultos possuem conhecimento significativo sobre os recursos naturais e seu manejo e transmitem-no para seus filhos. A geração mais jovem reconhece o seu valor e tem interesse em aprender e usar esse conhecimento. 0 conhecimento tradicional útil pode ser integrado em um programa de educação formal; os dois tipos de conhecimento podem estar reunidos; ou ambos os conhecimentos podem ser transmitidos com sucesso para a geração seguinte.

\section{I1.3.5 A destruição dos recursos naturais pelas comunidades locais é rara.}

\section{Pontuação de 1 - 3}

Exemplos de destruição são comumente relatados e ocasionalmente vistos durante as visitas de campo. 0s jovens podem incendiar áreas vizinhas de maneira irresponsável ${ }^{7}$; é provável que incêndios sejam provocados por pessoas descontentes ressentidas; pode ser comum a prática de pescarias com venenos comerciais; a extração de produtos florestais pode ser feita de forma descuidada. As pessoas locais não reconhecem a destruição como algo sério e ou acham que não podem fazer algo a respeito.

\section{Pontuação de 4 - 6}

Embora ocasionalmente ocorra destruição, ela não acontece com freqüência. As pessoas locais reconhecem a destruição como um problema. Observam-se algumas tentativas (nem sempre bem-sucedidas) de resolução. 
Pontuação de 7 - 10

Casos de destruição são raros, e as pessoas consideram a destruição dos recursos naturais como algo ruim. Quando as pessoas destroem coisas desnecessariamente há mecanismos para puni-las e fazê-las corrigir.

\section{I1.3.6 As pessoas mantêm vínculos espirituais ou emocionais com a terra.}

\section{Pontuação de 1 - 3}

Todos os vínculos espirituais (ou outras ligações semelhantes que motivam as pessoas a terem responsabilidade ou senso de unidade) com a terra têm sido destruídos (ou nunca existiram). As pessoas vêem a si mesmas totalmente separadas da floresta em que vivem. Elas não reconhecem qualquer responsabilidade pela saúde de seu ambiente florestal.

\section{Pontuação de 4 - 6}

Embora existam vínculos espirituais com a terra e floresta, eles são muitas vezes considerados secundários para as atividades econômicas. Existem alguns rituais que explicitamente ligam as pessoas à terra, mas eles podem estar sendo abolidos (em alguns casos por causa do escárnio dos forasteiros ou dos atores mais poderosos). Ou as pessoas na área podem ser recém-chegadas, procedentes de uma área sem floresta.

\section{Pontuação de 7 - 10}

A floresta é vista como algo de valor espiritual/cultural e sua manutenção é aceita como uma parte importante da vida das pessoas. As pessoas reconhecem sua dependência da floresta e possuem um senso de responsabilidade ou de cuidado em relação a ela. Durante o trabalho de campo, pode-se observar e ou as pessoas locais podem descrever rituais e outras evidências desta ligação. Há evidências da transmissão deste valor para as gerações mais jovens. 
P2 Os direitos e meios dos atores interessados para manejar florestas de forma cooperativa e eqüitativa são reconhecidos. (Valor total $=30 \%$ )

C2.1 Existem mecanismos efetivos para comunicação entre os atores no que diz respeito ao manejo florestal. $($ Peso $=10 \%)$

I2.1.1 > 50\% dos funcionários das empresas madeireiras e funcionários públicos do setor florestal falam um ou mais idiomas locais, ou $>50 \%$ das mulheres ${ }^{8}$ locais falam o idioma nacional.

Pontuação de 1 - 3

Virtualmente nenhum funcionário da empresa madeireira ou funcionário público do setor florestal fala algum idioma local. Além disso, poucas pessoas locais falam o idioma dos funcionários da empresa madeireira ou dos funcionários públicos do setor florestal.

Pontuação de $4-6$

Embora um número crescente de atores fale um idioma comum, muitos ainda não falam. Esse é particularmente 0 caso das mulheres (que provavelmente são as que menos falam os idiomas nacionais).

Pontuação de 7 - 10

Virtualmente todos os atores compartilham pelo menos um idioma comum.

I2.1.2 0s atores locais reúnem-se com freqüência satisfatória, representação da diversidade local e boa qualidade de interação.

Pontuação de 1 - 3

Os membros de diferentes grupos de atores/usuários raramente ou nunca se encontram. Muitos demonstram-se relutantes em fazê-lo.

Pontuação de 4 - 6

Há comunicação entre um grupo razoavelmente variado de atores locais (embora é provável que as mulheres sejam drasticamente sub-representadas, como são certos grupos étnicos em desvantagem), embora com certo desconforto ou tensão. 0 processo não é particularmente fácil.

\section{Pontuação de 7 - 10}

Há numerosas ocasiões em que os atores se encontram voluntariamente e discutem questões de relevância para o manejo florestal na área. Tais ocasiões incluem mulheres e representantes de outros grupos marginalizados (se eles existem) interagindo de uma maneira pró-ativa com outros atores. Há um sentimento de respeito mútuo entre os participantes.

80 fato de as mulheres conhecerem outros idiomas é particularmente um bom indicador, dado que freqüentemente elas são mais marginalizadas em relação aos homens locais na interação com forasteiros, tal como funcionários da empresa madeireira. 
I2.1.3 As contribuições de todos os atores são mutuamente respeitadas e valorizadas em um nível de satisfação geral.

\section{Pontuação de 1 - 3}

Quando tipos diferentes de atores se encontram, em raras ocasiões, a interação ocorre sob mal-estar social. Um exemplo comum é o desprezo por parte dos executivos das empresas madeireiras e o temor ou subserviência por parte da comunidade local. As pessoas podem expressar abertamente desprezo, temor, raiva, desconfiança e ou ressentimentos mútuos.

\section{Pontuação de 4 - 6}

Há evidências de desrespeito e antagonismo nas interações entre os atores (por exemplo, o desprezo dos que estão no poder e o temor daqueles que estão abaixo dele). Entretanto, também há evidências de que os menos poderosos podem expressar e negociar com sucesso alguns de seus desejos. 0s atores podem expressar antagonismo em relação ao outro, mas eles qualificam tais expressões com certo reconhecimento das contribuições e direitos dos outros atores.

Pontuação de 7 - 10

Há pouca evidência de atitudes negativas por parte dos executivos da empresa e dos membros e trabalhadores da comunidade. 0s atores expressam respeito mútuo livremente. Também pode haver mobilidade social de indivíduos de um grupo de atores para outro grupo.

C2.2 Os atores locais possuem conhecimento detalhado e reciproco sobre o uso dos recursos florestais (incluindo grupos de usuários e papel dos gêneros), bem como sobre os planos de manejo florestal anteriores a sua implementação. (Peso = 10\%)

I2.2.1 Existem planos/mapas demonstrando a integração de usos pelos diferentes atores.

\section{Pontuação de 1 - 3}

Os planos e mapas das empresas (se eles existem) não indicam se há outros atores envolvidos. Esses planos e mapas podem ter sido elaborados em algum lugar distante da comunidade, e não se observa nenhuma contribuição dos atores locais. Não existe nenhum mecanismo para os atores conquistarem tal participação.

Pontuação de 4 - 6

Os planos e mapas têm sido elaborados no local com alguma contribuição das pessoas locais. É possível que haja representação incompleta dos muitos usuários locais da floresta, mas há algum progresso nesse sentido. Por um lado, as pessoas locais podem explicar como ocorreu essa contribuição. Por outro, os executivos das empresas podem explicar como eles tentam obtê-la.

\section{Pontuação de 7 - 10}

Os planos e mapas da empresa estão disponíveis e mostram claramente os diferentes usos locais da floresta pelos vários atores. Existem mecanismos para atualizações regulares. 
I2.2.2 Planos atualizados, estudos de diagnóstico e mapas estão amplamente disponíveis. Esses documentos descrevem os detalhes da exploração, tais como as áreas de extração e a construção de estradas, além de incluir aspectos temporais.

\section{Pontuação de 1 - 3}

Nenhum plano, estudo de diagnóstico ou mapa relativos ao uso dos recursos naturais são observados nas vilas, nos escritórios locais, ou nas paredes e quadros de aviso locais.

\section{Pontuação de 4 - 6}

Raramente as pessoas locais encontram planos, estudos e mapas. 0 acesso a esses recursos nem sempre é fácil, ou tal informação pode ser incompleta (mostrando áreas de extração sem uma série temporal, por exemplo).

Pontuação de 7 - 10

Todas as vilas visitadas possuem informação completa recente e correta sobre os planos e atividades da empresa madeireira e ou as pessoas sabem onde obter e atualizar facilmente tal informação.

\section{I2.2.3 Estudos de diagnóstico dos sistemas humanos locais estão disponíveis e são consultados.}

\section{Pontuação de 1 - 3}

Não há nenhum estudo dos sistemas humanos locais na empresa madeireira ou próximos a ela, e nenhum executivo da empresa tem ouvido falar sobre tal estudo.

\section{Pontuação de 4 - 6}

A empresa madeireira tem observado alguns estudos, e até mesmo conduzido alguns deles (talvez requeridos por um programa governamental). Em alguns casos, é possível que os estudos tenham sido conduzidos por pessoas com formação em engenharia florestal ao invés de em ciências sociais. Isto porque os estudos refletem uma visão um pouco preconceituosa sobre as pessoas locais (muitas vezes enfatizando seu "atraso" ou "estado primitivo" ou "baixo nível de capacidade como recursos humanos" ao invés de seu conhecimento tradicional ou sua potencial contribuição ao manejo dos recursos naturais na área).

Pontuação de 7 - 10

0 escritório da empresa madeireira tem uma biblioteca pequena com informações sobre as comunidades na área e seus próprios trabalhadores. Essas informações podem incluir estudos etnográficos, relatórios do governo e de ONGs, trabalhos acadêmicos, relatórios de consultores etc. A literatura disponível reflete uma variedade de perspectivas, incluindo atitudes positivas em relação às pessoas locais. 
I2.2.4 A equipe de manejo reconhece a legitimidade dos interesses e dos direitos de outros atores.

\section{Pontuação de 1 - 3}

A equipe de manejo consistentemente defende os direitos da empresa, acima dos direitos de qualquer outro ator. A pessoas locais são vistas como "usurpadoras", "exploradoras selvagens", "caçadores furtivos", e outros nomes depreciativos que refletem a visão de que elas não possuem interesses e direitos legítimos na área.

Pontuação de 4 - 6

A administração da empresa começou recentemente a admitir a possibilidade de outros atores terem alguns interesses e direitos na área, bem como a tentar reconhecer esses interesses e direitos. Todavia, ela regularmente "abjura", usando termos que refletem uma visão menos aberta do manejo florestal. Além disso, ela freqüentemente se sente tentada a recorrer às leis do país (as quais, em muitos casos não reconhecem os interesses e direitos dos outros atores).

Pontuação de 7 - 10

A maioria dos funcionários da administração expressa a idéia da existência de vários atores com interesses e direitos legítimos no manejo florestal. Esse ponto de vista pode ser observado nos termos usados por eles, em suas afirmações, e na literatura disponível para os avaliadores.

\section{I2.2.5 0 manejo dos Produtos Florestais Não-Madeireiros (PFNMs) reflete os interesses e os direitos} dos atores locais.

\section{Pontuação de 1 - 3}

É provável que os planos de manejo da empresa não contenham nenhuma referência aos PFNMs; ou que eles determinem regras próprias de uso desses recursos, ignorando os usos de outros atores. Não há nenhum mecanismo para obter a contribuição de outros atores e nenhuma evidência de preocupação sobre a sustentabilidade dos PFNMs.

\section{Pontuação de 4 - 6}

Os planos de manejo incluem PFNMs, mas não incluem todos os usos locais. Também é provável que os PFNMs sejam incluídos parcialmente (por exemplo, focalizando somente aqueles que a empresa madeireira considera interessantes). Além disso, pode haver mecanismos inadequados para obter a contribuição de todos os grupos de usuários relevantes (particularmente mulheres ou grupos marginalizados).

\section{Pontuação de 7 - 10}

Os planos de manejo da empresa possuem uma descrição clara dos PFNMs, com direitos e responsabilidades relevantes. Os planos também incluem a sustentabilidade dos PFNMs. Há consideração evidente em relação aos usos de outros atores, bem como mecanismos que mostram como a contribuição de uma variedade de atores é obtida. 
C2.3 Existe acordo sobre os direitos e responsabilidades dos atores relevantes. $($ Peso $=10 \%)$

I2.3.1 0 nível de conflito é aceitável para os atores.

Pontuação de 1 - 3

Os conflitos são freqüentes e violentos. Cada ator tem uma estória diferente para contar sobre os últimos problemas com outros atores. As pessoas reconhecem que há excesso de conflitos e expressam sua incapacidade de resolvê-los.

\section{Pontuação de 4 - 6}

Conflitos sobre direitos e responsabilidades de diferentes atores são comuns. No entanto, o fundamento para o conflito é compreendido e os procedimentos para resolvê-lo são pelo menos parcialmente aceitos. É possível que haja algum ceticismo sobre o cumprimento das responsabilidades dos diferentes atores e talvez alguma suspeita de que eles estejam excedendo seus direitos.

\section{Pontuação de 7 - 10}

Não há virtualmente nenhum conflito. Ou, é possível que haja algum conflito, mas com comum acordo sobre os direitos e responsabilidades para manejar as florestas. Os conflitos são compreendidos, bem como existem mecanismos para resolvê-los. Todas as partes confiam suficientemente nesses mecanismos. 

por todos os atores. (Valor total $=30 \%$ )

C3.1 Há um equilíbrio evidente entre as atividades humanas e as condições ambientais. $($ Peso $=10 \%)$

I3.1.1 As condições ambientais afetadas pelas atividades humanas estão estáveis ou melhorando. ${ }^{9}$

\section{Pontuação de 1 - 3}

0s sistemas de uso dos recursos naturais estão em decadência. Por exemplo, os ciclos de pousio para a agricultura migratória têm sido reduzidos drasticamente; os problemas de fertilidade do solo e de erosão são excessivos; incêndios freqüentemente fogem ao controle; o nível de produção de PFNMs (incluindo peixe e animais silvestres) tem diminuído dramaticamente nos últimos anos; a biodiversidade está diminuindo.

Pontuação de 4 - 6

Os sistemas de uso dos recursos naturais ainda funcionam, mas há sinais de potenciais problemas. 0 período dos pousios tem sido reduzido, embora não abruptamente. É possível que surjam alguns problemas de fertilidade e erosão no solo. As pessoas ainda extraem PFNMs (incluindo peixe e animais silvestres), mas reclamam que há menos disponibilidade desses produtos do que havia anteriormente.

Pontuação de 7 - 10

Os sistemas de uso dos recursos naturais (particularmente a agricultura) estão funcionando bem. 0s ciclos de pousio nos sistemas de agricultura migratória são longos o bastante para manter e ou melhorar a fertilidade do solo. Os incêndios são controlados com sucesso num nível que as pessoas locais consideram bom. A pesca e a caça são bem-sucedidas (igual ou melhor que no passado). Os PFNMs são prósperos tal como eram no passado (ou melhores).

I3.1.2 0 aumento da migração interna e ou da população natural está em harmonia com a manutenção da floresta.

Pontuação de 1 - 3

Há influxos dramáticos de migrantes de outras áreas que planejam viver sob dependência direta dos recursos naturais locais; e ou há um aumento dramático na taxa de crescimento da população natural, sem alternativas para dependência direta dos recursos naturais locais. Não há nenhum programa governamental que promova o acesso das pessoas a métodos de planejamento familiar ou estratégias de subsistência que não dependam diretamente dos recursos naturais na área.

Pontuação de 4 - 6

Há um leve crescimento populacional. Além disso, há preocupação com a possibilidade de a "capacidade de suporte" local ser excedida (um conceito difícil de definir). As pessoas reconhecem a falta de terra para suas necessidades agrícolas, mas as condições ainda não são críticas. É possível que haja planos governamentais e ou da indústria privada para trazer mais famílias para a área (ou migração interna espontânea), com alguma atenção para as questões população-terra. É possível que haja programas de planejamento familiar em alguns lugares, mas não haja em outros; ou pode haver problemas significativos com a aceitação da idéia por outras razões, embora continue havendo esforços para tornar esses programas disponíveis.

9 Estes indicadores estão evidentemente intimamente relacionados aos indicadores ecológicos, disponíveis em outra parte deste manual. 
Pontuação de 7 - 10

Os níveis populacionais estão estáveis e "em sintonia" com o meio ambiente local; ou alternativas bem-sucedidas para depedência direta do uso dos recursos naturais locais (intensificação bem-sucedida da agricultura, desenvolvimento da indústria ou turismo ${ }^{10}$ ) têm sido criadas. Há pouca preocupação quanto à disponibilidade de terra para necessidades de subsistência. Os planos do governo e da indústria privada para a área reconhecem e tratam da necessidade de equilibrar a população humana com os recursos locais. Os serviços de planejamento familiar estão disponíveis e são considerados aceitáveis pelos atores locais.

\section{C3.2 A relação entre o manejo florestal e a saúde humana é reconhecida.}

I3.2.1 Os manejadores florestais cooperam com as autoridades de saúde pública no que diz respeito às doenças relacionadas ao manejo florestal.

\section{Pontuação de 1 - 3}

Não há nenhum contato entre as autoridades da saúde pública e a empresa madeireira em casos diretamente relacionados às atividades da empresa. Os exemplos incluem: i) a grande incidência de AIDS e outras DSTs em virtude do desequilíbrio da razão entre os sexos e da prostituição nos campos de exploração; ii) a incidência de malária e outras doenças provocadas por mosquitos tem aumentado por causa das más práticas de exploração (especialmente o empoçamento e a interferência nos habitats dos predadores dos mosquitos); iii) a poluição do ar causada pela queimada dos campos para a plantação de árvores destinadas à fabricação de pasta de celulose e papel aumenta os problemas respitatórios e oculares; iv) acidentes violentos de exploração são comuns; e ou v) a violência entre trabalhadores de diferentes grupos étnicos caracteriza a vida na base de campo.

Pontuação de 4 - 6

As autoridades da saúde pública interagem de alguma forma com a empresa madeireira, embora a interação não seja freqüente. A empresa fornece alguns serviços médicos para as pessoas na área, mas não aceita a total responsabilidade de monitorar os problemas de saúde relacionados às atividades de exploração. É provável que a empresa tenha uma opinião muito limitada sobre suas responsabilidades (por exemplo, apenas acidentes ocorridos na exploração); ou faça, o que é preferível, um trabalho irregular de inspeção e notificação. Existem problemas significativos, mas não alarmantes em relação a acidentes, violência entre grupos étnicos, incidência de DSTs, poluição do ar e água, e doenças provocadas por mosquitos.

\section{Pontuação de 7 - 10}

As autoridades da saúde pública mantêm registros parcialmente baseados em informações fornecidas pela empresa madeireira sobre a saúde das pessoas vivendo na floresta ou próximas a ela; a empresa pode financiar suas próprias clínicas de saúde, assim como oferecer cobertura médica de terceiros, particularmente para problemas de saúde diretamente relacionados às atividades da empresa. A incidência de AIDS, DSTs, malária, dengue, acidentes violentos e outras doenças/problemas potencialmente relacionados às atividades de exploração está estável ou diminuindo. 


\section{I3.2.2 0 estado nutricional é adequado entre as pessoas locais.}

\section{Pontuação de 1 - 3}

A alimentação consiste grandemente de amido, mas a variedade e ou quantidade são inadequadas. A obesidade é considerada atrativa e desejável. A falta de interesse é comum. Pode haver exemplos de bócio, cegueira noturna, fadiga crônica e doenças crônicas, tais como malária e tuberculose. 0 crescimento infantil pode ser significativamente mais baixo que os exigidos pelos padrões internacionais de altura para peso e ou as crianças podem ter barrigas grandes e braços magros. As taxas de mortalidade infantil de crianças abaixo de 5 anos pode ser alta. As mulheres podem ser anêmicas e mostrarem sinais de deficiência de cálcio, especialmente durante a gravidez.

Pontuação de 4 - 6

Embora haja, de um modo geral, bastante alimento, as pessoas mais velhas e as muito jovens podem estar muito magras. É provável que mulheres ativas aparentemente saudáveis se queixem de dores nos ossos durante a gravidez. Problemas dentários podem ser comuns em todas as idades (incluindo a perda completa dos dentes ainda cedo). A dieta local pode ser excessivamente dependente de carboidratos ou contém muito açúcar, cafeína e ou álcool.

Pontuação de 7 - 10

É provável que as pessoas façam três refeições ao dia e que sua dieta seja variada (incluindo todas as vitaminas, minerais, proteínas e fontes de energia importantes). A maioria das pessoas parece saudável e forte. 0 consumo de açúcar, cafeína e ou álcool está geralmente dentro dos limites considerados saudáveis. Os níveis de mortalidade e morbidez são baixos para todos os grupos de idades.

13.2.3 Os empregadores nas áreas florestais seguem os padrões de trabalho e condições de segurança da Organização Internacional do Trabalho - OIT e responsabilizam-se pelos riscos florestais à saúde dos trabalhadores.

\section{Pontuação de 1 - 3}

Virtualmente nenhum explorador é visto vestindo roupas protetoras (capacetes, botas de ponta de aço, jeans, luvas); o equipamento parece estar em más condições de funcionamento; e itens de segurança podem ter sido excluídos do equipamento de exploração; pode-se observar caminhões de transporte de toras sendo conduzidos de forma negligente. Os administradores e supervisores da empresa aparentemente não estão preocupados com a segurança. Aparentemente não há procedimentos de treinamento ou manuais de segurança. Não há nenhum recurso para assistência médica disponível na base de campo. Ferimentos ou mortes acidentais são comuns e não são considerados responsabilidade da empresa.

\section{Pontuação de 4 - 6}

A empresa possui normas de segurança, as quais são seguidas de modo irregular. Em grande parte dos casos a decisão sobre seguir ou não as normas de segurança é do trabalhador; verifica-se uma taxa regularmente alta de acidentes. A empresa pode assumir a responsabilidade por ferimentos e ou mortes acidentais, mas não paga consistentemente a indenização prometida. Pode haver pouco ou nenhum treinamento formal em precaução de acidentes, bem como provisão ou manutenção irregular de dispositivos de segurança dos equipamentos. Há assistência médica mínima disponível na base de campo. 
Pontuação de 7 - 10

A empresa tem um programa de treinamento para todos os empregados novatos, assim como cursos de reciclagem sobre segurança para empregados mais antigos. A empresa fornece equipamentos e determina procedimentos de segurança para os trabalhadores; o objetivo é assegurar que os equipamentos sejam regularmente inspecionados e que os trabalhadores sigam os regulamentos de segurança. 0s exploradores são vistos usando vestimentas protetoras e equipamentos bem-preservados e seguros. Há penalidades determinadas quando as pessoas não seguem os regulamentos de segurança. A empresa assume a responsabilidade financeira por prejuízos e ou mortes acidentais, através de seguros ou outros mecanismos. A base de campo possui uma clínica completa em operação para tratar ferimentos graves. Placas lembrando aos trabalhadores sobre as questões de segurança são visíveis em seus ambientes de trabalho.

C3.3 A relação entre a manutenção da floresta e a cultura humana é reconhecida como importante. $($ Peso $=10 \%)$

I3.3.1 Os gerentes florestais compreendem as relações entre as culturas humanas relevantes e a floresta local.

Pontuação de 1 - 3

Os gerentes da empresa demonstram uma clara falta de interesse e respeito pela cultura local (crenças, regras e comportamento costumeiro). Eles tendem a ser notavelmente ignorantes quanto aos modos de vida das pessoas locais, muitas vezes as considerando atrasadas ou mesmo repugnantes. É provável que eles não saibam que as pessoas locais possuem algum conhecimento sobre suas próprias florestas.

Pontuação de 4 - 6

Embora os executivos da empresa conheçam um pouco os modos de vida da população local e saibam que pode haver elementos positivos em sua cultura, este conhecimento é muito incompleto. Além disso, é provável que haja um sentimento significativo de que as pessoas locais são inferiores (talvez por causa dos seus baixos níveis de renda, poder ou habilidade tecnológica). A abertura para o envolvimento das pessoas locais no manejo pode ser limitada a uma abordagem muito "autocrática", na qual a empresa "dá as ordens".

Pontuação de 7 - 10

Os gerentes florestais sabem como funcionam as culturas tradicionais locais. Eles compreendem, por exemplo, a relação entre os longos pousios no sistema agroflorestal da população e a regeneração do solo. Ou, eles podem conhecer as visões cosmológicas das pessoas locais sobre os papéis de determinadas espécies na floresta; tabus a respeito de entrar em determinadas áreas; e conhecimentos tradicionais das pessoas sobre 0 comportamento da vida silvestre e manejo. Os executivos da empresa reconhecem que o manejo florestal sustentável requer a busca do conhecimento, valores e ações tanto da população local como dos outros atores. 
I3.3.2 Os planos de manejo florestal consideram as questões culturais.

\section{Pontuação de 1 - 3}

Os planos do manejo florestal não incluem nenhum compromisso ou reconhecimento dos usos culturais da floresta pelas pessoas locais. Sítios sagrados, cemitérios e áreas preservadas para gerações futuras podem ser explorados sem consulta prévia à população local. As áreas de prostituição mantidas pela empresa podem ter sido estabelecidas dentro dos limites da comunidade. As comunidades queixam-se bastante sobre o comportamento da empresa.

\section{Pontuação de 4 - 6}

Há certo entendimento e compreensão por parte da empresa quanto às questões culturais locais. Apesar de os planos de manejo incorporarem somente parcialmente tais questões, há evidências de que a empresa sente certa obrigação em lidar com elas. Quando surgem problemas, a empresa promove encontros com as pessoas locais para discutir a indenização, porém esses encontros são muito conturbados (por exemplo, acontecem após a área ter sido explorada, a indenização oferecida é considerada injusta ou não é paga).

Pontuação de 7 - 10

Os planos de manejo florestal são elaborados com um entendimento claro sobre as questões culturais humanas. Há mecanismos transparentes para determinar quais questões culturais importantes podem ser afetadas pela exploração na área, sendo complementados por mecanismos de atualização da informação e resolução de conflitos. Há pouca evidência de transgressões freqüentes pela empresa de exploração.

\section{I3.3.3 Não há aumento significativo dos sinais de desintegração cultural.}

\section{Pontuação de 1 - 3}

Roubos, prostituição, extermínios cruéis e crimes violentos podem ser sérios problemas na área. Crianças podem ser abandonadas ou deixadas sem supervisão. As pessoas mostram-se confusas e ambivalentes quanto a seus próprios valores, ou não se manifestam. Os níveis de estresse parecem altos, e os de interesse na vida, baixos. Pode haver desequilíbrio excessivo na razão entre os sexos. As tradições e valores culturais são enfraquecidos, ou possivelmente são substituídos por imitações dos ocidentais, adquiridas através da televisão ou outros meios de comunicação; os valores culturais não são transmitidos para as gerações mais jovens.

\section{Pontuação de 4 - 6}

É provável que haja conflitos inter-raciais consideráveis e certo desequilíbrio na razão entre os sexos. Pode haver alguma indicação de que estratégias de sobrevivência tradicionais não estão funcionando completamente (talvez por causa de uma dependência desmedida da empresa madeireira). Os rituais e cerimônias continuam, mas com menos entusiasmo que no passado.

\section{Pontuação de 7 - 10}

0s sistemas locais de crença parecem permanecer integrados e funcionais. Pessoas de todas as gerações expressam orgulho pelos seus próprios modos de vida e sistemas de valores tradicionais. Rituais tradicionais permanecem em evidência e seus sistemas econômicos de subsistência permanecem intactos ou mostram melhoria com incremento. 


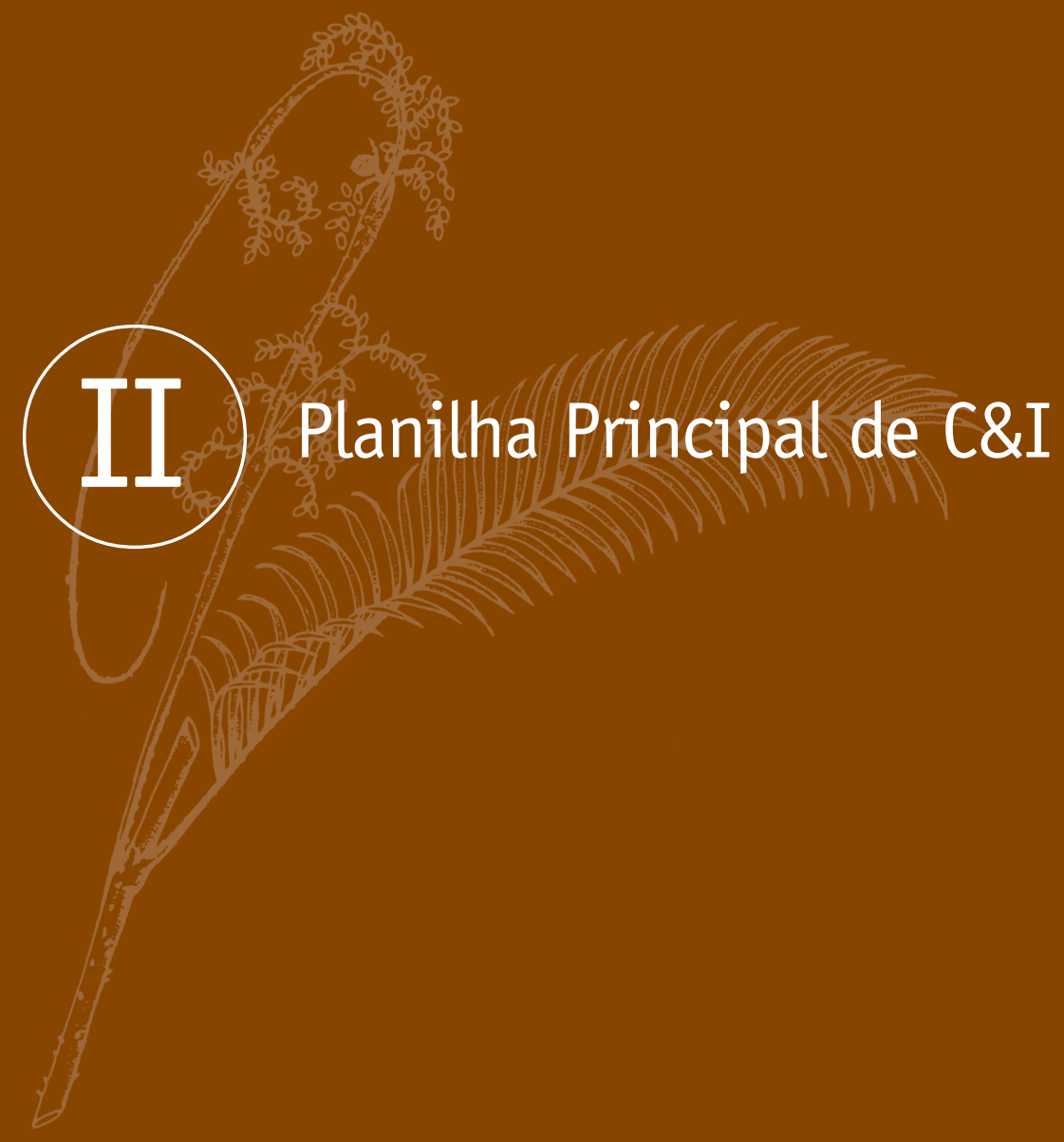


Série Manuais de C\&I do Cifor incluem duas ferramentas dedicadas especificamente aos métodos das ciências sociais para avaliar o bem-estar humano. Essas ferramentas, o GBA e Os Acessórios, assim como o Guia de Pontuação e Análise, foram elaboradas para avaliadores com vários níveis de especialidade em ciências sociais. Nesta seção, ensinamos os usuários inexperientes no uso de computadores ou em ciências sociais a montar uma planilha no programa Excel. Essa planilha é utilizada no tratamento sistemático das observações qualitativas e quantitativas e dos resultados relacionados aos C\&I sociais. Além disso, fornecemos exemplos dos tipos de evidências que servem como base para a avaliação das condições humanas, bem como apresentamos maneiras pelas quais essas condições têm sido pontuadas por vários avaliadores em um determinado local.

\section{A PLANILHA PRINCIPAL}

A planilha principal é um mecanismo para lidar sistematicamente com o excesso de dados qualitativos (e alguns quantitativos) que surgirão durante o processo de sua avaliação do bem-estar humano. Ela é mencionada repetidamente nos manuais $G B A$ e Os Acessórios como um meio para sistematizar suas observações. Você pode iniciar com uma planilha no Excel ${ }^{11}$ listando os princípios, critérios e indicadores e, gradualmente preenchê-la com exemplos, casos, evidências e outros materiais relacionados a cada uma dessas questóes.

Crie uma planilha principal tal como mostra a Figura 1, apresentando na primeira coluna (A) todos os princípios, critérios e indicadores sociais de sua lista (por exemplo, o Modelo Genérico dos C\&I do Cifor). Inserindo fileiras adicionais entre cada questão, você poderá introduzir, partindo da Coluna B (compare, Tabela 1), explicações completas de seu material do caso, durante o processo de coleta. A Tabela 1 é uma versão adaptada de 
parte de uma planilha principal que trata da segurança de acesso aos recursos entre geraçōes (Colfer et al. 1996). Neste exemplo resumido, casos da Reserva de Vida Silvestre Danau Sentarum (RVSDS), em Kalimantan Ocidental, foram listados e pontuados. Esses casos são apresentados para dar um exemplo "do mundo real" de uma avaliação e dos tipos de dados que foram registrados. Posteriormente, você poderá reunir esses casos em pontuações resumidas, para facilitar a apresentação (como na Tabela 2, a partir da mesma fonte).

Um dado importante não incluído na Tabela 1 é a fonte da informação. A fonte pode ser "uma observação pessoal em um casamento", "um homem punan de aproximadamente 30 anos com educação escolar", ou "um debate geral num encontro de mulheres iban". Essas fontes podem ser registradas abaixo de cada caso, a partir da Coluna C. É importante incluir a fonte porque posteriormente será necessário avaliar a veracidade e a potencial inclinação de cada sinal de evidência ou material do caso. Após reunir um número de informações, você avaliará (pontuará) cada caso considerando a contribuição de cada um para a sustentabilidade (usando o guia de pontuação, descrito no início deste manual).

Após avaliar o valor da sustentabilidade de cada caso, calcule as médias dessas pontuaçóes dentro de cada indicador para obter uma avaliação para o indicador. (Esteja alerta no caso de haver evidências que você considera particularmente importantes ou reveladoras, as quais podem necessitar de peso extra na avaliação). Da mesma forma, calcule a média das pontuaçôes dos indicadores para obter uma avaliação 
para cada critério; e a média das pontuaçóes dos critérios para obter uma avaliação para cada princípio.

Você poderá obter uma pontuação média global na sua planilha seguindo estes procedimentos:

1. Julgue a sustentabilidade de seus exemplos e material do caso;

2. Determine pontuações para cada caso/exemplo (por exemplo, evidências referentes aos indicadores, como na Tabela 2);

3. Calcule a média das pontuações para todos os casos que fornecem evidências relativas aos indicadores para um critério particular;

4. Multiplique essa pontuação média por um peso dentro dos C\&I sociais (por exemplo, 15\% para o critério 1.1 ("O manejo local é efetivo no controle da manutenção e acesso aos recursos"); $\mathrm{e}$

5. Calcule a média desses valores, determinados para cada critério, a fim de fornecer um valor para o princípio (por exemplo, o peso para o P1 é $40 \%$ dos C\&I sociais) e, por último, para todo o conjunto de C\&I sociais.

Para obter uma pontuação para o princípio (1), “O manejo florestal mantém ou melhora o acesso eqüitativo aos recursos e benefícios econômicos entre gerações", você deve aplicar a seguinte fórmula:

Pontuação (C.1) X Peso (C.1) + Pontuação (C.2) x Peso (C.2) + Pontuação (C.3) x Peso (C.3)

Onde os pesos para os C.1, C.2 e C.3 são 0,15; 0,15; 0,1, respectivamente. 
Em geral, os critérios e indicadores para o bem-estar humano são classificados sob três princípios, com os seguintes pesos:

P1 $\begin{aligned} & 0 \text { manejo florestal mantém ou melhora o acesso } \\ & \text { eqüitativo aos recursos e benefícios econômicos entre } \\ & \text { gerações. Peso } 1=40 \%\end{aligned}$
P2 direitos e meios dos atores interessados para manejar
florestas de forma cooperativa e eqüitativa são
reconhecidos. Peso $2=30 \%$
P3 saúde dos atores florestais e da floresta, bem como a
integridade cultural são aceitáveis por todos os atores.
Peso $3=30 \%$

Para pontuar o nível de bem-estar humano na área que você está avaliando, você pode calcular, de forma simples, a média de suas pontuações usando esta fórmula:

Bem-estar humano $=[\mathrm{P} 1($ pontuação $) \times$ Peso 1] $+[$ P2 (pontuação $) \times$ Peso 2] $+[$ P3 (pontuação $) \times$ Peso 3 $]$

Onde P1 = Princípio 1 e Peso 1 = Peso para aquele princípio.

É importante lembrar que esse procedimento é simplesmente uma maneira de sistematizar e registrar suas observaçôes e julgamentos. Ele ajuda você a lembrar de suas observações, o mantém concentrado nos C\&I de interesse, e ajuda a identificar falhas em seu entendimento durante o processo de avaliação. Como mencionado anteriormente, os valores que você confere ou as médias que você calcula não são "sagrados". Eles simplesmente refletem seu julgamento qualitativo, com base em observação sistemática das condições humanas na área. Eles são valores relativos e não absolutos. 


\section{FIGURA 1.}

Tela do computador mostrando parte de uma planilha principal de C\&I

(por exemplo, Princípio Social 2: "Os direitos e meios dos atores interessados para manejar florestas de forma cooperativa e eqüitativa são reconhecidos").

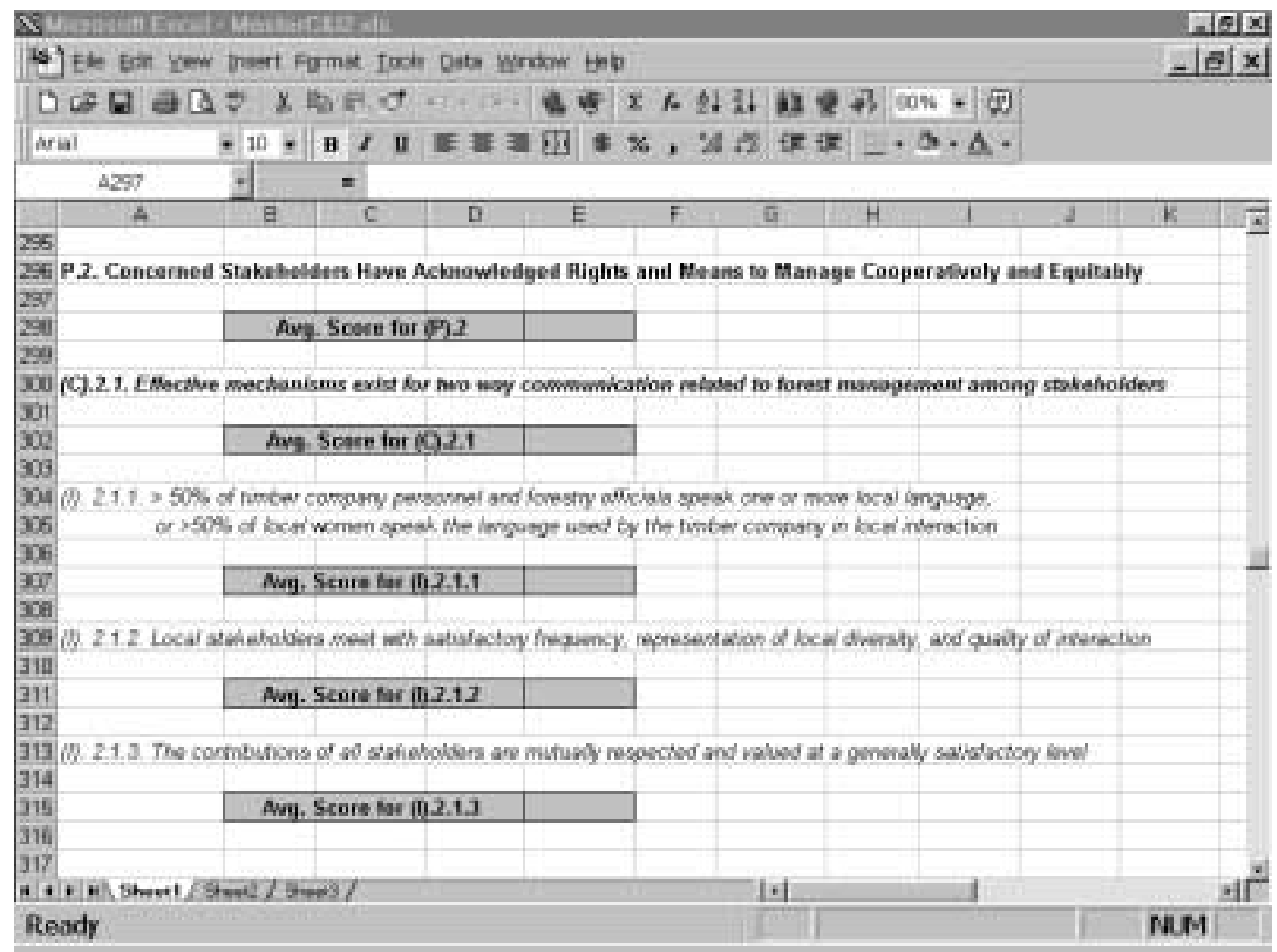




\section{TABELA 1.}

\section{Listagem de casos de amostra (sobre o Princípio Social 1: “0 manejo florestal mantém ou aumenta o acesso eqüitativo aos recursos e aos benefícios econômicos entre gerações"), com pontuação associada, da Reserva de Vida Silvestre Danau Sentarum, 1996.}

Nesta tabela, "C" refere-se a Colfer e "W", a Wadley. Cada indicador é numerado consecutivamente dentro de cada critério. Colfer e Wadley pontuaram cada caso. Embora Wadley tenha visto as pontuações de Colfer anteriormente, ele fez sua própria pontuação e se esforçou ao máximo para pontuar de acordo com o seu próprio ponto de vista. A média dessas pontuações foi calculada por indicador (Tabela 2).

\section{(C) 1: 0 manejo local é efetivo no controle da manutenção e acesso aos recursos.}

(I) 1.1 A propriedade e os direitos de uso dos recursos (entre e intragerações) são claros e respeitam os direitos preexistentes ${ }^{12}$.

1. Os habitantes de Nd. Kedebu, Bukit Rancong e Danau Seluang têm permissão para residir nas áreas de lagos de suas respectivas "vilas de origem" nas Kapuas. Nenhum deles tem habitado permanentemente a área por mais do que poucas décadas, além disso muitos são sazonais. Por outro lado, cada comunidade tem seu território definido, embora informalmente, de forma justa e clara.

$C=7 ; W=7$ (Melayu)

2. Wong Garai perdeu efetivamente o controle sobre grande parte de seus territórios tradicionais (ver Figura 4). Entretanto, essa redução do território não é acompanhada por qualquer sentimento de animosidade em relação às pessoas que agora ocupam aquela terra (as quais geralmente são parentes ou estão historicamente vinculadas às pessoas de Wong Garai, isto é, não são forasteiros). No passado, a população reduzida de Wong Garai não requeria o uso constante da área, e sua ética de generosidade permitiu que outros se estabelecessem na terra.

$C=5 ; W=5($ Iban $)$

3. Em 1989, Wong Garai conseguiu impedir que uma significativa região de floresta madura fosse explorada. 0 território de Wong Garai está na concessão P.T. Militer, no entanto, a população apelou para os governos distritais e regional e, assim, recebeu ajuda importante de um dos seus cidadãos, que na época era membro do Poder Legislativo. A floresta foi declarada área protegida pelo Chefe do Poder (ver Colfer e Wadley, 1996). $C=7 ; W=7$ (Iban)

4. Há algum tempo os habitantes de Kelayang permitiram que uma comunidade Melayu residisse em suas terras. A comunidade Melayu recentemente vem tentando reivindicar a terra como sua, inclusive fazendo solicitação oficial para membros do governo local. Até o momento, o grupo Kelayang tem conseguido resistir à reivindicação. A comunidade Melayu menciona as fronteiras administrativas do distrito atual do qual ela é parte, enquanto 0 grupo Iban se refere a seus sistemas tradicionais (antigos sítios habitacionais e cemitérios servem como evidências de seus direitos).

$\mathrm{C}=3 ; \mathrm{W}=3$ (Iban; Melayu)

12 Nossa ênfase aqui é sobre a propriedade e os direitos de uso locais, no entanto, podemos acrescentar que há diferenças consideráveis de opinião sobre os direitos reais aos recursos. Por exemplo, enquanto as pessoas locais consideram os recursos sua propriedade, o governo considera-os propriedade da nação. 
5. Em 1996, Bemban, em cooperação com outras comunidades Ibans e seus líderes na sede do parlamento do distrito de Badau, foram bem-sucedidos ao persuadir os gerentes de uma plantação e de uma concessão (ambas em estágio avançado de planejamento e em fase inicial de implementação, em 1993) a abandonarem seus planos de trabalhar em território Bemban [em parte relacionados aos direitos locais por compensação ${ }^{13}$ relativos ao pulau (pequenas áreas florestais protegidas) e tembawais (antigos sítios habitacionais)].

$C=6 ; W=6$ (Iban)

6. Bemban foi legalmente definido como parte da comunidade Melayu de Pulau Duri', em 1989. Desde essa época, Pulau Duri' tem tentado transformar em propriedade os seus direitos de uso de terra agrícola voluntariamente concedidos em área tradicional de Bemban (emprestada para Pulau Duri' por um longo período). Até o momento, Bemban tem resistido com sucesso a essa tentativa de apropriação de parte de sua área tradicional. $\mathrm{C}=7$ (Iban); $\mathrm{C}=2 ; \mathrm{W}=2$ (Melayu)

(I) 1.2 As regras e padrões de uso dos recursos são monitorados e efetivamente aplicados ${ }^{14}$

1. Os habitantes de Nr. Kedebu expressaram "raiva justa" pelas outras comunidades próximas, de onde vieram membros para seu território, os quais coletaram junco ou pescaram. Essa atitude contraria seus regulamentos. $C=7 ; W=7$ (Melayu)

2. Em território Bemban foi descoberta uma equipe de exploração que não havia pedido permissão para explorar a área. No dia $1^{\circ}$ de julho, todos os homens da vila foram juntos, primeiro para Pulau Duri' (onde vivia o líder oficial da vila) e, em seguida, para o acampamento na floresta, questionar as intenções da equipe de exploração. $C=5 ; W=5$ (Iban)

3. Um grupo de crianças e jovens mulheres de Bemban saíram para o tembawai (antigo sítio habitacional) para coletar samambaias para o jantar. Eles explicaram que somente as pessoas da comunidade poderiam coletar samambaias naquela área. Uma jovem tomou uma fruta que Colfer estava carregando, dizendo que Colfer podia ser penalizada por isso, enquanto a própria moça tinha permissão para fazê-lo (ver Sandin, 1980).

$\mathrm{C}=8 ; \mathrm{W}=8$ (Iban)

4. Em 1994, habitantes de Wong Garai notaram que membros de outra aldeia organizavam-se para plantar nas planícies de florestas de várzea em suas áreas. Embora no passado a outra aldeia tenha obtido uma área de várzea restrita, algumas pessoas estavam tentando expandir suas propriedades sem permissão. Realizou-se uma audiência em Wong Garai, evitando, dessa forma, uma disputa maior e garantindo que as pessoas da outra aldeia desistissem de seu intento de cultivar naquela floresta (ver Wadley, 1997). Desde então, as pessoas de Wong Garai têm expressado sua necessidade e desejo de preservar as planícies de florestas de várzea para seu próprio uso no futuro. ${ }^{15}$

$C=9 ; W=9$ (Iban)

13 De acordo com relatos, foram reivindicados e recebidos 20 milhões de rúpias (aproximadamente US\$ 8.500) por compensação, com base nas perdas de árvores frutíferas, determinada pela adat (lei costumeira local).

14 Mais uma vez nossa ênfase é sobre os regulamentos locais. No entanto, há uma quantidade de regulamentos de diferentes partes do Ministério da Silvicultura, os quais não são normalmente monitorados ou aplicados (por exemplo, engenheiros florestais do governo que não conhecem os regulamentos sobre extração de madeira nem quem os imporia; ou funcionários do Projeto de Conservação que administram a Reserva de Vida Silvestre, mas regularmente ignoram as garças vermelhas e as cegonhas da tempestade presas nas balsas melayus, bem como os macacos e pequenos pássaros mantidos como animais de estimação pelo grupo Iban.

15 Essa necessidade pode ter sido conseqüência da eterna e crescente ameaça de transmigração para a área rio abaixo de Wong Garai - 200 famílias de Java. 
5. Ocasionalmente, durante o início dos anos 90, os habitantes de Wong Garai eram abordados por forasteiros solicitando permissão para procurar por gaharu (Aquilaria spp.) nas florestas de Wong Garai. Constantemente, e apesar do receio, o grupo Iban concedia acesso a suas florestas, ocasionalmente participando da busca por gaharu, com a promessa de que seria recompensado (pagamentos, divisão da colheita, ou compra). Além disso, a comunidade freqüentemente se sentia enganada, e os membros queixavam-se entre si (alguns gaharus eram escondidos, ou os pagamentos não compensavam o trabalho). Embora essa atitude sugira ingenuidade por parte do grupo Iban em relação aos forasteiros, ela representa uma profunda ética de generosidade e hospitalidade, tornando a recusa extremamente difícil (ver Peluso, 1994, Colfer et al. (1997), para um padrão similar entre outros dayaks).

$\mathrm{C}=4 ; \mathrm{W}=4$ (Iban)

(I) $1.30 \mathrm{~s}$ meios para resolução de conflitos funcionam sem violência.

1. No final dos anos 80, Wong Garai participou de uma disputa de terra com uma aldeia vizinha. Em anos anteriores, Wong Garai permitiu que membros da outra aldeia cultivassem dentro do seu território. No entanto, depois de algum tempo, a outra aldeia reclamou a terra como sua. Essa aldeia trouxe o caso diante do temenggong (líder de leis tradicionais) para uma audiência. 0 temenggong decidiu que as duas aldeias deveriam dividir a terra. Wong Garai recusou-se a aceitar a decisão (o que é considerado seu direito localmente), argumentando que a outra aldeia não possuía tembawai (antigo sítio habitacional) em território Wong Garai, o que justificaria seu direito à terra. [Ver também (I) 1.2, Caso 4] $C=8 ; W=8$ (Iban)

2. Os habitantes de $\mathrm{Ng}$. Kedebu tinham desavenças com a P.T. Hutan Hebat, uma empresa madeireira que regularmente rebocava balsas que transportavam toras através do território de $\mathrm{Ng}$. Kedebu. Um membro da comunidade serviu como piloto de rebocador para a empresa, além de mediador informal na resolução dessas disputas. Havia queixas com respeito aos níveis de compensação por danos causados aos equipamentos de pesca local, no entanto o sistema parecia funcionar.

$C=8 ; W=8$ (Melayu)

3. Em 1994, vários comerciantes ibans usaram grandes quantidades de pesticidas comerciais a fim de capturar maior quantidade de peixes para vender na Malásia. Esse evento provocou a morte de centenas de viveiros de peixes, os quais eram mantidos como "poupança", todos ao longo do rio Tawang, pelos membros da comunidade $\mathrm{Ng}$. Kedebu (e outras). A ira local foi tão grande que o Projeto de Conservação, membros do governo local e regional, a polícia e militares se envolveram para resolver a disputa. No final, todas as comunidades na Reserva de Vida Silvestre Danau Seluang - RVSDS e ao seu redor assinaram um pacto para não usar veneno. $\mathrm{C}=4 ; \mathrm{W}=4$ (Melayu)

4. Os habitantes de Danau Seluang contaram uma história que ocorreu entre 1982-83, quando o povo Iban vivendo rio acima de Danau Seluang usou veneno para peixe onze vezes. ${ }^{16}$ Nenhuma providência foi tomada todas as vezes em que as pessoas reclamaram e informaram o fato às autoridades. A falta de providência por parte das autoridades estimulou a própria comunidade a envenenar os peixes, em retribuição. Essa atitude, por sua vez, estimulou ações governamentais que resultaram, por um tempo, na redução do uso de veneno para pesca. $C=6 ; W=6$ (Iban, Melayu)

16 Wadley ressalta que pode ter havido percepções conflituosas sobre os direitos tradicionais de uso, com o povo Iban em questão considerando possivelmente ser esse seu direito. Divergências similares são possíveis em muitos desses casos. 


\section{(I) 1.40 acesso aos recursos florestais é considerado justo localmente.}

1. Em Ng. Kedebu', recentemente, toras haviam sido removidas sorrateiramente de balsas da P.T. Hutan Hebat que estavam de passagem. As toras seriam serradas para confecção de tábuas e usadas na construção de uma mesquita. Essa ação foi consentida pelos membros da comunidade e justificada com referência aos lucros que as empresas madeireiras estavam tendo em relação aos benefícios provenientes dos recursos locais.

$\mathrm{C}=2 ; \mathrm{W}=2$ (Melayu)

2. Incêndios florestais ocorreram extensivamente em 1992 (o último ano realmente seco) em território de Danau Seluang. Isso resultou numa redução significativa da disponibilidade de junco e madeira, bem como em perdas relacionadas a aproximadamente 500 tikungs de madeira (colméias artificiais). As causas das queimadas eram descritas de forma variada; como intencionais e relacionadas à inveja e raiva dos forasteiros (pelo fato de não terem permissão para explorar); ou totalmente por causa do descuido.

$\mathrm{C}=3 ; \mathrm{W}=3$ (Melayu)

3. Ver também (I) 1.2 , Caso 5.

$\mathrm{C}=4 ; \mathrm{W}=4$ (Iban)

4. Entre as comunidades Melayus, o uso da jermal padat (uma grande rede de pesca) é considerado injusto. As redes são grandes e caras; somente poucos habitantes têm condições de comprá-las. Além disso, elas são eficientes na captura dos peixes, reduzindo a quantidade disponível para outros pescadores com acesso somente a técnicas de pesca mais intensivas em mão-de-obra.

$C=2 ; W=2$ (Melayu)

(I) 1.5 As pessoas locais se sentem seguras em relação ao acesso aos recursos.

1. Wong Garai divide o acesso a algumas florestas e áreas fluviais com outra aldeia. Há certa preocupação de que isso esteja levando à superexploração, particularmente dos recursos fluviais (por exemplo, peixe). As pessoas também estão preocupadas se futuramente poderão pescar nos lagos durante a estação seca (atividade que elas têm realizado durante pelo menos 150 anos e sobre a qual reividicam direitos tradicionais de uso) dada a crescente presença de melayus em áreas tradicionais de uso dos ibans e a possibilidade de, no futuro, o próprio governo começar a impor fronteiras diferentes.

$\mathrm{C}=5 ; \mathrm{W}=5$ (Iban)

2. No início de 1994, o líder de Wong Garai recebeu uma carta de um escritório do distrito de Lubok Rian, explicando que militares estariam passando pela área fazendo um amplo projeto de mapeamento de todos os limites dos distritos. Aproximadamente um mês mais tarde, vieram soldados para o território de Wong Garai, transportados em helicópteros para um terreno aberto a certa distância da aldeia. Os soldados ficaram por alguns dias na floresta, mas nunca fizeram contato com a aldeia. 0s habitantes de Wong Garai estavam perturbados com esse episódio já que localmente essa atitude é considerada como uma ruptura da cortesia comum. Eles entenderam tal falta de preocupação por comportamento apropriado como um sinal de arrogância e como um reflexo de sua própria impotência diante da situação.

$\mathrm{C}=4 ; \mathrm{W}=4$ (Iban) 
3. Em toda a área da RVSDS, expressa-se preocupação de que outros (por exemplo, empresas madeireiras, outros grupos étnicos, transmigrantes) estejam invadindo as áreas de uso tradicional, o que poderia por em risco a capacidade dos habitantes da comunidade de usar aqueles recursos no futuro. 0 grupo Iban está mais preocupado com os seus recursos florestais, enquanto o Melayu se preocupa com os recursos pesqueiros.

$\mathrm{C}=4 ; \mathrm{W}=4$ (Iban; Melayu)

4. Em Bemban, Ng. Kedebu' e Kelayang a maioria das pessoas expressou a convicção de que seus direitos às áreas e recursos em uso são reconhecidos e legítimos - apesar da competição por parte de outros atores presentes na área (especialmente do Projeto de Conservação e de empresas madeireiras).

$\mathrm{C}=8 ; \mathrm{W}=8$ (Iban; Melayu)

\section{(C) 2: Os atores florestais possuem uma parte justa dos benefícios econômicos derivados do uso} da floresta.

(I) 2.1 As empresas oferecem oportunidades de emprego e treinamento para as pessoas locais e aquelas que dependem da floresta.

1. Muito poucos habitantes dentro e ao redor da RVSDS trabalham para as concessões madeireiras. A maioria dos trabalhadores é trazida de outros lugares. Kelayang está na concessão P.T. Panggau Libau, a qual pertence parcialmente aos ibans da área de Lubok Rian, sendo que alguns são parentes de habitantes de Kelayang. Embora o envolvimento econômico dos Kelayangs com essa empresa seja maior do que o observado entre outras empresas (tais como P.T. Militer ou P.T. Hutan Hebat) e comunidades locais, ainda há conflitos recorrentes (ver Colfer e Wadley 1996). As causas desses conflitos incluem oportunidades inadequadas de emprego, aluguel de terra prometido e não pago, solicitação por junco que efetivamente não era comprado e indenização injusta quando um membro da comunidade era morto por uma lancha da empresa.

$C=3 ; W=3$ (Iban)

2. $\mathrm{Em} \mathrm{Ng}$. Kedebu', considera-se que somente uma pessoa teve uma relação de longo prazo com a empresa madeireira. Homens jovens ocasionalmente trabalham por um período para as empresas madeireiras, mas, segundo a opinião de algumas pessoas, eles deixam a empresa quando a pesca se torna boa. Isso pode significar que os rendimentos da pesca (e atividades econômicas relacionadas) são melhores que os rendimentos provenientes da empresa. $C=2 ; W=2$ (Melayu)

3. Ver também (I) 2.3, Caso 1.

$\mathrm{C}=2 ; \mathrm{W}=2$ (Melayu)

(I) 2.2 Os danos são compensados de forma justa.

1. Em 1992, um subempreiteiro da P.T. Militer/P.T. Hutan Hebat negociou com Bemban o direito de extrair um número indeterminado de hectares em sua área tradicional, dando em troca um gerador portátil de 500 watts. As pessoas locais estão mais astutas, embora muitas vezes thes falte poder e voz para reivindicar justiça. $\mathrm{C}=2 ; \mathrm{W}=2$ (Iban) 
(I) 2.3 0s salários e outros benefícios seguem os padrões da Organização Nacional e ou Internacional do Trabalho (0IT).

1. Os trabalhadores com quem Colfer conversou - uma mistura de pessoas locais e recem-chegados — consideravamse razoavelmente bem pagos, com benefícios, condições de trabalho e padrões de segurança justos. ${ }^{17}$ Por outro lado, Wadley observou que ibans que têm trabalhado para as empresas de exploração indonésias geralmente se queixavam dos baixos salários locais (comparados àqueles que eles poderiam obter por trabalho semelhante na Malásia), das perigosas condições de trabalho e dos equipamentos ineficientes. Um número razoável de pessoas de Wong Garai tinha trabalhado para a P.T. Panggau Libau. Essas pessoas disseram que nunca foram pagas e jamais trabalhariam nessa empresa outra vez.

$\mathrm{C}=2 ; \mathrm{W}=2$ (Iban)

(I) 2.4 Existem mecanismos para divisão dos benefícios com comunidades locais.

1. Em Ng. Kedebu' e Bukit Rancond, as pessoas achavam que os fundos disponíveis para o Projeto de Conservação, provenientes de ecoturistas, e os pagamentos de salários e outras ajudas monetárias do projeto eram injustamente distribuídos.

$C=2 ; W=2$ (Melayu)

2. 0 pagamento de royalties para as comunidades locais, em reconhecimento de seus direitos anteriores, tem sido sugerido por alguns como um mecanismo para divisão mais justa dos benefícios. Nenhum royalty é pago para as comunidades da RVSDS ou para aquelas nas áreas adjacentes. As empresas pagam várias taxas para o agente florestal estabelecido nas Kapuas, mas essas taxas vão para Potianak (e um parte também vai para Jakarta; compare Acher, 1993).

$\mathrm{C}=2 ; \mathrm{W}=2$ (Melayu)

3. 0 governo indonésio exige que as concessionárias implementem o HPH Bina Desa, ou um programa de "orientação da vila". Esse programa, a ser executado de forma participativa, pode incluir projetos de geração de renda, melhoramentos estruturais na vila, melhoramentos agrícolas e contribuições para a educação, religião ou outros serviços comunitários (Confira, Wentzel, 1995). A P.T. Panggau Libau (parte dela pertencente aos ibans locais - uma situação única em nossa experiência) forneceu-nos uma listagem de igrejas e escolas construídas por ela, salários de professores que ela havia pago etc. Mesmo assim, havia reclamações significativas em relação às atividades da empresa por parte dos kelayangs (ver acima; e também trabalho anterior de Wadley em outras comunidades). A maioria das pessoas indagada na reserva e próximo a ela nunca tinha ouvido falar do HPH Bina Desa. As respostas das poucas pessoas que já haviam ouvido falar desse programa (um dos administradores do distrito e um executivo em uma concessão madeireira) esclareceu que o nível de atividade era mínimo. $C=4 ; W=4$ (Iban, Melayu)

\section{(C) 3: As pessoas associam o seu futuro e o de seus filhos ao manejo do recursos florestais.}

(I) 3.1 As pessoas investem em seu meio ambiente circundante (isto é, tempo, esforço, dinheiro).

1. Construção recente de muitas escolas e mesquitas na área da RVSDS. $\mathrm{C}=10 ; \mathrm{W}=10$ (Melayu)

17 Assim como ocorreu com a idéia da segurança de posse e uso, trabalhadores locais podem ter percepções diferentes das dos avaliadores vindos de outro lugar. As condições de trabalho locais não estão de acordo, por exemplo, com aquelas propostas pelas equipes do Cifor, ou com os padrões da 0IT. 
2. Aplicação dos regulamentos locais para proteger os recursos. Para o grupo Melayu esses regulamentos envolvem proteger áreas especiais, tais como viveiros de peixes; proibir o uso de redes de malha fina e a captura de peixes abaixo de um tamanho determinado; restringir o acesso ao junco ou à madeira de valor comercial; declarar ilegal a queimada. Para os ibans, envolvem manter a preservação de florestas especiais (pulau) e antigos sítios habitacionais (tembawai), além de proibir a agricultura no cume das montanhas, a fim de permitir a regeneração florestal das roças (ver Wadley et al. 1996). C = 10; W = 10 (Iban); C = 8 (Melayu)

3. Níveis educacionais crescentes (com sacrifício e investimento significativo por parte dos pais e filhos). Esse fato também tem consequiências negativas profundas e reconhecidas, tais como a perda do conhecimento tradicional do ritual ecológico da terra, desvalorização do trabalho e do conhecimento tradicional, bem como o aumento do consumismo.

$C=6 ; W=6$ (Iban; Melayu)

(I) 3.2 Os níveis de migração externa são baixos.

1. Há migração sazonal para a Reserva, principalmente de habitantes ao longo das Kapuas com ligações de parentesco com as comunidades dentro da Reserva. Os laços próximos de parentesco e os laços econômicos entre as comunidades da Reserva e suas "vilas de origem" ao longo das Kapuas também tornam difícil o controle dessa população sazonal crescente. Muitas dessas pessoas que começaram como pescadores sazonais na Reserva se estabeleceram e construíram lares permanentes. Muitos também expressam compromisso de permanecer e melhorar a comunidade para seus filhos.

$C=5 ; W=5$ (Melayu)

2. Os homens do grupo Iban são migrantes circulares regulares para a Malásia, onde trabalham por causa dos salários mais altos disponíveis nessa região. Eles normalmente retornam para casa, trazendo um prêmio de boasvindas com eles (muitas vezes na época da colheita).

$C=5 ; W=5$ (Iban)

3. A migração externa permanente não parece ser comum. Há muitos exemplos de jovens que partiram para estudar e retornaram. Também há exemplos de pessoas de meia idade que partiram para trabalhar por um período mas retornaram para sua comunidade de origem a fim de contribuir com suas novas habilidades e experiência. $\mathrm{C}=7 ; \mathrm{W}=7$ (Iban; Melayu)

(I) 3.3 As pessoas reconhecem a necessidade de equilibrar o número de indivíduos com o uso dos recursos naturais.

1. 0 controle de natalidade tem sido amplamente aceito - aceitação muitas vezes associada às questões de uso dos recursos. Todavia, as mulheres do grupo Iban se preocupam com a possibilidade de os níveis baixos ou estáveis de fertilidade entre os povos indígenas (como elas próprias) fornecerem uma desculpa para trazer transmigrantes para a área, os quais podem sobrepujá-los numericamente (mesmo reconhecendo que famílias com menos crianças são mais fáceis de manter, que elas estariam livres do risco real de morte na gravidez e no parto e que poderiam ser economicamente mais produtivas). $\mathrm{C}=7 ; \mathrm{W}=7$ (Iban) 
2. Parece haver considerável migração interna para a Reserva, com nenhum esforço ou meios para controlá-la. De fato, há uma ética de hospitalidade que tornaria difícil tal controle sem o apoio externo.

$C=3 ; W=3$ (Melayu)

3. Ver também (I) 3.2

(I) 3.4 As crianças são educadas (formal e informalmente) para o manejo dos recursos naturais.

1. Seleção pelos pais de uma variedade de valores a serem seguidos por seus filhos (dentro da família). A expectativa é que os filhos retornem de seus estudos e repassem o conhecimento sobre manejo dos recursos naturais para suas famílias e comunidades de origem. Encontramos muitos exemplos de jovens que fizeram exatamente isso. $C=5 ; W=5$ (Iban)

2. Os ibans possuem, até o momento, um sistema de posse da terra e regras e práticas sobre propriedade de árvores (ver Wadley 1997), além de manterem muitos rituais associados ao cultivo. No entanto, eles temem que esses "modos antigos" - os cantos de rituais, a rica linguagem cerimonial e os conhecimentos florestais e agrícolas - estejam sendo perdidos pela geração mais jovem. A competição entre a educação nacional e a televisão é constante. Em junho de 1996, por exemplo, um grupo de importantes rituais da aldeia estava sendo realizado à 1 hora da manhã (execução de oferendas, canto de invocação a deuses ancestrais). Nessa mesma hora, jovens haviam instalado um aparelho de som para tocar música pop indonésia, a qual era ouvida na outra extremidade da aldeia. As fontes de conhecimento cultural e ecológico (essencial ao manejo sustentável) adquirido por seus ancestrais imediatos e distantes estavam sendo perdidas.

$C=4 ; W=5$ (Iban)

(I) $3.5 \mathrm{~A}$ destruição dos recursos naturais pelas comunidades locais é rara. ${ }^{18}$

1. Envenenamento recorrente de peixes com pesticidas comerciais, em geral por uma minoria de comerciantes ibans, mas também por alguns melayus. $\mathrm{C}=4 ; \mathrm{W}=4$ (Iban; Melayu)

2. Uso da jermal padat, por poucos indivíduos melayus comparativamente ricos (sob uma política governamental esquizofrênica). $C=3 ; W=3$ (Melayu)

3. Notou-se super exploração da floresta de várzea (rawa) pelas pessoas locais - os estoques atuais de espécies disponíveis à população local estão significativamente reduzidos (tembesu', kawi, kelansau, medang, menyawai). [aquelas usadas pelos melayus são em sua maioria espécies da várzea.]

$\mathrm{C}=5 ; \mathrm{W}=5$ (Melayu)

18 Outros C\&I terão de tratar da destruição feita por outros atores (por exemplo, extração de madeira pelos concecionários sem respeito aos regulamentos; transmigração de grande número de famílias para áreas de floresta já ocupadas, conversão de áreas de floresta natural em propriedades industriais madeireiras ou plantações de dendê/seringueira). 


\section{(I) 3.6 As pessoas mantêm vínculos espirituais com a terra.}

1. Durante a breve estadia de Colfer em Kelayang foram observadas três cerimônias religiosas relacionadas aos recursos, as quais incluíam o envolvimento ativo de jovens (uma para "alimentar" um espírito de crocodilo no rio, cuja fome tinha sido revelada em um sonho constituindo uma ameaça a um membro da comunidade; uma para "alimentar" o solo antes de começar a limpar um arrozal, e outra para "alimentar" o solo em preparação para o plantio).

$C=10 ; W=10$ (Iban)

2. Forte senso de tradição local (entre os ibans) e um senso explicitamente declarado de responsabilidade em cuidar dos filhos, netos e descendentes subseqüentes. $C=8 ; W=8$ (Iban)

3. Os ibans referem-se às florestas como seput menoa, "a respiração da terra", e reconhecem as conseqüências hidrológicas resultantes da excessiva exploração florestal — por exemplo, a secagem das fontes de água. ${ }^{19}$ $C=8 ; W=8$ (Iban)

4. Os pais de $\mathrm{Ng}$. Kedebu' expressam um senso de responsabilidade pelos seus descendentes, incluindo expressões de preocupação em relação à sustentabilidade dos recursos que são importantes para o seu estilo de vida (madeira, peixe, junco, abelhas).

$C=5 ; W=5$ (Melayu)

19 Esse conhecimento hidrológico possui um componente espititual. Os ibans afirmam que se eles não cuidarem da terra tanto ecologicamente quanto ritualmente, a terra e eles tornar-se-ão ameaçados pelo "calor" sobrenatural (angat) que se manifesta na saúde das pessoas e em desagregação social. 
TABELA 2.

Pontuação dos C\&I sobre Segurança de Acesso aos Recursos entre Gerações* (Colfer, Wadley e Harwell)

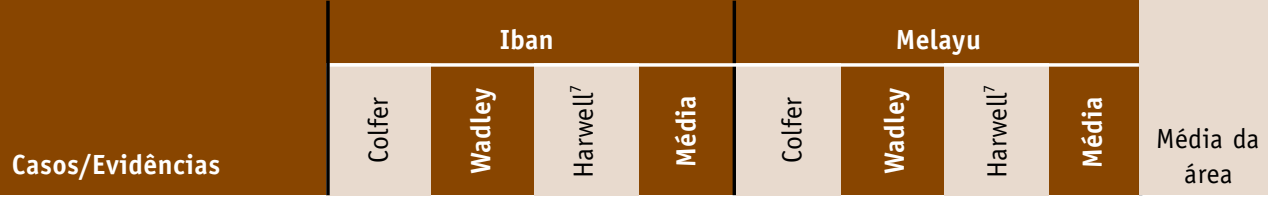

(C) 1: 0 manejo local é efetivo no controle da manutenção e acesso aos recursos.

\begin{tabular}{|c|c|c|c|c|c|c|c|c|c|}
\hline e respeitam os direitos preexistentes ${ }^{1}$ & 5,60 & 5,25 & 8,00 & 6,28 & 4,00 & 4,00 & 4,00 & 4,00 & 5,30 \\
\hline $\begin{array}{l}\text { (I) } 1.2 \text { As regras e padrões de uso dos } \\
\text { recursos são monitorados e efetivamente } \\
\text { aplicados }^{1}\end{array}$ & 6,50 & 6,50 & 7,50 & 6,83 & 5,50 & 5,50 & 4,50 & 5,17 & 6,12 \\
\hline $\begin{array}{l}\text { (I) } 1.3 \text { 0s meios para resolução de conflitos } \\
\text { funcionam sem violên } \text { cia }^{2}\end{array}$ & 6,00 & 6,00 & 8,00 & 6,67 & 5,00 & 5,00 & 4,00 & 4,67 & 5,81 \\
\hline $\begin{array}{l}\text { (I) } 1.40 \text { acesso aos recursos florestais é } \\
\text { considerado justo localmente }\end{array}$ & 4,00 & 4,00 & 5,00 & 4,33 & 2,33 & 2,33 & 3,00 & 2,56 & 3,57 \\
\hline $\begin{array}{l}\text { (I) } 1.5 \text { As pessoas locais se sentem seguras } \\
\text { em relação ao acesso aos recursos }{ }^{3}\end{array}$ & 5,25 & 5,25 & 4,00 & 4,83 & 6,00 & 6,00 & 4,00 & 5,33 & 5,05 \\
\hline
\end{tabular}

(C) 2: Os atores florestais possuem uma parte justa dos benefícios econômicos derivados do uso da floresta.

\begin{tabular}{|c|c|c|c|c|c|c|c|c|c|}
\hline $\begin{array}{l}\text { (I)2.1 As pessoas locais recebem emprego } \\
\text { e treinamento das empresas florestais }{ }^{4}\end{array}$ & 3,00 & 3,00 & 2,00 & 2,67 & 2,00 & 2,00 & 2,00 & 2,00 & 2,38 \\
\hline $\begin{array}{l}\text { (I)2.2 0s danos são compensados de } \\
\text { uma maneira justa }{ }^{5}\end{array}$ & 3,50 & 3,50 & 3,00 & 3,33 & & & 3,00 & 3,00 & 3,27 \\
\hline $\begin{array}{l}\text { (I)2.3 0s salários e outros benefícios estão } \\
\text { de acordo aos padrões nacionais e ou da } \text { OIT }^{6}\end{array}$ & 2,00 & 2,00 & 3,00 & 2,33 & & & 3,00 & 3,00 & 2,47 \\
\hline $\begin{array}{l}\text { (I)2.4 Existem mecanismos justos para } \\
\text { divisão dos benefícios com as comunidades } \\
\text { locais }^{4}\end{array}$ & 4,00 & 4,00 & 2,00 & 3,33 & 2,67 & 2,67 & 2,00 & 2,44 & 2,95 \\
\hline
\end{tabular}

(C) 3: As pessoas associam o seu futuro e o de seus filhos ao manejo dos recursos florestais.

\begin{tabular}{|c|c|c|c|c|c|c|c|c|c|}
\hline $\begin{array}{l}\text { (I) } 3.1 \text { As pessoas investem em seu meio } \\
\text { ambiente circundante (isto é, tempo, } \\
\text { esforço, dinheiro etc.) }\end{array}$ & 8,00 & 8,00 & 8,00 & 8,00 & 8,00 & 8,67 & 4,00 & 6,89 & 7,52 \\
\hline \multicolumn{10}{|l|}{$\begin{array}{l}\text { (I) } 3.2 \text { As pessoas reconhecem a } \\
\text { necessidade de equilibrar o número }\end{array}$} \\
\hline de indivíduos com os recursos naturais ${ }^{2}$ & 6,33 & 6,33 & 7,00 & 6,56 & 5,00 & 5,00 & 2,50 & 4,17 & 5,53 \\
\hline $\begin{array}{l}\text { (I) } 3.3 \text { As crianças são educadas } \\
\text { (formal e informalmente) para o manejo } \\
\text { dos recursos naturais }{ }^{4}\end{array}$ & 6,00 & 6,00 & 4,00 & 5,34 & & & 4,00 & 4,00 & 5,00 \\
\hline $\begin{array}{l}\text { (I) } 3.4 \mathrm{~A} \text { destruição dos recursos naturais } \\
\text { pelas comunidades locais é rara }{ }^{4}\end{array}$ & 4,00 & 4,00 & 5,00 & 4,33 & 4,00 & 4,00 & 5,00 & 4,33 & 4,33 \\
\hline $\begin{array}{l}\text { (I) } 3.6 \text { As pessoas mantêm ligações } \\
\text { espirituais com a terra }{ }^{3}\end{array}$ & 8,67 & 8,67 & 9,00 & 8,78 & 5,00 & 5,00 & 3,00 & 4,33 & 6,87 \\
\hline
\end{tabular}


* A expressão pode diferir um pouco porque os testes de campo aconteceram em 1996; e a soma e cálculo da média de alguns indicadores na tabela anterior não obterão as mesmas médias precisas, isso porque nós retiramos as referências e casos que estavam nos quadros dos textos originais de Colfer e Wadley.

1 Baseados nas pontuações médias (Colfer, Wadley) para seis casos (ver Tabela 1)

2 Baseados nas pontuações médias (Colfer, Wadley) para cinco casos (ver Tabela 1)

3 Baseados nas pontuações médias (Colfer, Wadley) para quatro casos (ver Tabela 1)

4 Baseados nas pontuações médias (Colfer, Wadley) para três casos (ver Tabela 1)

5 Baseados nas pontuações médias (Colfer, Wadley) para dois casos (ver Tabela 1)

6 Baseados nas pontuações médias (Colfer, Wadley) para um caso (ver Tabela 1)

7 Harwell pontuaou critérios e indicadores, mas nenhum caso

0 fato de as florestas e seus arredores na RVSDS estarem em condições comparativamente boas sugere que essas pontuações podem ser altas em uma escala global. A pontuação média baixa para o critério $2(2,5)$ sugere um possível sinal de alerta. De fato, a percepção da injustiça em relação à parte dos benefícios florestais recebida pelas pessoas locais era tanto uma reclamação recorrente como uma razão para confronto violento. Nossa avaliação comparativamente alta da força do sentimento de segurança das pessoas em relação ao acesso aos recursos (7) e a clara ligação conceitual entre elas próprias e o bem-estar de seus filhos e das florestas $(5,4)$ parece, provavelmente, contribuir para a sustentabilidade por: i) confirmar seu "interesse" na floresta; e ii) fornecer motivação para protegê-la contra novas diligências potencialmente destrutivas na área. 


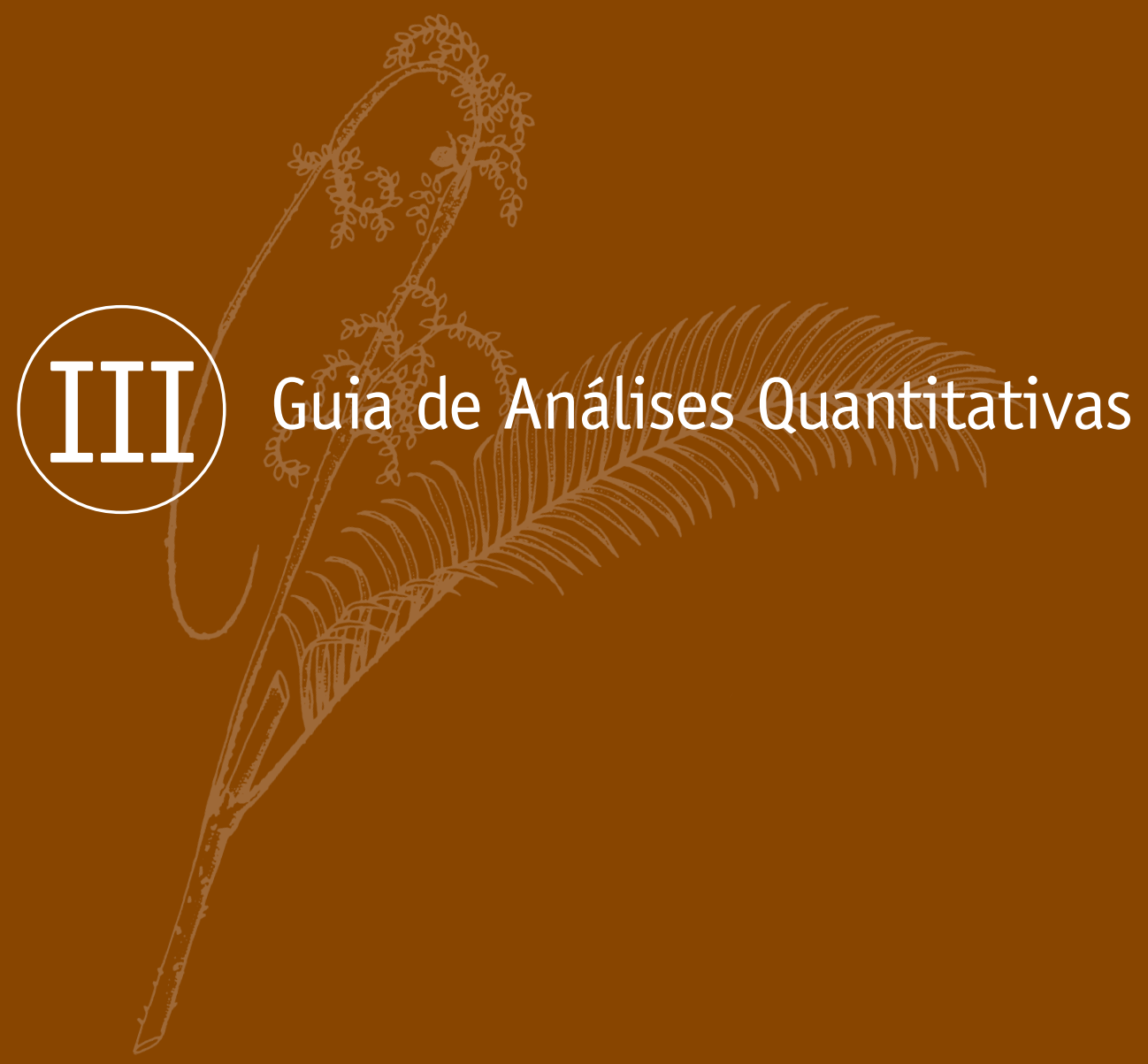


guia de Análises Quantitativas foi elaborado para ajudar os usuários interessados em analisar os dados derivados dos métodos quantitativos disponíveis nos manuais GBA e Os Acessórios. Nesta seção, fornecemos orientação detalhada sobre o uso de planilhas eletrônicas; análises descritivas simples dos dados; e uma introdução a testes estatísticos mais complexos. Visto que em nossos testes de métodos de avaliação dos C\&I sociais encontramos diferentes níveis de conhecimento em computação, concluímos que o caminho mais seguro seria "começar de forma simples”. Se você já tem experiência com planilhas eletrônicas, você não precisa ler grande parte do material a seguir. Por outro lado, se você tem pouca experiência no uso de computadores, esperamos que essas instruções lhe sejam bastante úteis.

\section{A - ANÁLISE DOS RESULTADOS DE UM MÉTODO DE IDENTIFICAÇÃO DE ATORES (CATPAC)}

O CatPac é um programa de computador que usa a análise da rede neural para identificar agrupamentos de palavras nas conversas das pessoas. A maioria dos especialistas em comunicação argumenta que a conversa é o reflexo do pensamento. O CatPac tem sido utilizado no contexto de avaliação do bem-estar humano nas florestas para identificar atores florestais relevantes na República dos Camarões, Indonésia e Brasil. Instruções sobre o uso dos métodos estão disponíveis no manual Os Acessórios. Este manual trata somente da análise dos resultados.

\section{GUIA DE USO DO CATPAC ${ }^{20}$}

Esta seção descreve aos novos usuários do CatPac os procedimentos para inserir texto/dados no computador, alguns dos atributos relacionados ao computador que requerem decisóes e os procedimentos para criar os dendogramas e mapas cognitivos que compreendem os resultados do CatPac.

20 Há um manual do usuário do CatPac feito por Woefel (1998), o qual contém informações mais abrangentes sobre esse programa de computador. 0 objetivo do nosso guia é apenas orientar você sobre os procedimentos mais cruciais no uso do CatPac. 


\section{a. Como inserir o texto/dados}

- Após gravar a entrevista, a próxima etapa é inserir o texto no computador. Você pode fazê-lo usando qualquer programa processador de texto, mas lembre-se de teclar Enter ${ }^{\mathrm{NT}}$ no final de cada linha. Dessa forma, quando você abrir o texto usando o programa CatPac, ele permanecerá em um formato legível ${ }^{21}$.

- Após terminar de introduzir o texto de cada participante, tecle '- 1 ' para separar um participante do outro. Certifique-se de ter introduzido os dados de uma categoria (homem/mulher, diferentes grupos étnicos, ocupação etc.) em um arquivo.

- Salve o arquivo no formato de texto (*.txt.), pois o CatPac abre somente arquivos de texto.

\section{b. Como escolher um método adequado de agrupamento}

Todas as técnicas de agrupamento fornecidas pelo CatPac são baseadas em um método aglomerativo. Não há uma regra exata a escolher. Para saber mais sobre as vantagens e desvantagens de cada método, vá ao item Option no menu e, em seguida, escolha o método de agrupamento que desejar. Um menu de diálogo aparecerá na tela. Para saber mais sobre cada método de agrupamento, clique na opção $\underline{H}$ elp no menu.

\section{c. Com criar um arquivo exclude}

Visto que você está interessado em agrupar palavras/conceitos significativos, provavelmente você terá de excluir de suas análises certas palavras com significado essencialmente gramatical e outras (tais como "é/está", "muito", "isto/isso"). O CatPac possui um arquivo predefinido exclude $^{22}$ em inglês. Entretanto, é provável que em muitos casos esse arquivo não lhe ajudará muito, visto que a maioria das entrevistas deverá estar no idioma local. Neste caso, você terá de fazer um arquivo exclude para tal idioma. Inicialmente, você pode traduzir o arquivo em

\footnotetext{
NT A tradução dos termos em inglês em itálico e negrito você encontra no glossário no final desta seção.

21 Muitos dos nossos colaboradores notaram que o texto que eles já haviam introduzido, tornou-se uma única linha longa de texto quando eles abriram o arquivo de texto no programa CatPac. Isso ocorreu porque eles não haviam teclado Enter no final de cada linha.

22 Um arquivo que contém uma lista de palavras que aparecem no texto de suas entrevistas, as quais têm um significado essencialmente gramatical e, portanto, não contribuem significativamente para o entendimento de conceitos relacionados ao estudo.
} 
inglês para o idioma local e usar a tradução como o novo arquivo exclude. Você pode fazê-lo salvando o arquivo em inglês em outro arquivo com extensão *.exc. Talvez seja mais fácil imaginar marcadores gramaticais semelhantes no idioma local e listá-los no arquivo exclude. Se você notar que há mais palavras irrelevantes que precisam ser excluídas, você pode adicioná-las à lista agrupandoas na parte inferior de seu novo arquivo exclude.

\section{d. Como criar um dendograma}

Um dendograma é uma figura representando grupos cognitivos de conceitos baseados nas conversas (ou texto) que você inseriu no computador e analisou. Ele normalmente possui a forma de uma luva (ver exemplo a seguir).

- Primeiramente, ative o arquivo exclude, abrindo-o. Em seguida, abra o arquivo do texto que você quer analisar. Você pode usar a configuração predefinida para opções, incluindo tamanho da janela, tamanho do quadro, técnicas de agrupamento etc. ${ }^{23}$

- Vá para a opção Fíle no menu e escolha $\underline{R} u n$ e, em seguida, escolha Make Dendogram. O CatPac dará a você os resultados em poucos segundos. Você pode imprimir o dendograma diretamente, escolhendo Print na opção File no menu. Você também pode salvar o dendograma como arquivo *.den, escolhendo Save As na opção File no menu (ver a seguir, dendograma de amostra). 


\section{DENDOGRAMA DE AMOSTRA}

$\begin{array}{lrlr}\text { TOTAL WORDS } & 96 & \text { THRESHOLD } & 0.000 \\ \text { TOTAL UNIOUE WORDS } & 25 & \text { RESTORING FORCE } & 0.100 \\ \text { TOTAL EPISODES } & 101 & \text { CYCLES } & 1 \\ \text { TOTAL LINES } & 27 & \text { FUNCTION } & \text { HYPerbolic } \\ & & \text { CLAMPING } & \text { Yes }\end{array}$

\section{DESCENDING FREQUENCY LIST}

CASE CASE

\section{WORD}

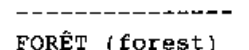

\section{SAUVAGES (Wild)}

DONNE (give)

MaNGUES (mango)

MIEL (honey)

NKONO

NoYaux (pits)

TROUVE (find)

ANIMAUX (animals)

IGNAMES (Yams)

MANGIR (to eat)

MOABI [a tree]

MOI (me)

EARTIE (part)

cHose (thing)

MANGUIERS

NEES (bOIn)

FRODUITs (producta)

SE [reflexive, self]

VIE (life)

VIS (lives)

ANCÊTRES (ancestors) 1 1.0

AUCUN (none)

WARDS METHOD

FREQ PCNT FREQ PCNT

$2526.0 \quad 9493.1$

$48 \quad 47.5$

$34 \quad 33.7$

$27 \quad 25.7$

$\begin{array}{lll}31 & 30.7\end{array}$

$28 \quad 27.7$

$28 \quad 27.7$

$36 \quad 35.6$

2120.8

$28 \quad 27.7$

2120.8

$28 \quad 27.7$

2120.8

98.9

$10 \quad 9.9$

$10 \quad 9.9$

1312.9

1413.9

1413.9

1413.9

1413.9

1413.9

1413.9

$7 \quad 6.9$

$7 \quad 6.9$
ALPHABETICALLY SORTED LIST

CASE CASE

WORD FREO PCAT FREQ PCET

$\begin{array}{lrrrr}\text { ANCETRES } & 1 & 1.0 & 7 & 6.9 \\ \text { ANIMAUX } & 3 & 3.1 & 21 & 20.8 \\ \text { AUCUN } & 1 & 1.0 & 7 & 6.9 \\ \text { CHOSE } & 2 & 2.1 & 10 & 9.9 \\ \text { DONNE } & 5 & 5.2 & 34 & 33.7 \\ \text { FORET } & 25 & 26.0 & 94 & 93.1 \\ \text { IGNAMES } & 3 & 3.1 & 28 & 27.7 \\ \text { MANGER } & 3 & 3.1 & 21 & 20.8 \\ \text { MANGUES } & 4 & 4.2 & 27 & 26.7 \\ \text { MANGUIERS } & 2 & 2.1 & 10 & 9.9 \\ \text { MIEL } & 4 & 4.2 & 31 & 30.7 \\ \text { HOAEI } & 3 & 3.1 & 29 & 27.7 \\ \text { MOI } & 3 & 3.1 & 21 & 20.8 \\ \text { NKONO } & 4 & 4.2 & 28 & 27.7 \\ \text { NOYAUX } & 4 & 4.2 & 28 & 27.7 \\ \text { NES } & 2 & 2.1 & 13 & 12.9 \\ \text { PARTIE } & 3 & 3.1 & 9 & 8.9 \\ \text { PRODUITS } & 2 & 2.1 & 14 & 13.9 \\ \text { SAUVAGES } & 8 & 9.3 & 48 & 47.5 \\ \text { SE } & 2 & 2.1 & 14 & 13.9 \\ \text { TROUVE } & 4 & 4.2 & 36 & 35.6 \\ \text { VIANDE } & 2 & 2.1 & 14 & 13.9 \\ \text { VIE } & 2 & 2.1 & 14 & 13.9 \\ \text { VIS } & 2 & 2.1 & 14 & 13.9 \\ \text { VIVRE } & 2 & 2.1 & 14 & 13.9\end{array}$




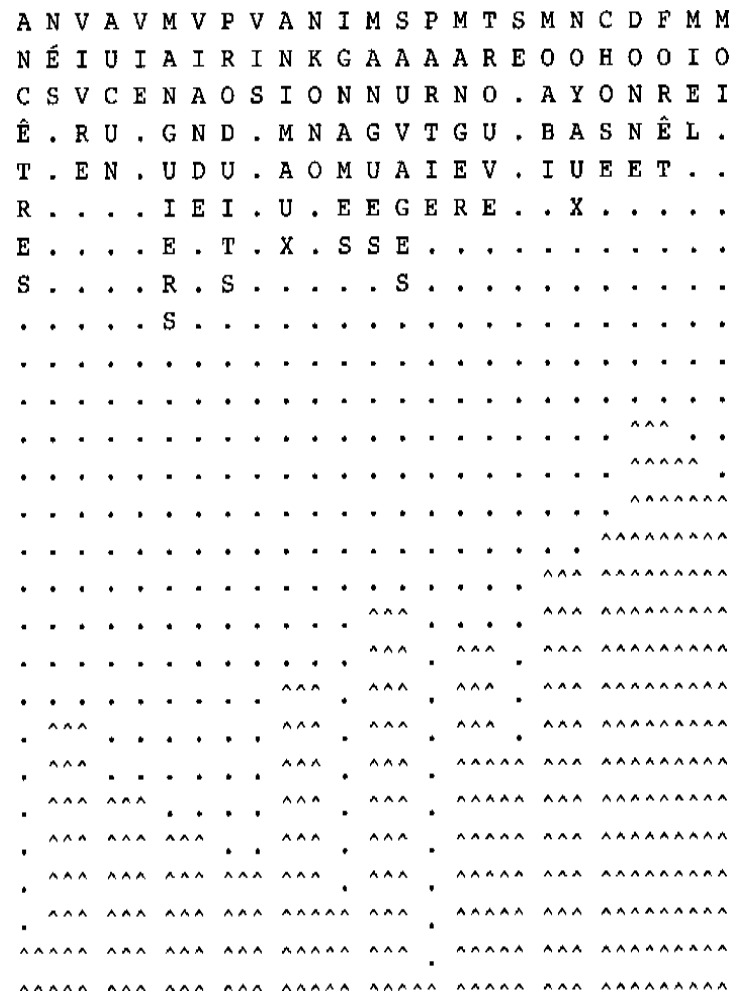

Interpretação: Esses dados proporcionam uma visualização do agrupamento de palavras do texto gravado. Os grupos de palavras ganham importância na medida em que partimos do pressuposto de que as conversas das pessoas refletem seus pensamentos, até um certo grau. Deste modo, se, por exemplo, as palavras "floresta" e "boa" aparecem freqüentemente juntas (formando um grupo), podemos concluir que essas pessoas conferem à floresta um valor positivo, o que pode ser interpretado como favorável à sustentabilidade. No exemplo acima, as palavras em francês para coisa (chose), dar (donne), floresta (forêt), mel (miel) e $\operatorname{mim}(m o i)$ representam o grupo mais importante. 
Isso sugere um papel importante do mel no manejo florestal local. Noyaux (caroços) e moabi (uma espécie de árvore da República dos Camarôes) estão em outro grupo importante de palavras próximo ao anterior, sugerindo que esses podem ser produtos florestais importantes utilizados pelas pessoas. $\mathrm{O}$ agrupamento de palavras na conversa das pessoas sobre assuntos tal como floresta (ou qualquer outra questão para pesquisa) fornece dicas importantes sobre as relações entre floresta e outros elementos no ambiente local, humanos ou não.

\section{e. Como criar um mapa cognitivo ${ }^{24}$ usando o CatPac}

- O CatPac também é capaz de produzir um mapa cognitivo. Para obtê-lo, salve o arquivo dendograma como um arquivo coordenada (*.crd). Quando aparecer uma caixa de diálogo, apenas clique em $O K$ e digite o nome de seu arquivo "coordenada".

- Abra o programa Thought View ${ }^{25}$ e, em seguida, o arquivo coordenada. Você pode fazer algumas alteraçōes no desenho (por exemplo, girá-lo, diminuir ou aumentar o seu tamanho; mudar o cubo, a grade, ou a cor da letra etc.).

- Quando o desenho estiver como você deseja, copie-o e cole-o ao outro programa, escolhendo $\underline{C} \boldsymbol{o p y}$ (Ctrl+Ins) na opção $\underline{\text { Edit no }}$ menu. Veja a seguir um mapa cognitivo de amostra.

240 mapa cognitivo pode ser usado para ajudar a interpretar os grupos de palavras. Na maioria das vezes, o mapa cognitivo fornece a mesma configuração do dendograma, mas algumas vezes ele pode fornecer novos entendimentos. Se os resultados dados pelos dois métodos forem conflitantes, recomenda-se fortemente o uso dos resultados do dendograma visto que esses são mais exatos.

250 Thought View é um programa complementar para o CatPac. Você pode instalá-lo clicando em Setup.exe no menu, no CD anexado ao programa CatPac e seguindo as instruções. 


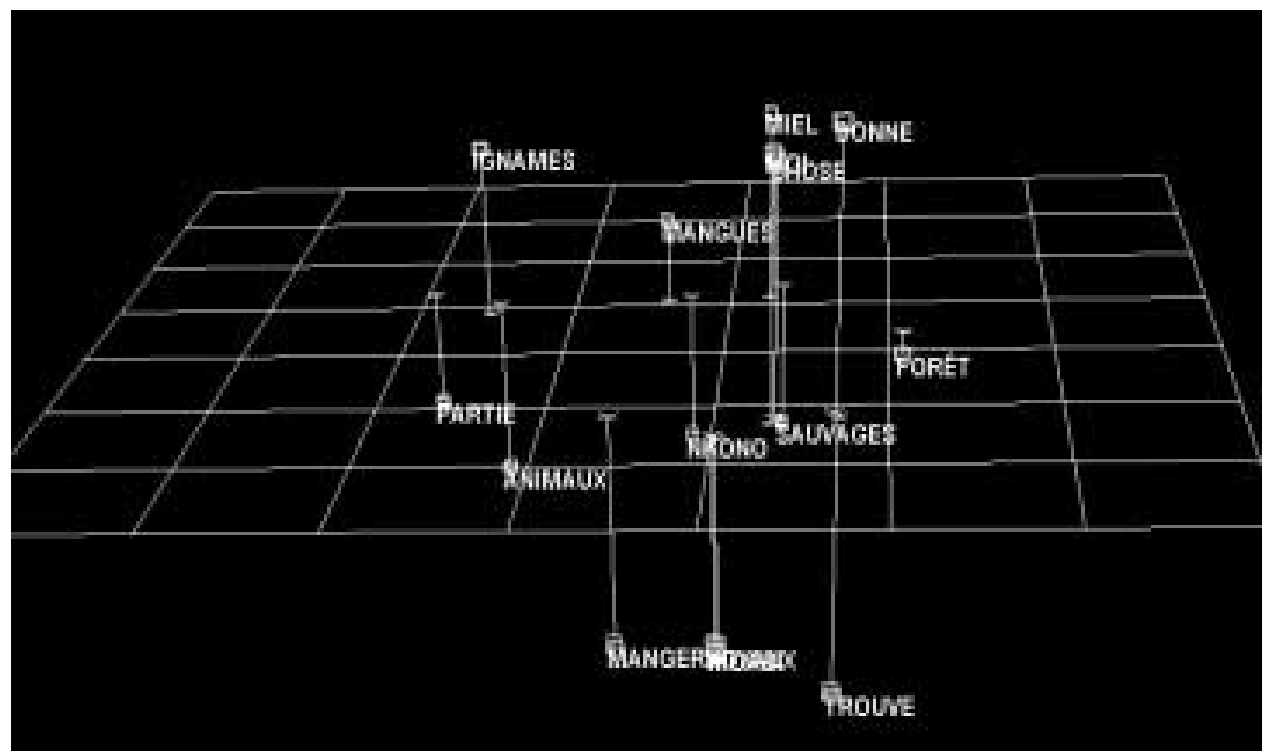

FIGURA 2. Mapa cognitivo para as mulheres baka (Reserva Dja, República dos Camarões).

O mapa cognitivo às vezes é útil para obter uma representação visual aproximada do pensamento das pessoas. Novamente você pode observar as relações próximas entre as palavras miel (mel), moi (mim), chose (coisa) e donne (dar). Diferente do que alguém poderia supor, a palavra forêt (floresta) aparece mais distante da análise do grupo de palavras. Na parte inferior da figura, os dois termos ilegíveis são noyaux (caroço) e moabi (uma árvore de valor comercial da República dos Camarões). 


\section{B - ANÁLISE DOS MÉTODOS DE AVALIAÇÃO DA SEGURANÇA DE ACESSO AOS RECURSOS ENTRE GERAÇÕES}

Esta seção contém um guia de análise para três métodos de avaliação das ciências sociais: Matriz Histo-Ecológica, Acesso aos Recursos ao longo das Geraçôes e Divisão dos Benefícios entre os Atores. Esses métodos têm sido considerados úteis na avaliação da segurança de acesso aos recursos entre gerações em determinadas florestas entre determinados grupos de pessoas.

\section{GUIA DE MONTAGEM DA MATRIZ HISTO-ECOLÓGICA}

a. Introduzindo os dados

Você pode seguir o mesmo formato apresentado na Figura 3. Os recursos identificados no campo são listados na parte superior da planilha (palmeiras, carne bovina, Egusi), enquanto os anos são listados verticalmente. Sugerimos que você introduza os dados em anos consecutivos, pois isto facilita a sua leitura. Porém, você não é obrigado a fazê-lo caso não queira.

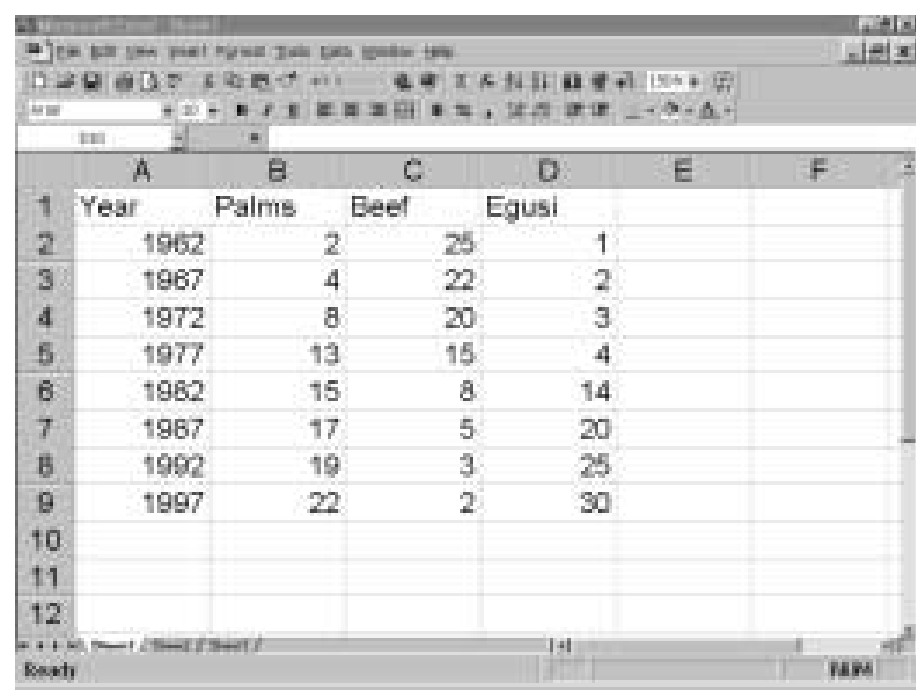

FIGURA 3. Formato da planilha para os dados histo-ecológicos. 


\section{b. Verificando a tendência linear ao longo do tempo}

Você pode determinar se os dados mostram uma tendência ao longo do tempo, usando a função Regression no programa Excel. Adicione o comando Regression no Excel, instalando o seu programa Add-Ins.

Para instalar o programa, siga os procedimentos a seguir:

- Vá para a opção Tools no menu e escolha Add-I Ins (Figura 4)

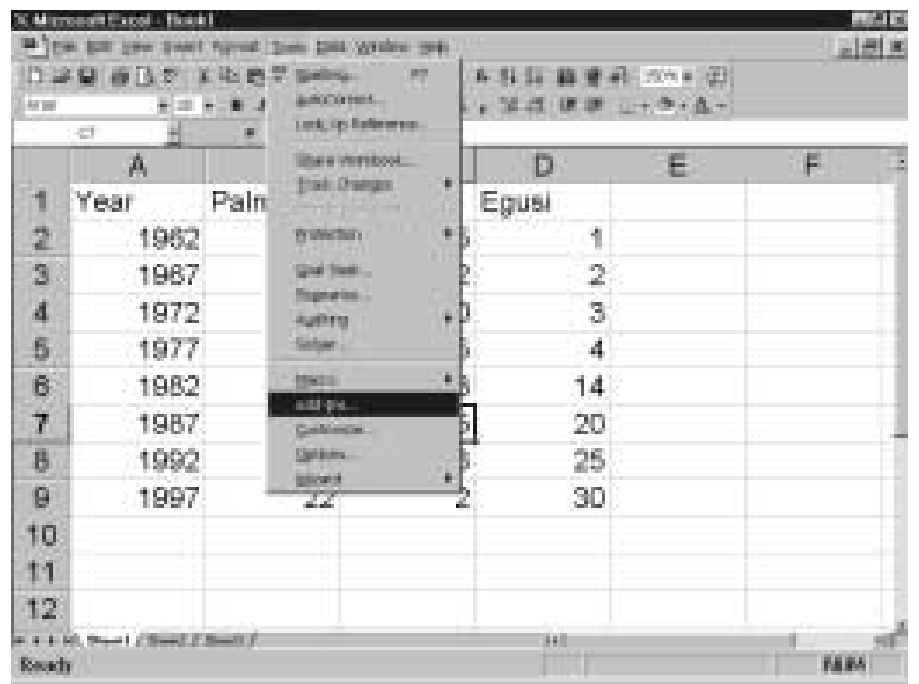

FIGURA 4. Escolhendo o submenu Add-Ins (dados histo-ecológicos).

Clique em Analysis ToolPak e Analysis ToolPak-VBA (Figura 5). Não clique nas opçôes se elas já estiverem marcadas, o que significa que o programa Add-Ins já foi instalado no seu computador. 


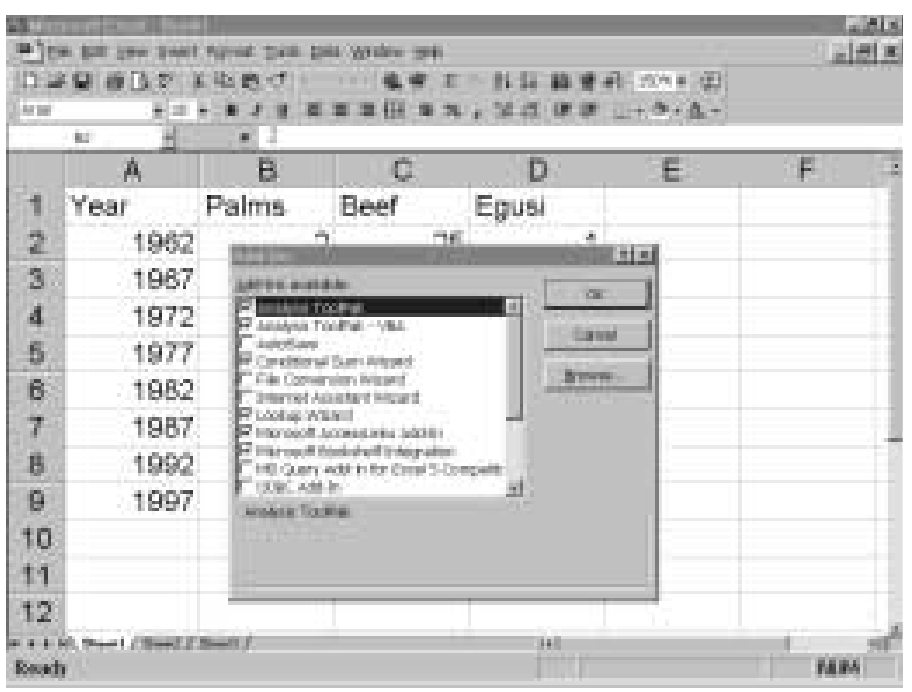

FIGURA 5. Escolhendo o módulo Suplementos (Add-Ins) especificado (dados histo-ecológicos).

- Após instalar esse programa, você verá que há um novo submenu na parte inferior da opção Iools do menu: Data Analysis. Você pode fazer a análise de regressão escolhendo o submenu $\underline{\text { Data }}$ Analysis.

- O menu de diálogo aparecerá na tela, como mostra a Figura 6. Escolha a opção Regression da lista de Analysis Tools e, em seguida, clique em $O K$ (Figura 6). 


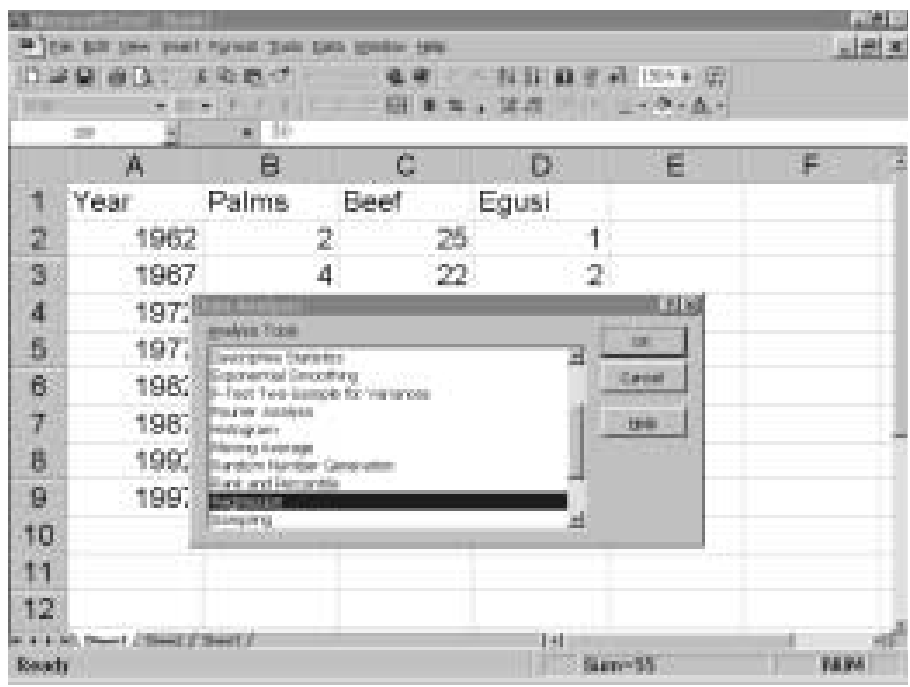

FIGURA 6. Iniciando a análise de regressão dos dados histo-ecológicos.

- O próximo passo é definir o intervalo (as "células" da planilha que contêm os dados) para as variáveis dependente $(Y)$ e independente $(\mathrm{X})$. Digite o intervalo de células no menu de diálogo como mostra a Figura 7. Por exemplo, se você quer verificar as tendências para as palmeiras (exemplo acima), você pode tratar a variável "palmeiras" como variável dependente e o "ano" (época) como variável independente. Não esqueça de clicar nas opções Residual Plot, Line Fit Plot e Normal Probability Plot, visto que você precisará delas mais tarde para verificar a adequação do modelo. Em seguida clique em $O K$. 


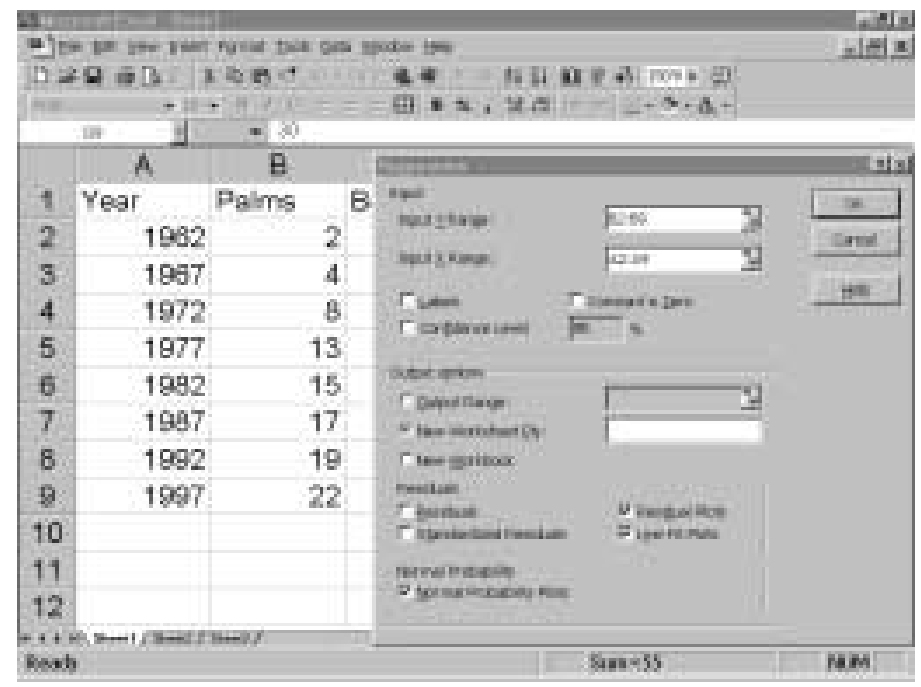

FIGURA 7. Definindo o intervalo de células da variável (dados histo-ecológicos).

- A Figura 8 apresenta o produto que você obterá da análise. Você pode verificar a significância do modelo, observando o Value- $P$ (indicado pela seta). Se o Value-P for abaixo de $5 \%(0,05)$, podese concluir que há uma tendência linear ${ }^{26}$ ao longo do tempo. A inclinação da linha indicará informações importantes sobre as percepções das pessoas sobre as mudanças nos recursos ao longo do tempo. Se a inclinação apresentar um sinal negativo, significa que a quantidade daquele recurso é percebida como decrescente. Se a inclinação apresentar um sinal positivo, a quantidade do recurso é percebida como crescente. Você também pode verificar o quanto a equação se ajusta aos dados, observando o $R$-square. Quanto mais alto for o $R$-square, melhor o ajuste. ${ }^{27}$

26 Se você encontrar que o Value-P não é significativo, isso não quer dizer que os dados não possuem um padrão ou tendência ao longo do tempo. Eles podem apresentar uma tendência não-linear (por exemplo, quadrática, cúbica etc.). 0 programa Excel não fornece ferramentas de análise para tendências nãolineares. Em tais casos, você pode usar programas estatísticos mais sofisticados, tais como o SPSS, o SAS ou o Minitab.

$270 R$-square é muito sensível às observações dos pontos discrepantes e às observações influentes. Há várias estatísticas usadas no lugar do $R$-square, as quais têm sido introduzidas para avaliar a boa qualidade do ajuste, incluindo o PRESS estatistic (Draper \& Smith 1982). Todavia, para o nosso modelo simples, o $R$-square é adequado. 


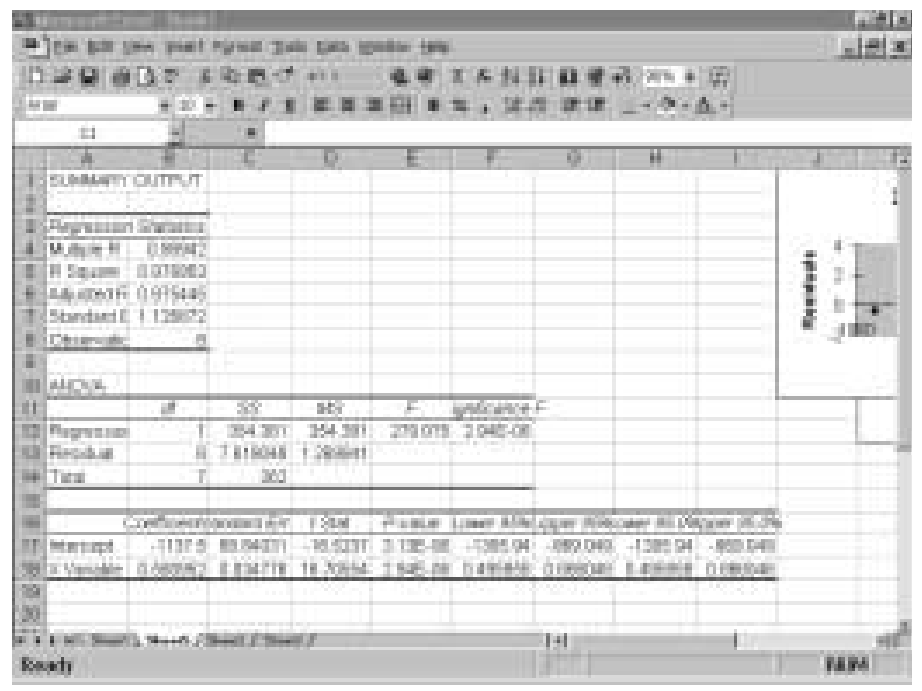

FIGURA 8. Produto da análise de regressão dos dados histo-ecológicos.

\section{c. Verificando a validez do modelo}

A análise de regressão, a qual tem sido utilizada amplamente para modelar a relação entre duas variáveis, possui vários pressupostos que precisam ser satisfeitos a fim de obter um modelo válido (confiável). Esses pressupostos são a normalidade dos resíduos, homogeneidade das variâncias dos resíduos, ausência de correlação entre resíduos etc. Uma discussão mais detalhada sobre esses pressupostos pode ser encontrada em Draper \& Smith 1981, embora o Apêndice A deste manual possa ensinar como investigálos usando abordagens explanatórias e gráficas. Entretanto, sugerimos firmemente que você use programas estatísticos, tais como o Minitab, o SAS e o SPSS (Pacote Estatístico para as Ciências Sociais), para fazer exame mais detalhado. Pelo fato de nossos dados serem similares aos dados de série temporal, é mais provável que haja resíduos correlacionados que violam os pressupostos. Nesse caso, regressão autoregressiva (Makridakis et al. 1983). 


\section{GUIA DE MONTAGEM DA MATRIZ “ACESSO AOS RECURSOS POR GERAÇÃO”}

Inicialmente, esta seção fornece informaçôes sobre como montar uma planilha e inserir os dados obtidos através do Método de Distribuição de Peças sobre o acesso aos recursos por geração (no $G B A$ ). Em seguida, explicamos como realizar a análise estatística simples desses dados, incluindo como verificar a distribuição dos dados e gerar tabelas descritivas simples. Os avaliadores que estão satisfeitos com as análises simples não precisam prosseguir. A parte final é para aqueles que desejam conduzir análises mais avançadas, tais como o teste da significância das diferenças de opinião entre os diferentes grupos (com base na etnia, idade, gênero etc.).

a. Introduzindo os dados

- Insira os dados usando programas de planilha, tais como o Excel ou o Lotus, se possível.

- Insira os dados demográficos (grupo de usuários, gênero, idade, nível educacional etc.) nas colunas à esquerda (como mostra a Figura 9, colunas de A a D). Se possível, insira os dados demográficos usando códigos numéricos. Se você possui dados referentes às categorias como gênero, nível educacional etc., você precisa convertê-los em códigos numéricos (por exemplo, feminino $=0$, masculino $=1$ etc.). É muito importante manter a folha de códigos, assim você saberá o significado de cada um deles. Você precisará dessa folha para conduzir a análise. Sugerimos que você registre a informação codificada na planilha. 


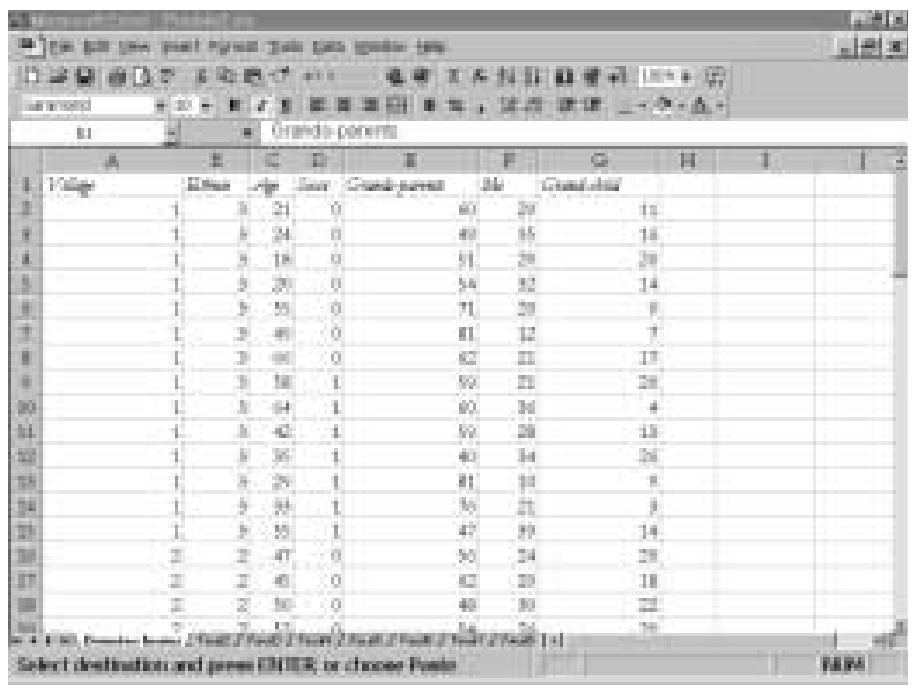

FIGURA 9. Formato da planilha para os dados intergeracionais.

- Você pode usar a coluna seguinte (neste caso a Coluna E) para introduzir o número de peças alocado pelos respondentes para cada geração (por exemplo, avós, eu, netos ${ }^{28}$ ). Você precisa apenas de uma fileira para cada respondente.

- Após introduzir os dados para todos os respondentes, não esqueça de salvar o arquivo no formato Lotus 123 (*.wk1).

a. Conduzindo análise simples dos dados usando o programa SPSS ${ }^{29}$

Usamos o SPSS para analisar os dados.

- Abrindo os dados - Você pode abrir o arquivo Lotus $123 \mathrm{em}$ uma planilha do programa SPSS. Use a opção read variable names. ${ }^{30}$

28 Normalmente usamos três categorias: avós, eu e netos, mas a equipe de Kalimantan Oriental (1997) acrescentou mais duas categorias: pais e filhos.

29 Nós também criamos diretrizes para aqueles que desejam fazer análises simples usando o programa Excel (ver a Parte C desta seção).

$30 \mathrm{Na}$ barra do menu do programa SPSS, você pode escolher o submenu Open da opção File. Em seguida, mude o tipo de arquivo para Lotus (*wk1) e escolha o arquivo que você deseja abrir. O processador do SPSS automaticamente perguntará se você quer ler o nome da variável ou não. Apenas clique na opção read variable names. 
- Rotulando os dados - Use a folha de códigos (aquela que você fez quando codificou os dados demográficos em códigos numéricos para rotulá-los). Coloque o cursor na coluna onde estão os dados demográficos. Veja abaixo um exemplo de rotulação de dados sobre gênero.

No menu, escolha:

\section{Data}

Define variable (Figura 10)

Clique no botão Labels (indicado pela seta).

O programa pedirá que você insira seu rótulo (Figura 11).

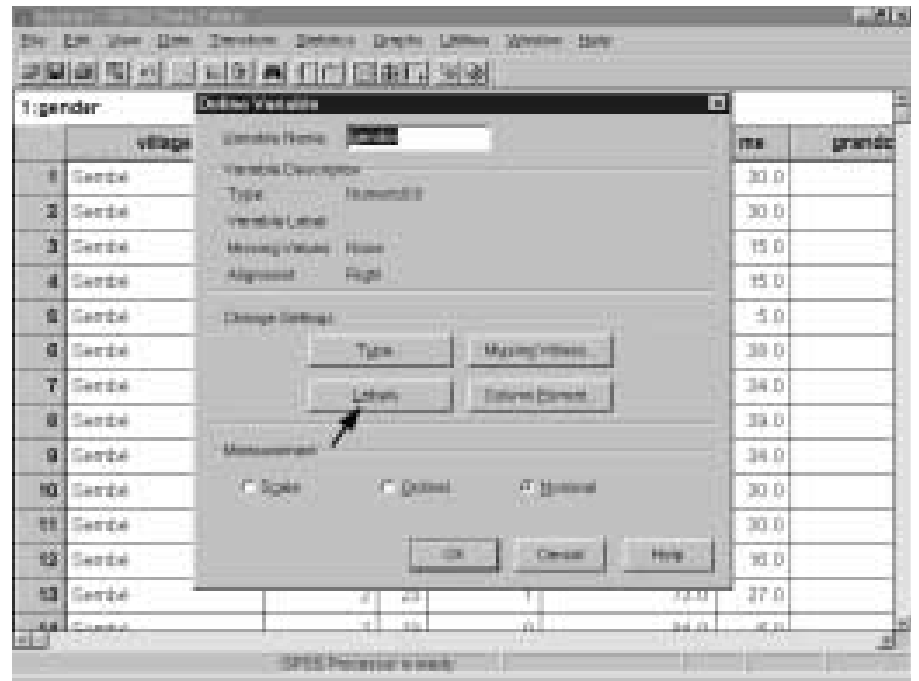

FIGURA 10. Botão Labels (dados intergeracionais). 


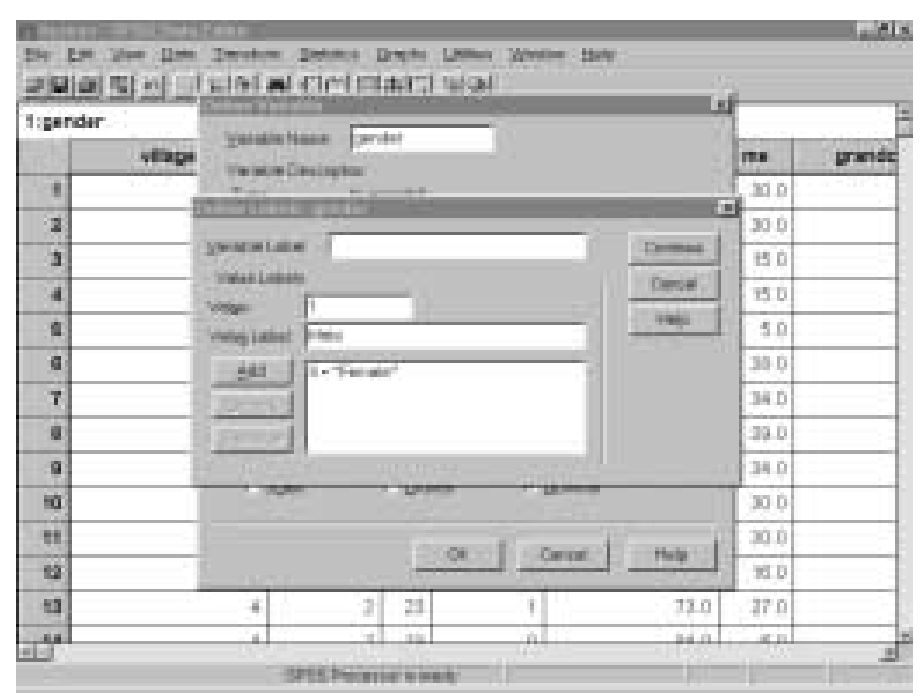

FIGURA 11. Definindo os rótulos (labels) por gênero nos dados intergeracionais.

Insira o rótulo demográfico (no exemplo acima, feminino) e, quando terminar, clique em Continue.

Siga os mesmos procedimentos para os outros dados demográficos.

- Verificando a distribuição dos dados - Normalmente calculamos a média aritmética para avaliar a distribuição de peças de acordo com os respondentes. Entretanto, o uso dessa média apresenta algumas desvantagens quando os dados não estão dispostos simetricamente ou quando há uma ou mais observaçôes discrepantes. Se esse for o caso, pode-se usar um valor mediano no lugar da média. Para verificar se os dados estão dispostos simetricamente ou não, podemos usar um diagrama de distribuição dos dados (boxplot). Verificamos os dados separadamente para cada geração, uma vez que cada uma foi considerada como uma variável separada. Se a maioria das gerações foi disposta assimetricamente, podemos usar a mediana. Por outro lado, se a maioria das gerações foi distribuída simetricamente, podemos usar a média aritmética. 
Para obter um diagrama de distribuição dos dados siga as instruções abaixo:

No menu, escolha Graphs

$$
\text { Boxplot }
$$

Escolha simple e, em seguida, summaries for separate variables (Figura 12).

Clique no botão Define.

Insira todas as gerações como variáveis (Figura 13) e, em seguida, clique em $O K$.

* Você obterá um diagrama de distribuição dos dados (boxplot) como mostra a Figura 14. A linha em preto dentro da barra mostra a posição mediana. As bordas superior e inferior da barra mostram a posição dos $3^{\circ}$ e $1^{\circ}$ quartis, respectivamente. Os dados estão distribuídos simetricamente se, e somente se, os valores intermediários estiverem localizados no meio da barra, aproximadamente a mesma distância dos $3^{\circ}$ e $1^{\circ}$ quartis. 


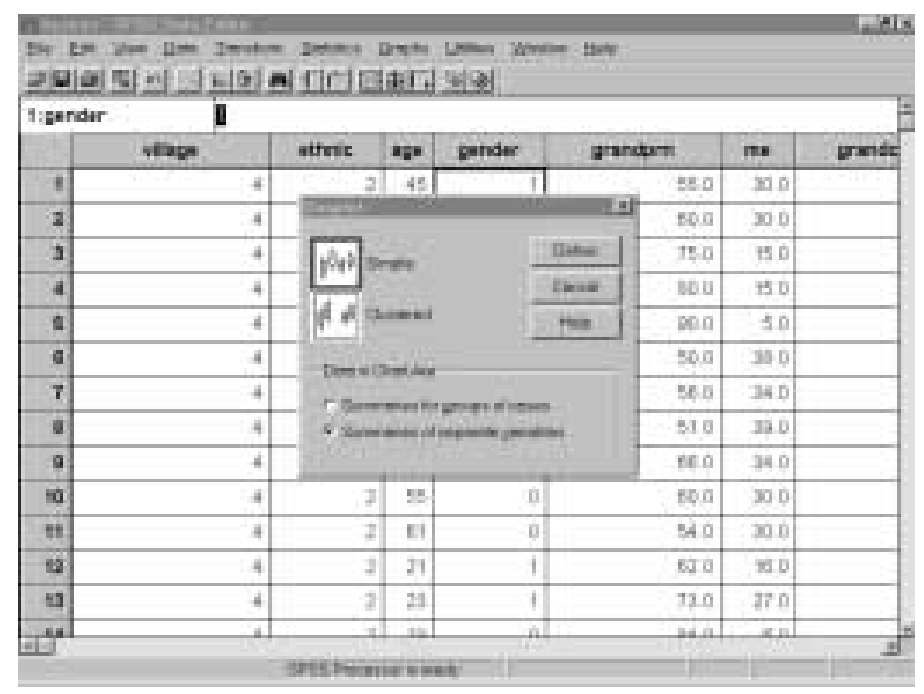

FIGURA 12. Escolhendo o tipo de diagrama de distribuição dos dados (boxplot) intergeracionais.

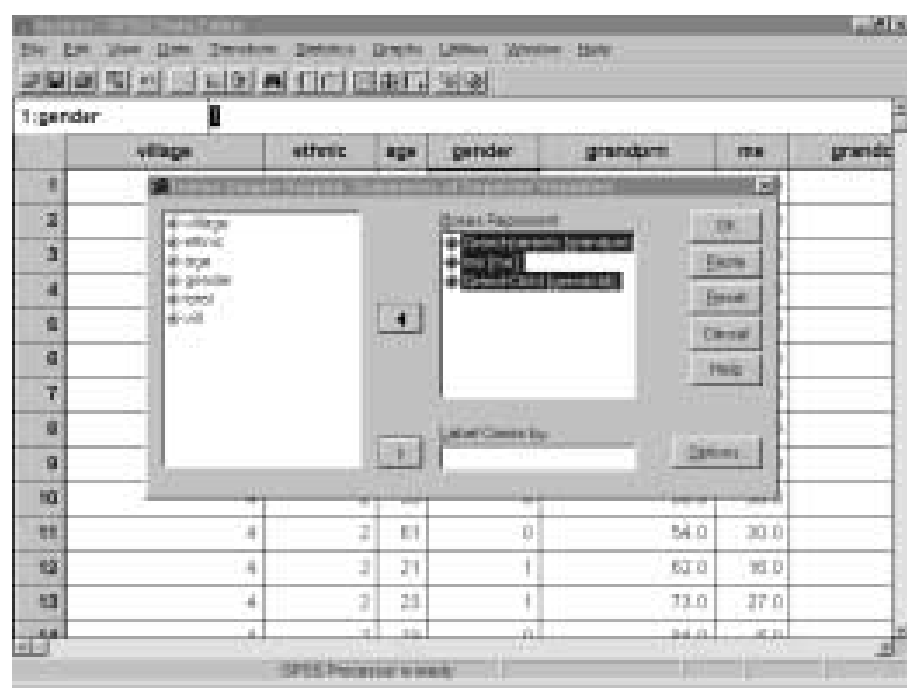

FIGURA 13. Escolhendo as variáveis dos dados intergeracionais (para verificar a distribuição dos dados). 


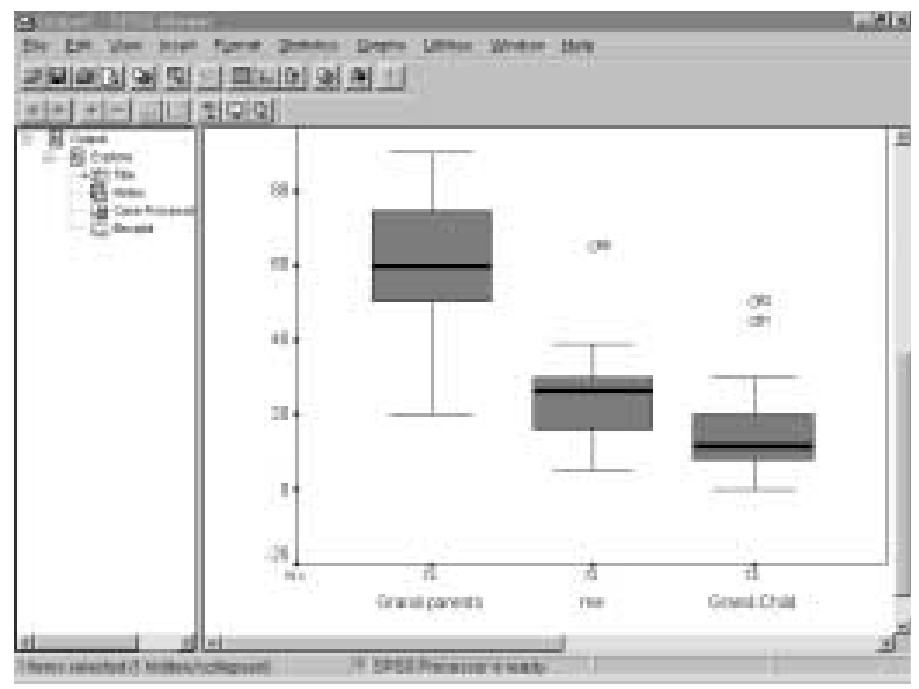

FIGURA 14. Diagrama de distribuição dos dados (boxplot) intergeracionais.

* Se a distribuição dos dados estiver muito assimétrica ou houver algumas observações discrepantes (usualmente indicadas por asteriscos ou círculos), sugerimos que você use a mediana. Nos diagramas de distribuição dos dados acima, consideramos "eu" e "netos" como tendo uma distribuição assimétrica, visto que a posição mediana está descentralizada e há algumas observações discrepantes. Portanto, usamos uma mediana para analisar os dados referentes à distribuição do acesso aos recursos entre gerações.

- Criando a tabela que descreve a distribuição do acesso aos recursos ao longo das geraçóes de acordo com todos os respondentes

* No menu, escolha

\author{
Statistics \\ Custom Tables \\ Basic Tables
}


Insira todas as gerações no item summaries. Você pode fazê-lo clicando no nome da variável e, em seguida, clicando sobre a seta diante do quadro summaries (Figura 15).

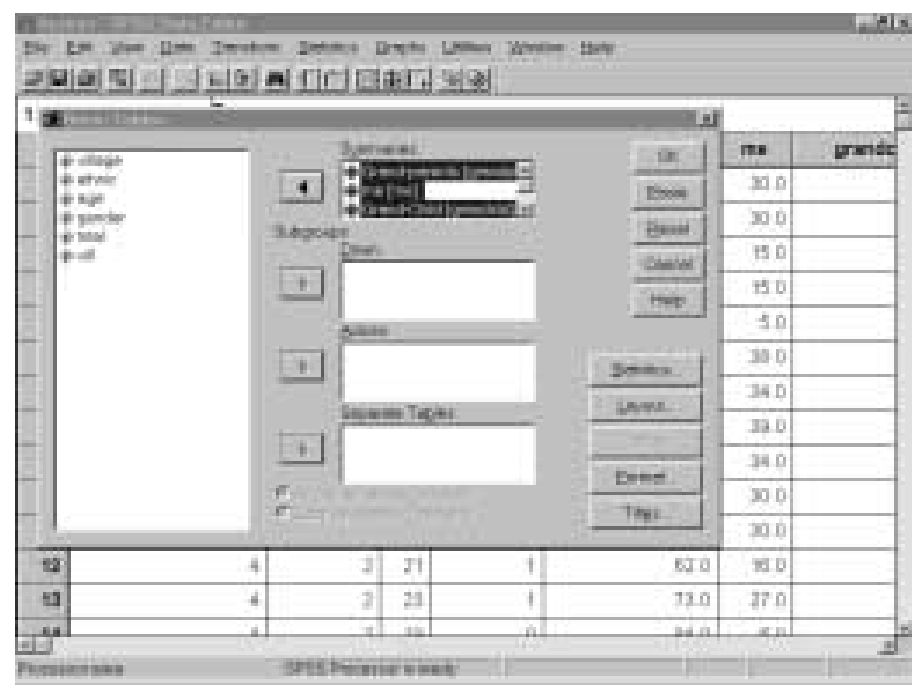

FIGURA 15. Selecionando as variáveis intergeracionais.

Clique no botão Statistics e acrescente mean ou median (dependendo de qual medida você decidir usar) como a estatística a ser calculada na célula.

Clicando em $O K$ você obterá os resultados (Figura 16). 


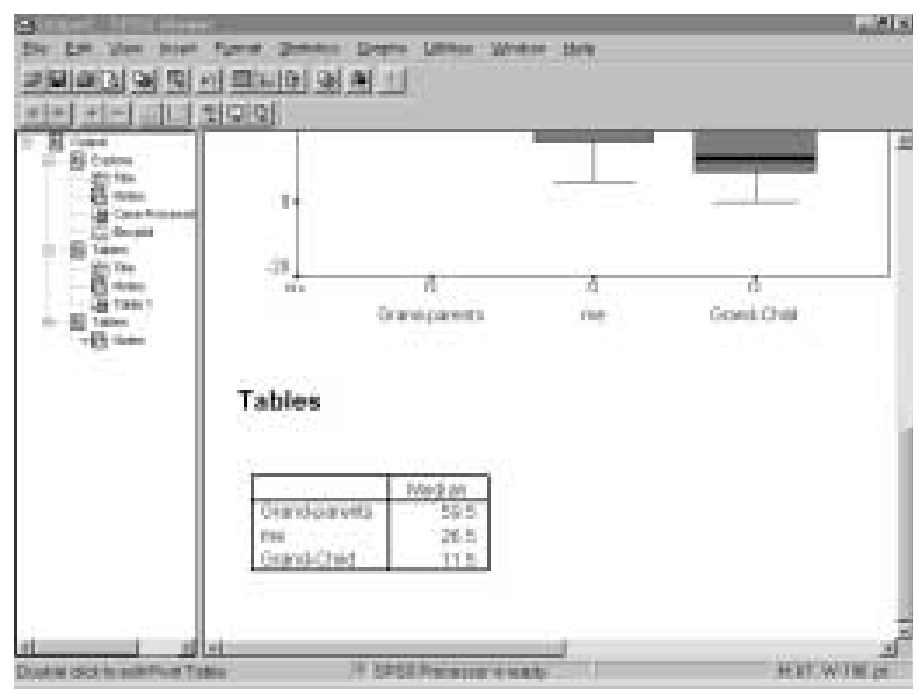

FIGURA 16. Tabela do programa SPSS descrevendo a distribuição do acesso aos recursos ao longo das gerações de acordo com todos os respondentes.

c. Conduzindo análise simples usando o programa Excel

- Criando a tabela que descreve a distribuição de peças de acordo com todos os respondentes

* Na opção Data no menu, escolha Pivot Table Report. Você verá uma caixa de diálogo como mostra a Figura 17. 


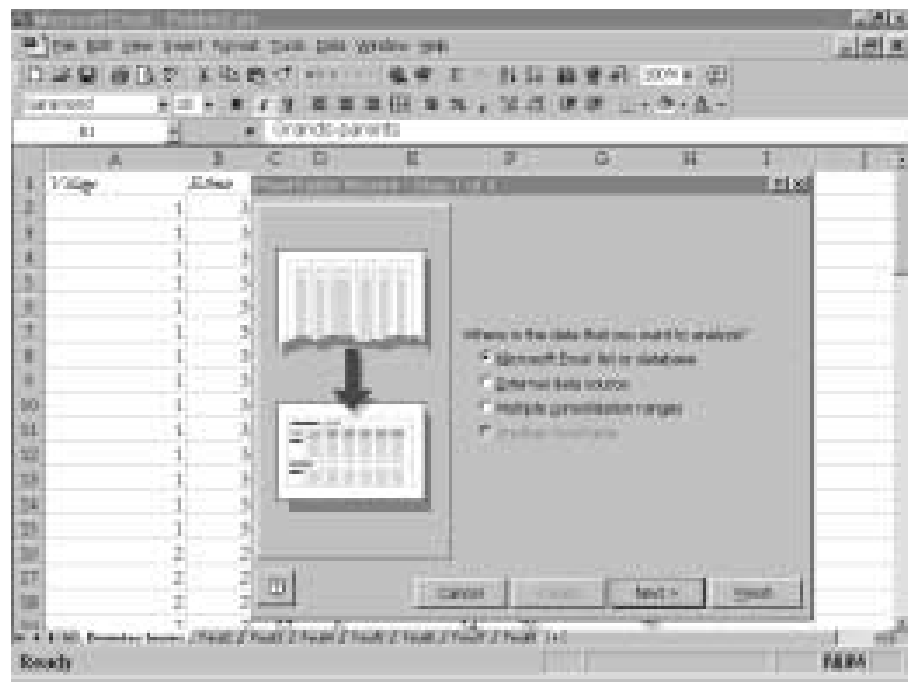

FIGURA 17. Assistente da tabela dinâmica (pivot table wizard) (dados intergeracionais).

Clique no botão Next> e você verá um caixa de diálogo como mostra a Figura 18.

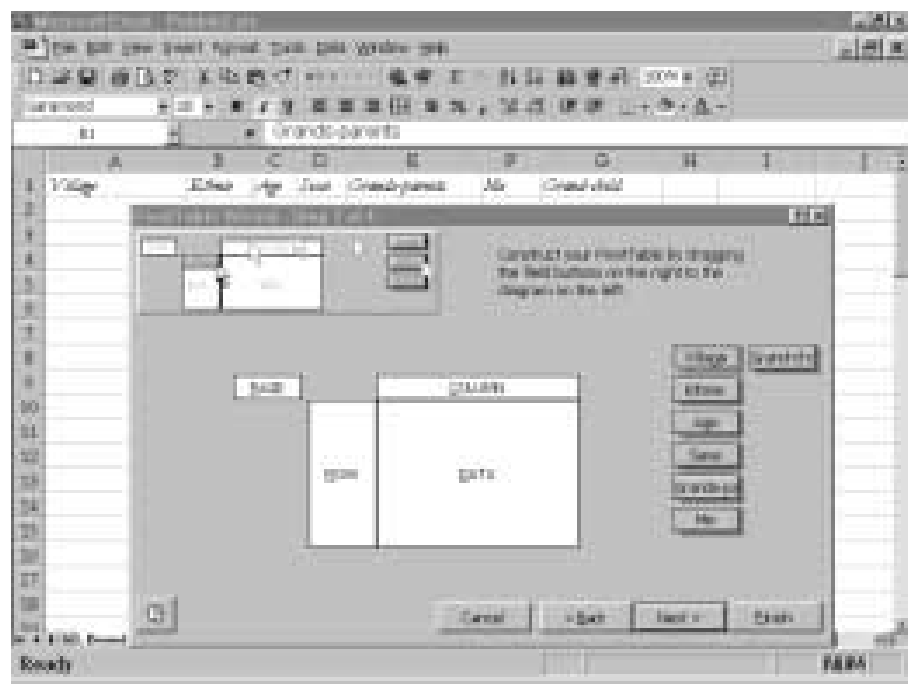

FIGURA 18. Construindo uma tabela dinâmica (pivot table) para a análise simples dos dados intergeracionais ( $1^{\text {a }}$ etapa). 
Arraste com o mouse todas as geraçóes para o espaço dos dados (Figura 19).

A soma é a estatística predefinida. Você pode mudar a estatística pressionando no botão e escolhendo a estatística que você deseja calcular (Figura 20). ${ }^{31}$

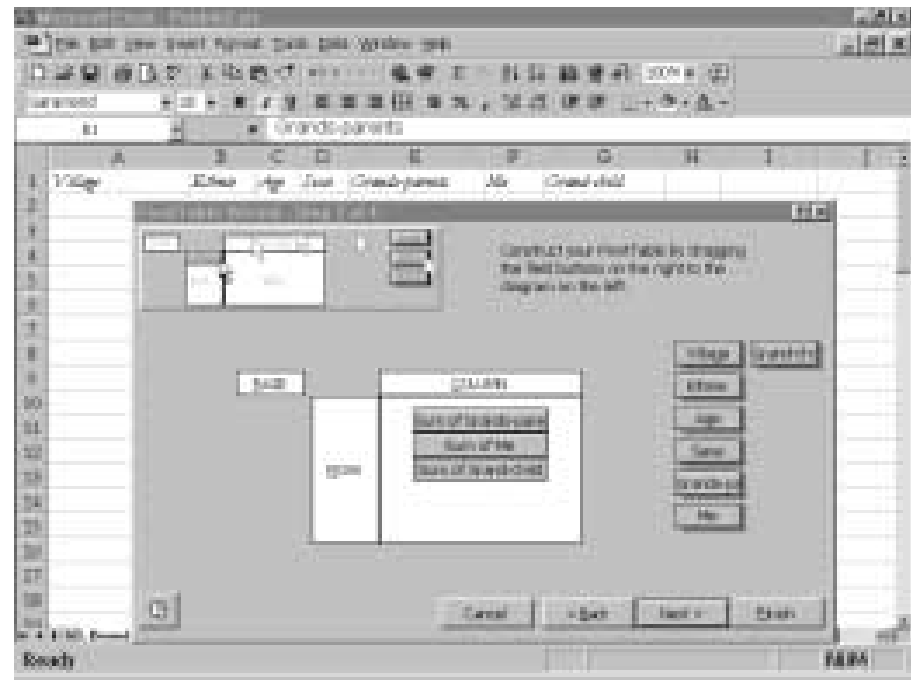

FIGURA 19. Construindo uma tabela dinâmica (pivot table) para análise simples dos dados intergeracionais ( $2^{\mathrm{a}}$ etapa). 


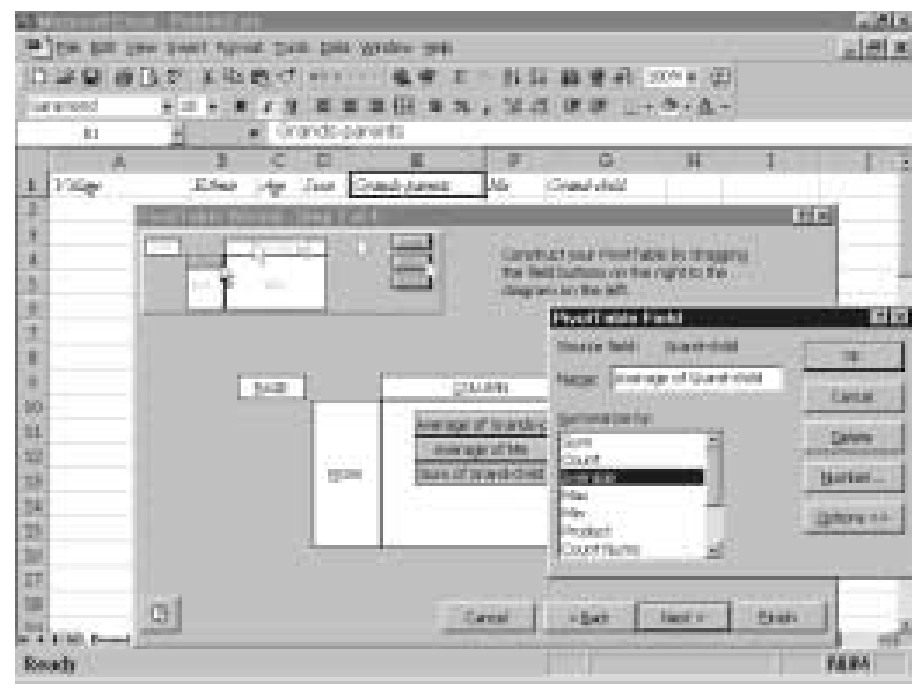

FIGURA 20. Mudando a estatística predefinida nos dados intergeracionais.

* Após decidir a estatística mais adequada para sua análise, clique no botão Finish e você obterá a tabela como mostra a Figura 21. Se você preferir um número menor de dígitos, você pode ajustar a classe decimal. ${ }^{32}$

32 Para ajustar a classe decimal, vá para a opção Format do menu, escolha Cells, e sob a categoria, Numbers. Em seguida, você pode ajustar a classe decimal aumentan do ou diminuindo a classe decimal predefinida (predefinida $=2$ ). 


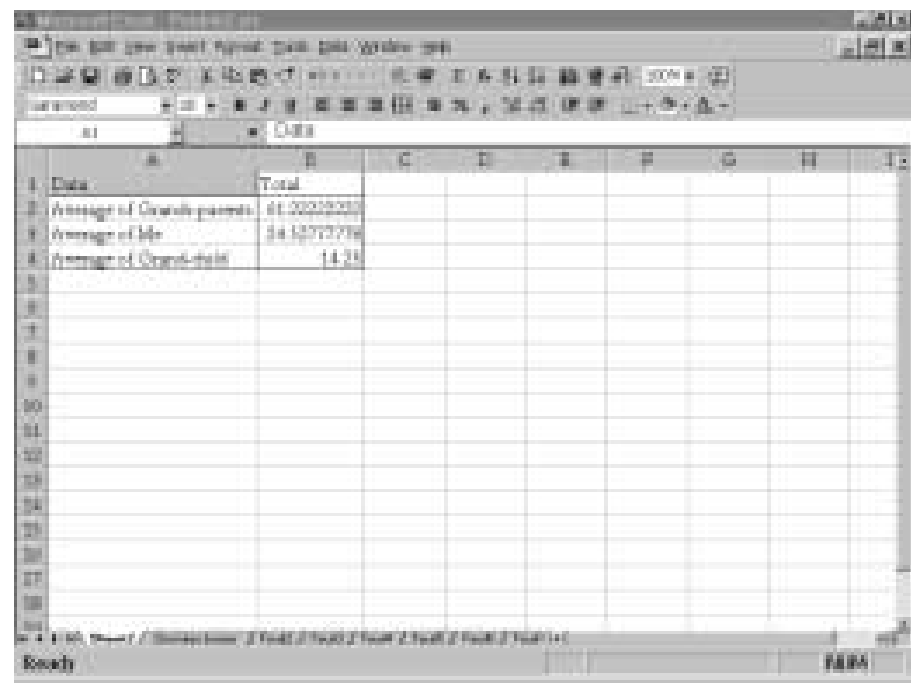

FIGURA 21. Tabela do Excel descrevendo o acesso aos recursos ao longo das gerações, de acordo com todos os respondentes.

d. Conduzindo análise avançada dos dados usando o programa SPSS

- Criando a tabela que descreve a distribuição do acesso aos recursos ao longo das geraçóes de acordo com um subgrupo particular

Em alguns casos é interessante comparar subgrupos diferentes dentro de cada elemento demográfico (etnia, gênero, nível educacional etc.) de acordo com suas opiniōes sobre a distribuição de peças entre os atores. Para comparar as opinióes desses subgrupos, precisamos conhecer o resultado da distribuição de peças entre as gerações de acordo com cada subgrupo. Para obter esses números, siga nossas instruções abaixo. Imagine que temos um grupo de respondentes destes três grupos étnicos: Baka, Kako e Nzime. ${ }^{33}$ 
No menu, escolha:

\section{Statistics \\ Custom Tables \\ Basic Tables}

Coloque todas as gerações no item summaries. Faça-o clicando no nome da variável e, em seguida, clicando na seta diante do quadro summaries (Figura 22).

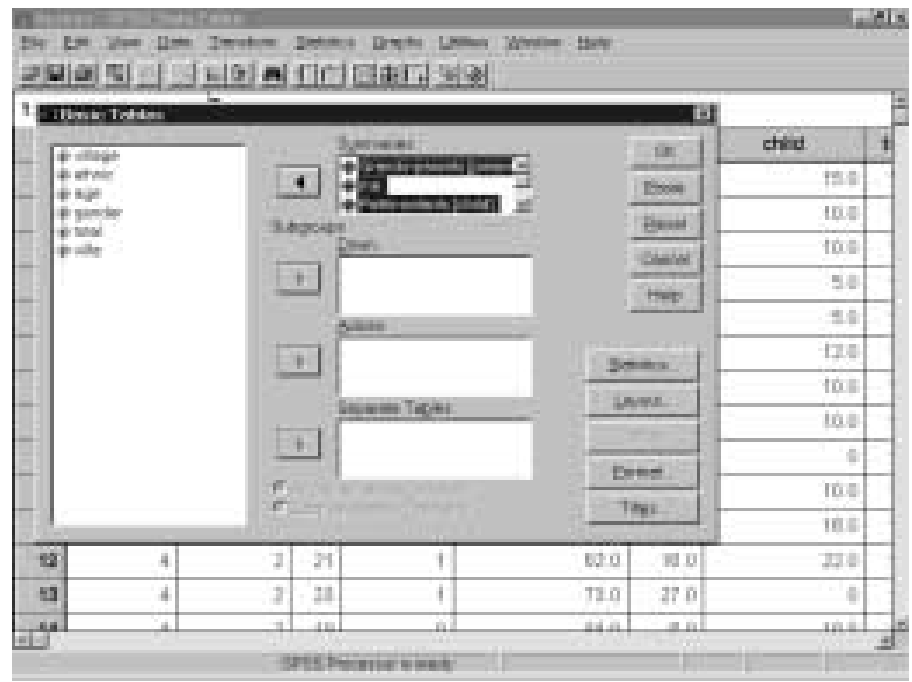

FIGURA 22. Selecionando as variáveis intergeracionais (para resumir).

Coloque a coluna contendo os dados dos subgrupos que você quer comparar no item subgroup-down (Figura 23). Em nosso caso a informação sobre etnia está na coluna Ethnic. Em seguida, clique em $O K$. 


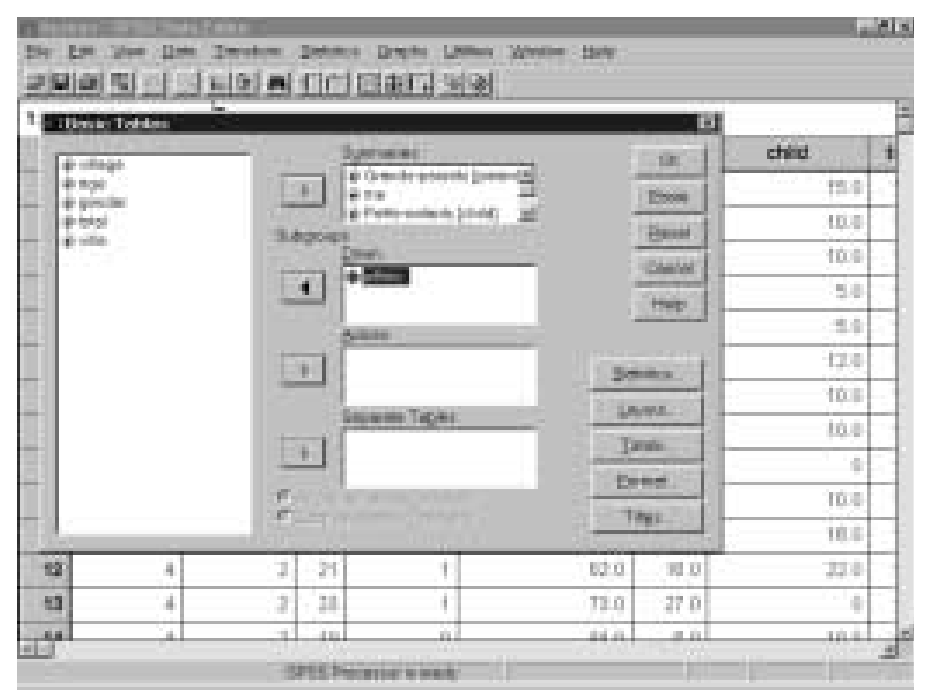

FIGURA 23. Selecionando a variável demográfica nos dados intergeracionais.

* Agora podemos comparar as diferenças da distribuição de peças para cada geração de acordo com os três grupos étnicos (Figura 24). 


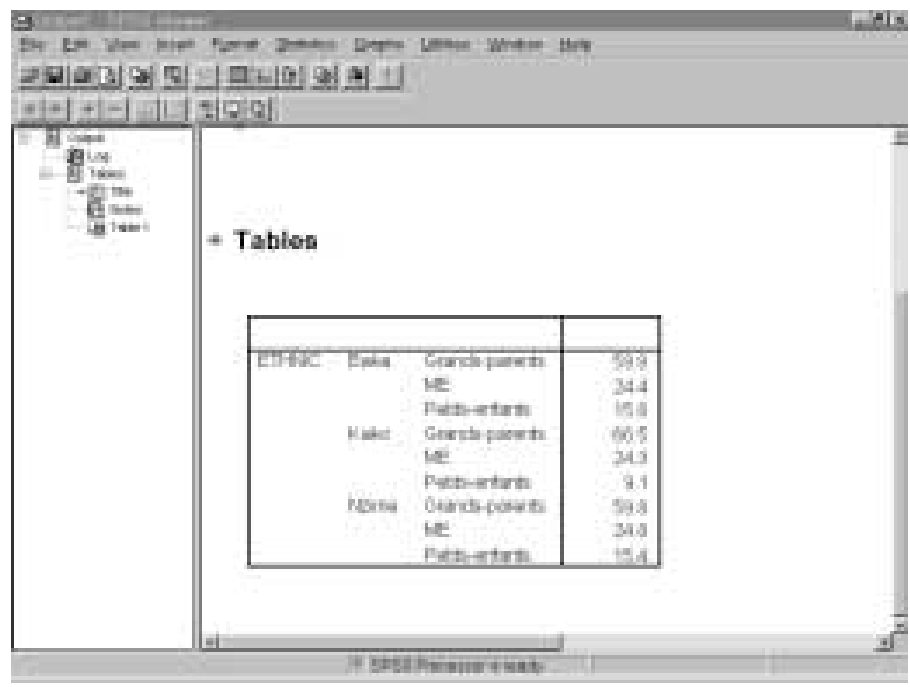

FIGURA 24. Tabela do programa SPSS descrevendo a comparação da distribuição do acesso aos recursos ao longo das gerações com base na etnia.

Se você possui mais de três categorias em seus dados demográficos (por exemplo, quatro ou mais grupos étnicos), você pode proceder da mesma forma para obter o valor da média/mediana da distribuição de peças entre os atores para as outras categorias.

- Testando se há acordo/desacordo entre os diferentes grupos sobre a distribuição do acesso aos recursos ao longo das geraçôes - Você pode verificar se há acordo ou desacordo entre os diferentes grupos $^{34}$ sobre a quantidade de peças atribuída a cada geração.

No menu, escolha

\author{
Statistics \\ Nonparametric test \\ $\underline{2}$ independent samples ou \\ $\underline{K}$ independent samples ${ }^{35}$ \\ (Ver Figura 25)
}

340 s grupos aqui poderiam ser gênero, nível educacional, etnia etc.

35 Se você deseja testar os dados com apenas duas categorias ou dois grupos, você deve escolher $\underline{2}$ independent samples e, em seguida, usar o teste de Mann-Whitney. Porém, se você está lidando com dados de mais de duas categorias, você deve escolher $\underline{K}$ independent samples, e, em seguida, usar os teste de Kruskall-Wallis. 


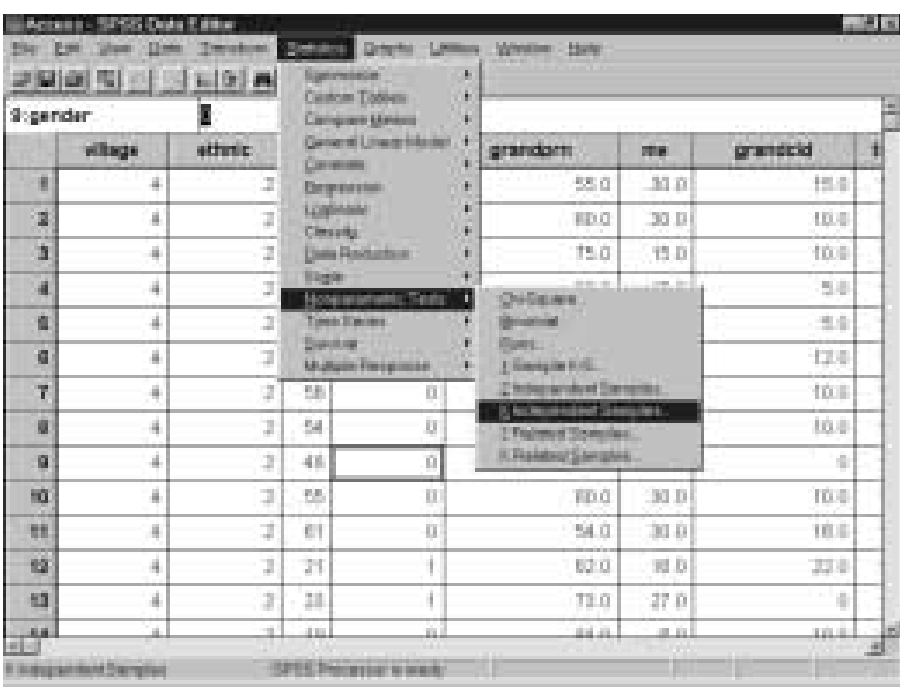

FIGURA 25. Selecionando o teste estatístico para examinar se há acordo nos dados intergeracionais.

Coloque as variáveis de teste ${ }^{36}$ no quadro test variable list e a variável de agrupamento no quadro grouping variable (Figura 26). Em seguida, defina um valor mínimo e um valor máximo da variável de agrupamento (você pode verificar o significado de cada código em sua folha de códigos). Ver Figura 27 para detalhes. 


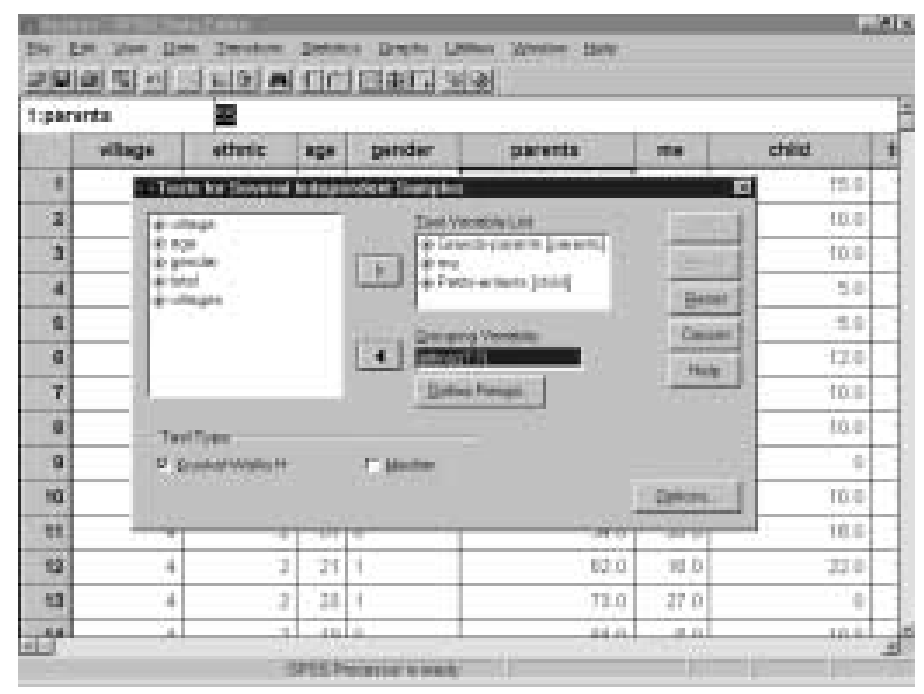

FIGURA 26. Selecionando as variáveis de teste (test variables) e a variável de agrupamento (grouping variable) (dados intergeracionais).

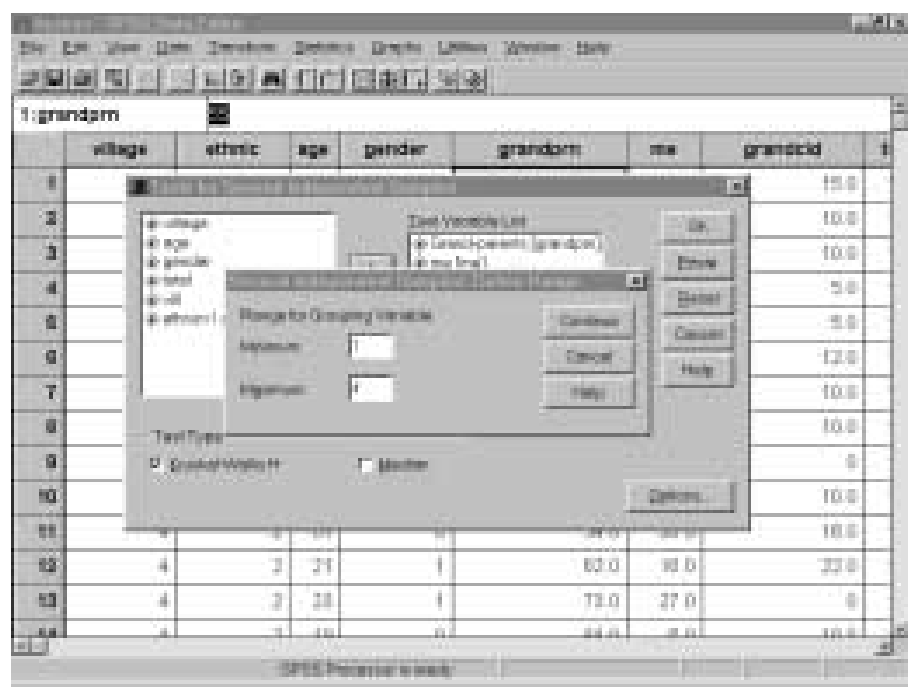

FIGURA 27. Definindo o intervalo para a variável de agrupamento (grouping variable) (demográfico) (dados intergeracionais). 
* Clique em Continue e, em seguida, clique em $O K$.

Você obterá os resultados como mostra a Figura 28. O teste terá de ser realizado para cada geração. Não esqueça de verificar a significância de cada teste.

Verifique o Value-P(indicado pela seta). Se o Value- $P$ for abaixo de 0,05 , rejeitamos a hipótese nula ${ }^{37}$ e concluímos que há desacordo entre os grupos sobre a quantidade de peças alocada para as geraçôes. Se o Value- $P$ for acima de 0,05 , concluímos que há acordo entre os diferentes grupos. $\mathrm{O}$ teste foi realizado para cada geração; não esqueça de verificar a significância do teste para cada geração.

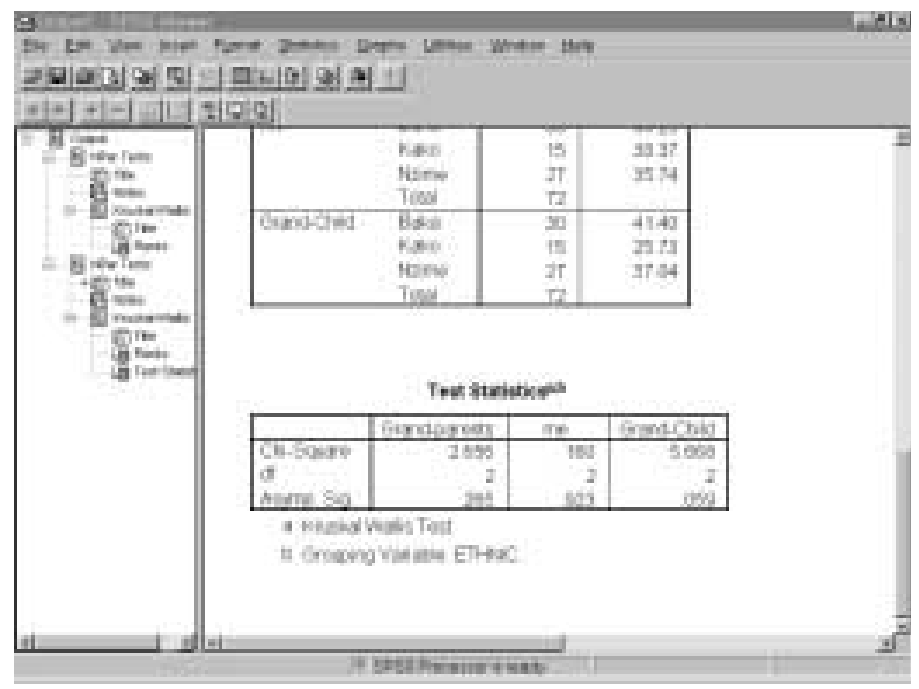

FIGURA 28. Produto do teste estatístico para cada geração (dados intergeracionais).

37 A hipótese nula: todos os subgrupos alocaram a mesma quantidade de peças para cada geração. Em outras palavras, eles concordam sobre a quantidade de peças atribuída a cada geração. 
e. Conduzindo análise avançada dos dados usando o programa Excel

- Criando a tabela que descreve a distribuição do acesso aos recursos ao longo das gerações de acordo com subgrupos particulares

Você pode usar o mesmo procedimento utilizado para obter a tabela de distribuição de peças de acordo com todos os respondentes (Parte C desta seção). Porém, para construir a tabela dinâmica (pivot table), o procedimento será diferente. Ao invés de você apenas arrastar com o mouse todas as geraçóes para o espaço dos dados, você também deve arrastar a coluna onde os subgrupos particulares estão para o espaço da coluna ${ }^{38}$ (Figura 29). Aqui usamos os grupos étnicos como um exemplo.

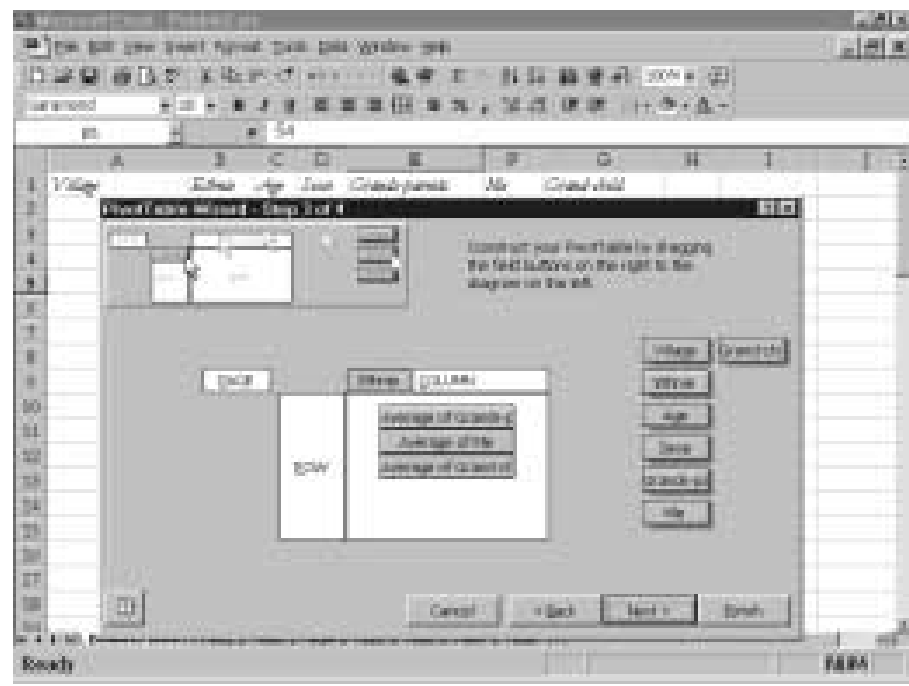

FIGURA 29. Construindo uma tabela dinâmica (pivot table) para análise avançada dos dados intergeracionais. 
Clicando no botão Finish você obterá o resultado (Figura 30). Note que as duas subtabelas para cada grupo étnico (tanto neste exemplo como no anterior, étnico1 significa Baka; étnico2, Kako; e étnico3, Nzime).

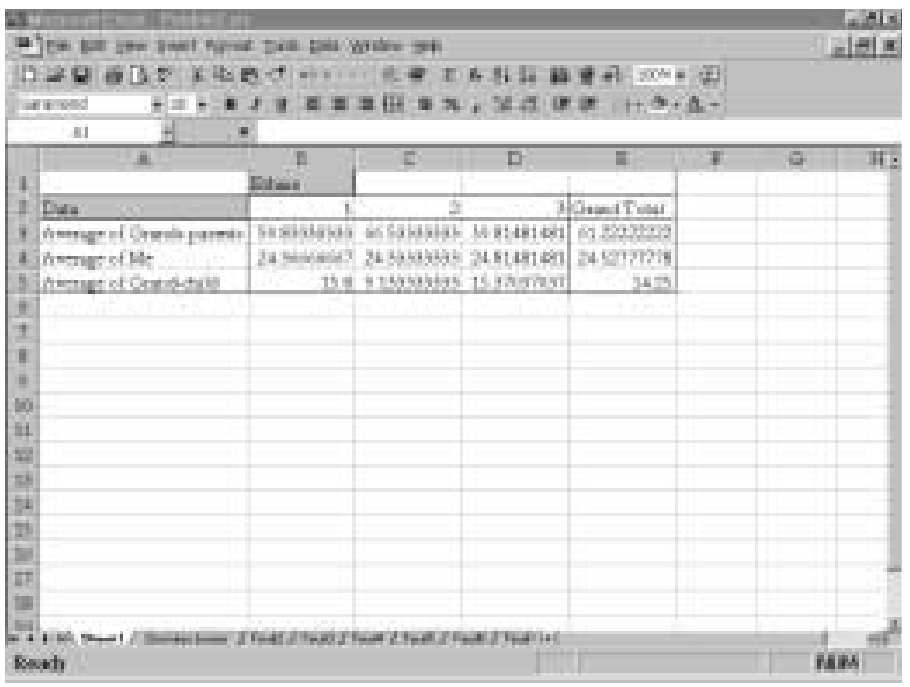

FIGURA 30. Tabela do Excel descrevendo a comparação da distribuição do acesso aos recursos ao longo das gerações com base na etnia.

\section{DIVISÃO DOS BENEFÍCIOS ENTRE OS ATORES: DIRETRIZES}

Nesta seção, fornecemos inicialmente informação sobre como montar uma planilha para o método de distribuição de peças sobre a divisão dos benefícios entre os atores (descrito no manual Os Acessórios) e inserir os dados no computador. Em seguida, explicamos como executar a análise estatística simples dos dados, principalmente como verificar o modo em que os dados estão distribuídos e criar tabelas descritivas simples. Aqueles que estão satisfeitos com análises simples não precisam prosseguir. Finalmente, fornecemos ajuda para aqueles que desejam fazer análises mais avançadas, tais como o teste de significância das diferenças de opinião entre os diferentes grupos (baseado na etnia, idade, gênero etc.). 


\section{a. Introduzindo os dados}

- Insira os dados usando um programa de planilha, tal como o Excel ou o Lotus.

- Insira os dados demográficos (grupo de usuários, gênero, idade, nível educacional etc.) nas colunas à esquerda (Figura 31, colunas de A a F). Na medida do possível, insira os dados demográficos usando os códigos numéricos. Se você possui dados de categoria como gênero, nível educacional etc., você precisa convertê-los em códigos numéricos (por exemplo, feminino $=0$, masculino $=1$ ). É muito importante manter a folha de códigos, assim você saberá o significado de cada um deles. Recomendamos que você também mantenha a informação codificada em algum lugar na planilha.

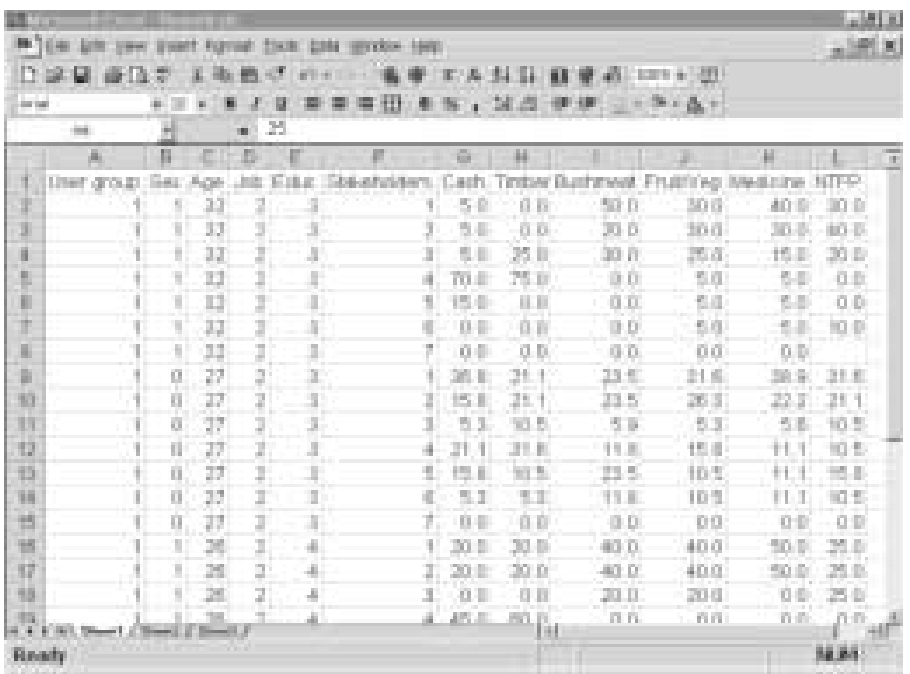

FIGURA 31. Formato das planilhas para os dados sobre divisão dos benefícios. 
- Use uma fileira para cada ator. Por exemplo, na Figura 31, incluímos um conjunto de dados de Long Segar, no qual identificamos sete atores. Você deve usar as fileiras de 2 a 8 (sete fileiras) para o respondente1, as fileiras de 9 a 15 (sete fileiras) para o respondente2, e assim por diante. Você precisa de uma coluna para inserir os códigos dos atores ${ }^{39}$, indicando quais fileiras pertencem a quais atores. A Coluna $\mathrm{F}$ em nosso exemplo acima contém o código dos atores.

- Na coluna seguinte, você pode inserir a quantidade de peças alocada pelos respondentes para cada ator. Você precisa de uma coluna para cada benefício. Em nosso exemplo acima, usamos a Coluna $\mathrm{G}$ para dinheiro, a Coluna $\mathrm{H}$ para madeira, e assim por diante (Figura 31).

- Quando terminar de inserir os dados para todos os respondentes, não esqueça de salvar o arquivo em formato Lotus 123 (*.wk1).

\section{a. Conduzindo análise simples dos dados usando o programa SPSS ${ }^{40}$}

Usamos o SPSS para analisar os dados.

- Abrindo os dados - Você pode abrir o arquivo Lotus 123 em uma planilha do programa SPSS. Use a opção read variable name. ${ }^{41}$

- Rotulando os dados - Use a folha de códigos que você elaborou quando codificou os dados demográficos em códigos numéricos para rotulá-los. Coloque o cursor na coluna onde estão os dados demográficos. Veja a seguir um exemplo de rotulação dos dados sobre nível educacional.

39 Usou-se um número para codificar cada ator. Se temos $n$ atores, podemos determinar um único número para cada ator arbitrariamente. Mas sugerimos que você codifique os atores com códigos de fácil memorização, o que tornará sua análise mais fácil. Você pode, por exemplo, determinar 1 para pessoas locais; 2 para empreiteiros e comerciantes; e 3 para governo e concessões madeireiras. Seu esquema de códigos dependerá do uso que você fará dele.

40 Nós também criamos diretrizes para aqueles que querem executar análises simples usando o programa Excel (ver Parte C desta seção).

41 Na barra do menu do programa SPSS, você pode escolher o submenu Open da opção File, em seguida mude o tipo de arquivo para Lotus 123 (*wk1) e escolha o arquivo que você quer abrir. O processador do SPSS automaticamente perguntará se você quer ler o nome da variável ou não. Apenas clique na opção read variable name. 
No menu, escolha:

\section{$\underline{\text { Data }}$}

\section{Define variable}

(Figura 32).

* Clique no botão Labels (indicado pela seta). O programa pedirá para você inserir seu rótulo (Figura 33).

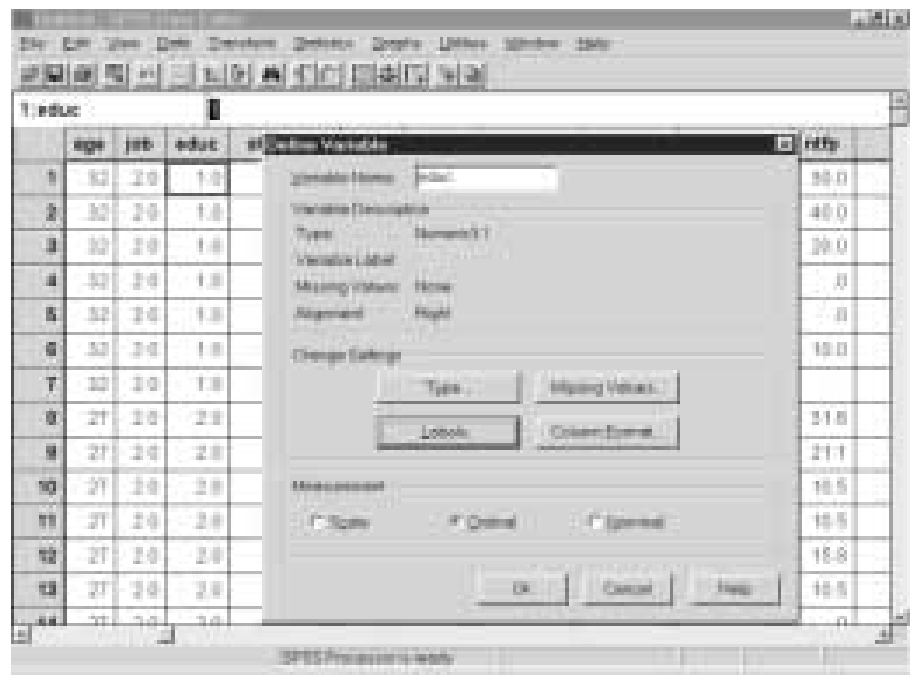

FIGURA 32. Botão Label (dados sobre benefícios florestais). 


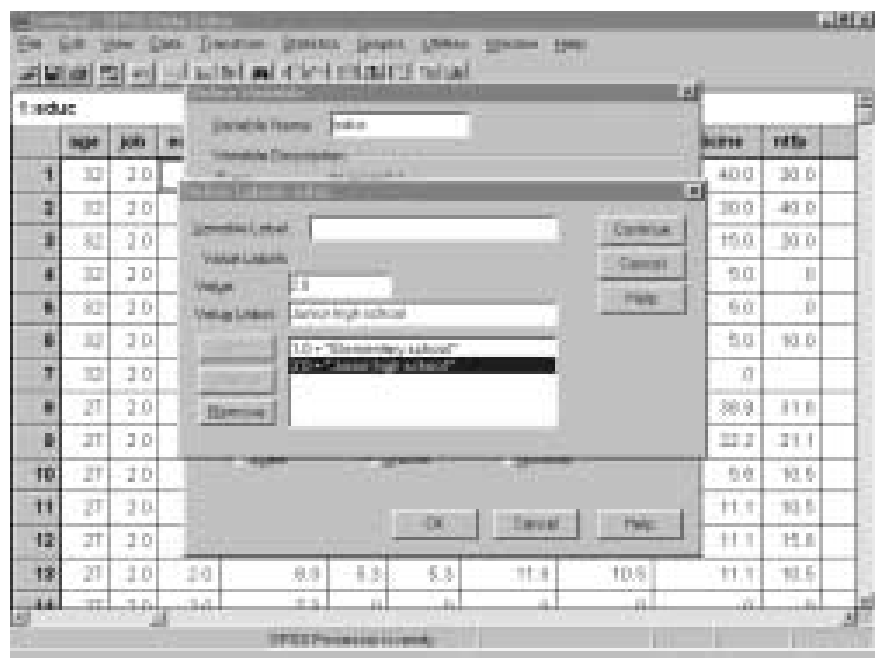

FIGURA 33. Definindo os rótulos (labels) para nível educacional nos dados referentes aos benefícios florestais.

* Insira o rótulo demográfico (por exemplo, básico do ensino secundário, no exemplo acima) e, quando finalizar, clique em Continue.

Siga os mesmos procedimentos para os outros dados demográficos.

\section{- Verificando a distribuição dos dados}

Geralmente, calculamos uma média para avaliar a distribuição de peças de acordo com os respondentes. Entretanto, o uso da média aritmética possui algumas desvantagens quando os dados não estão dispostos simetricamente ou quando há uma ou mais observações discrepantes. Se isso ocorrer, podemos usar o valor mediano. Para verificar se os dados estão dispostos simetricamente ou não, usamos um diagrama de distribuição dos dados (boxplot). Através desse método verificamos os dados para cada benefício separadamente, uma vez que esses benefícios foram considerados como variáveis separadas. Se a maioria dos benefícios for distribuída assimetricamente, pode-se usar o valor mediano. Por outro lado, se a maioria dos benefícios for distribuída simetricamente podemos usar a média. 
Para obter um diagrama de distribuição dos dados (boxplot) siga as instruções abaixo:

No menu, escolha: $\quad \begin{aligned} & \text { Graphs } \\ & \text { Boxplot }\end{aligned}$

Escolha clustered e summaries para variáveis separadas (Figura 34).

Clique no botão Define.

Insira todos os benefícios como variáveis e ator ${ }^{42}$ como o eixo de categoria (Figura 35).

Você obterá o diagrama de distribuição dos dados (boxplot), como mostra a Figura 36. A linha em preto dentro da barra mostra a posição mediana. As margens superiores e inferiores da barra mostram a posição dos $3^{\circ}$ e $1^{\circ}$ quartis, respectivamente. Os dados estão distribuídos simetricamente se, e somente se, a mediana estiver localizada no meio da barra, aproximadamente a mesma distância dos $3^{\circ}$ e $1^{\circ}$ quartis. 


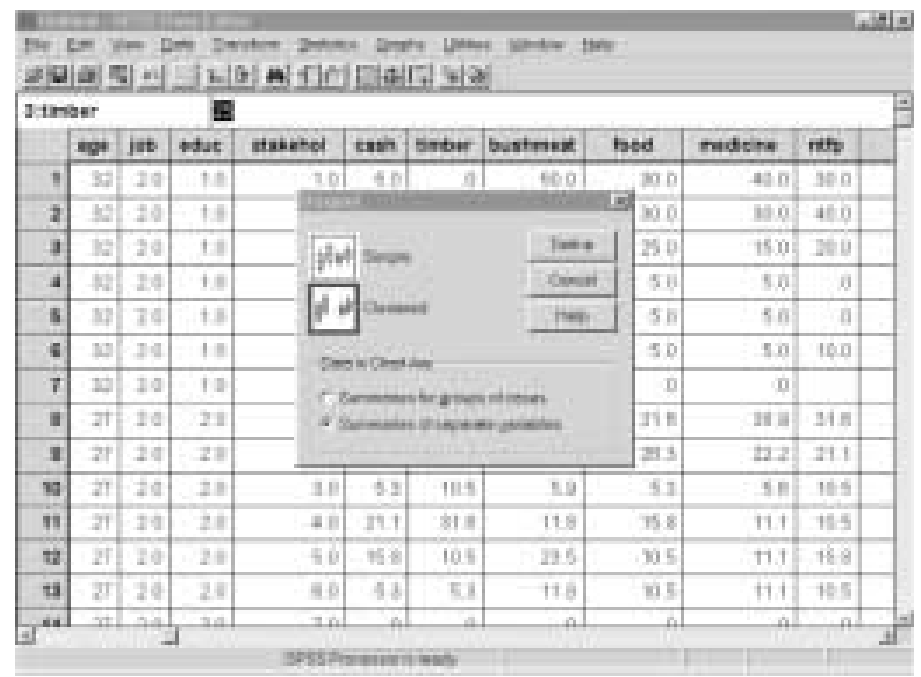

FIGURA 34. Escolhendo o tipo de diagrama de distribuição dos dados (boxplot) sobre benefícios florestais.

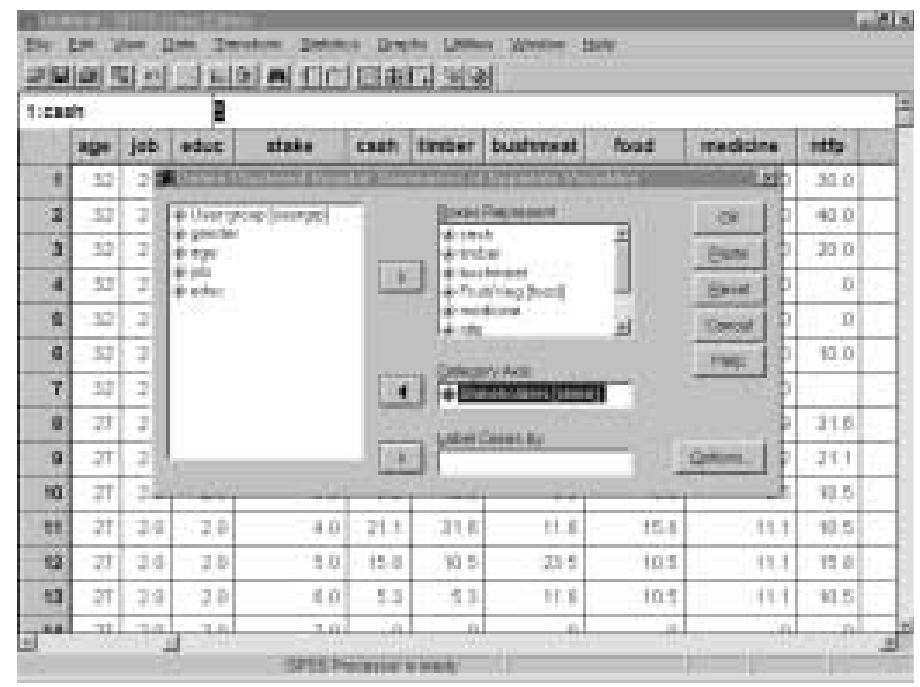

FIGURA 35. Escolhendo as variáveis dos dados sobre benefícios florestais (para verificar a distribuição dos dados). 


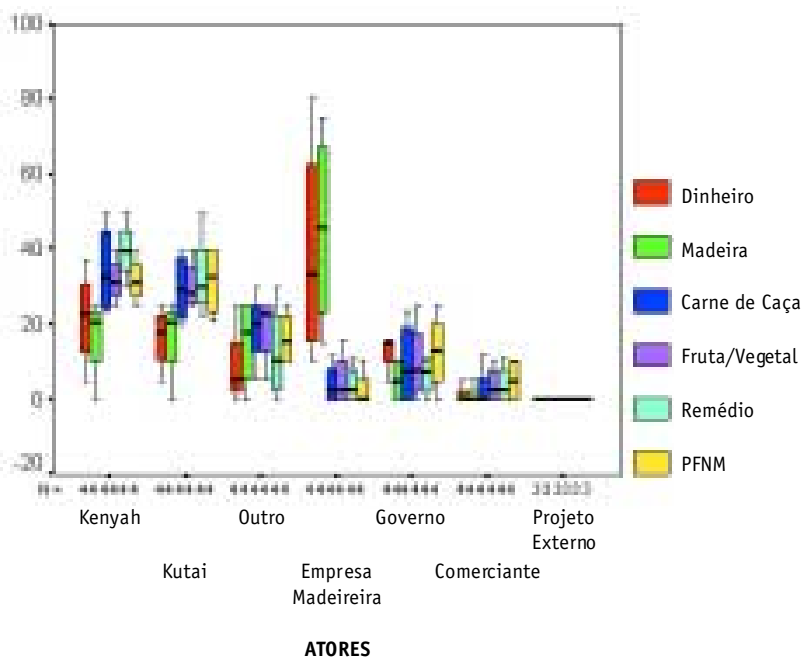

FIGURA 36. Diagrama de distribuição dos dados (boxplot) sobre benefícios florestais.

Se a distribuição dos dados estiver muito assimétrica ou houver algumas observações discrepantes (geralmente indicadas por asteriscos ou círculos), sugerimos que você use o valor mediano.

- Criando a tabela que descreve a distribuição dos benefícios florestais de acordo com todos os respondentes

No menu, escolha:

\section{Statistics \\ Custom Tabels \\ Basic Tabels}

Coloque todos os benefícios no item summaries. Você pode fazê-lo clicando no nome da coluna e, em seguida, clicando na seta diante do quadro summaries (Figura 37). 
Coloque ator no quadro subgroups - item down (Figura 38).

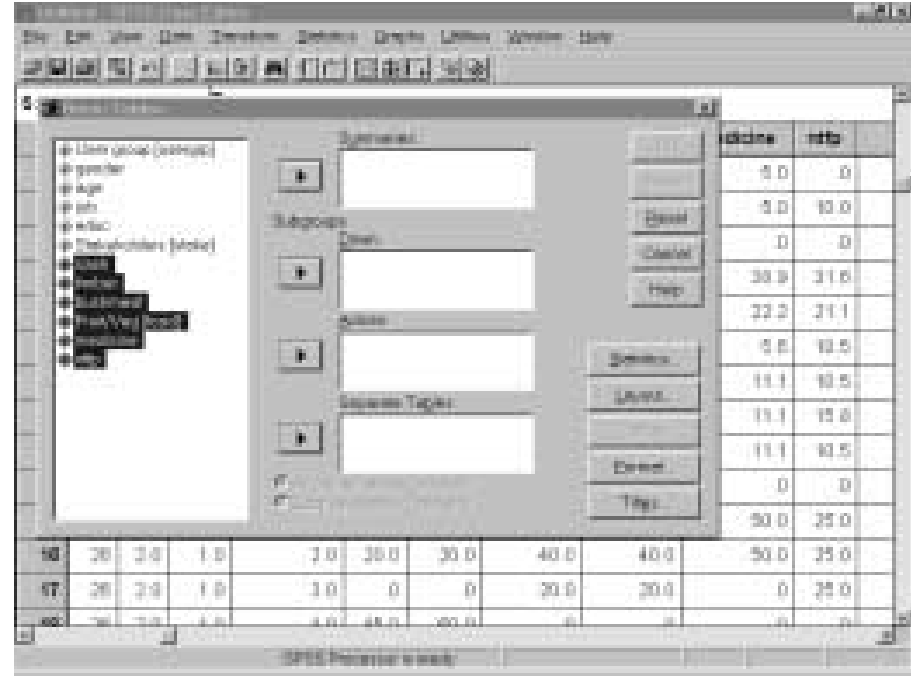

FIGURA 37. Primeira etapa da seleção das variáveis dos dados sobre benefícios florestais (para resumir).

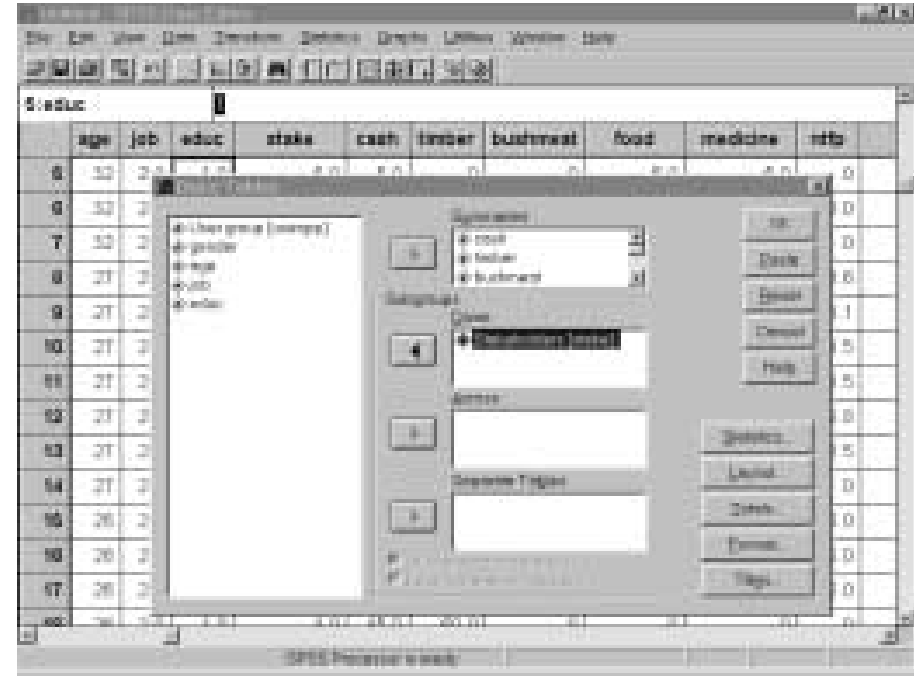

FIGURA 38. Segunda etapa da seleção das variáveis dos dados sobre benefícios florestais (para resumir). 
Clique no botão Statistics e acrescente mean ou median (dependendo de qual medida você decidir usar) como a estatística a ser calculada na célula.

Clicando no botão $O K$ você obterá os resultados (Figura 39).

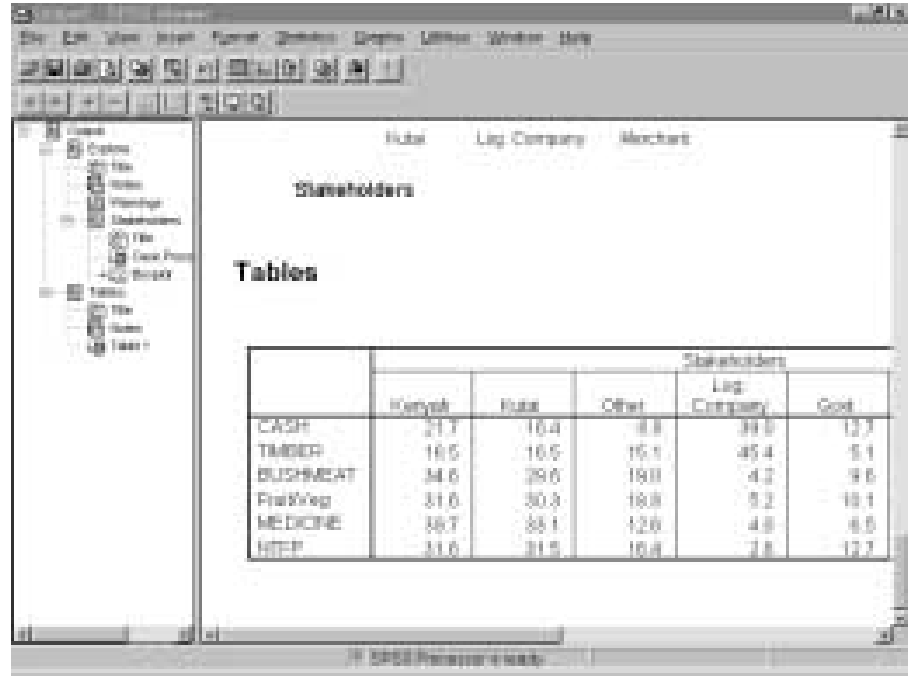

FIGURA 39. Tabela do SPSS descrevendo a distribuição dos benefícios florestais de acordo com todos os respondentes.

c. Conduzindo análise simples usando o programa Excel

- Criando a tabela que descreve a distribuição dos benefícios florestais de acordo com todos os respondentes

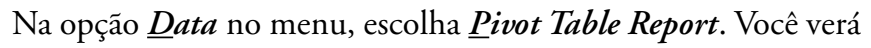
a caixa de diálogo como mostra a Figura 40. 


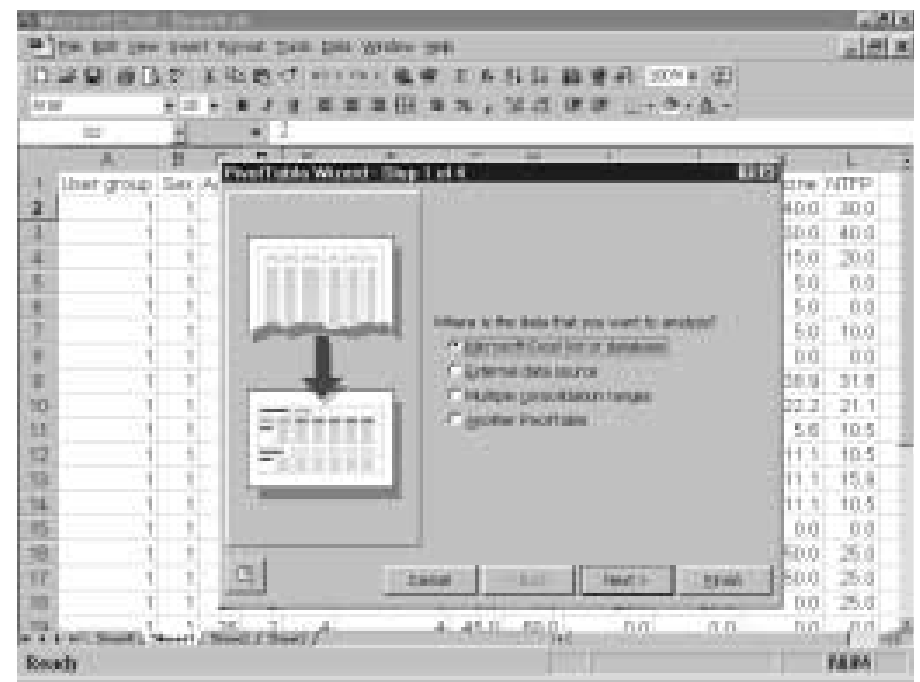

FIGURA 40. Assistente da tabela dinâmica (pivot table wizard) (dados sobre benefícios florestais).

Clique duas vezes no botão Next> e você verá uma caixa de diálogo como mostra a Figura 41.

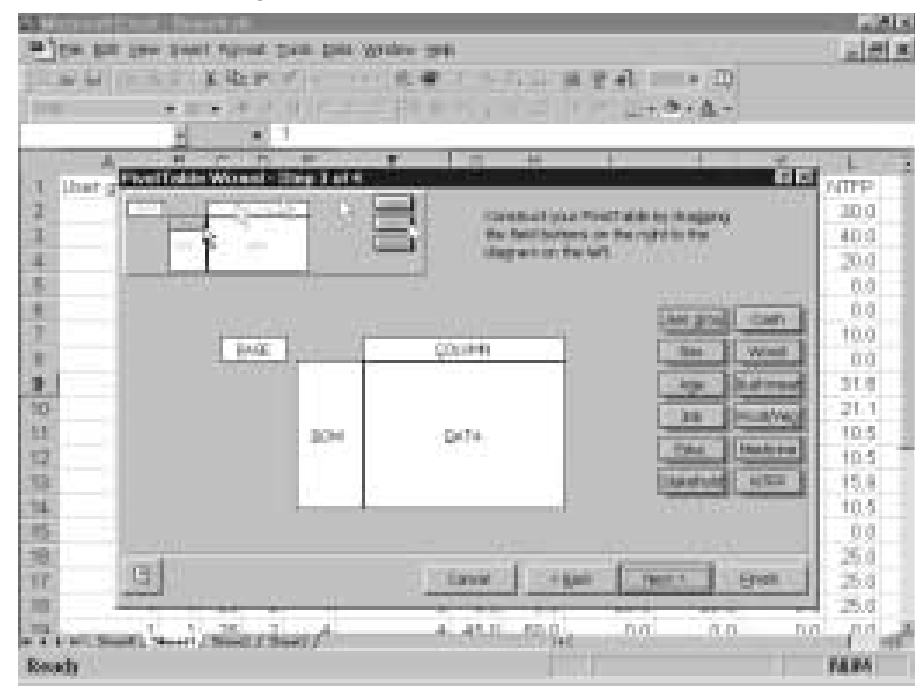

FIGURA 41. Construindo uma tabela dinâmica (pivot table) para análise simples dos dados sobre benefícios florestais ( $1^{\text {a }}$ etapa). 
Arraste com o mouse todas as colunas onde estão os dados sobre benefícios florestais para o espaço dos dados e a coluna onde estão os códigos dos atores para o espaço da coluna (Figura 42).

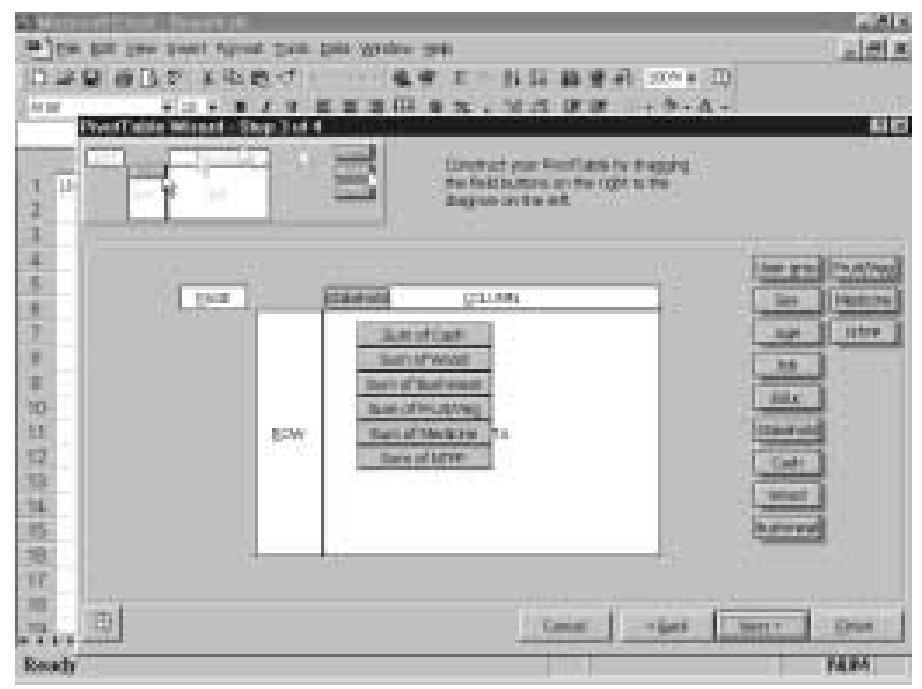

FIGURA 42. Construindo uma tabela dinâmica (pivot table) para análise simples dos dados sobre benefícios florestais ( $2^{a}$ etapa).

* A soma é a estatística predefinida. Você pode mudar a estatística clicando no botão e escolhendo a estatística que você deseja calcular (Figura 43). 


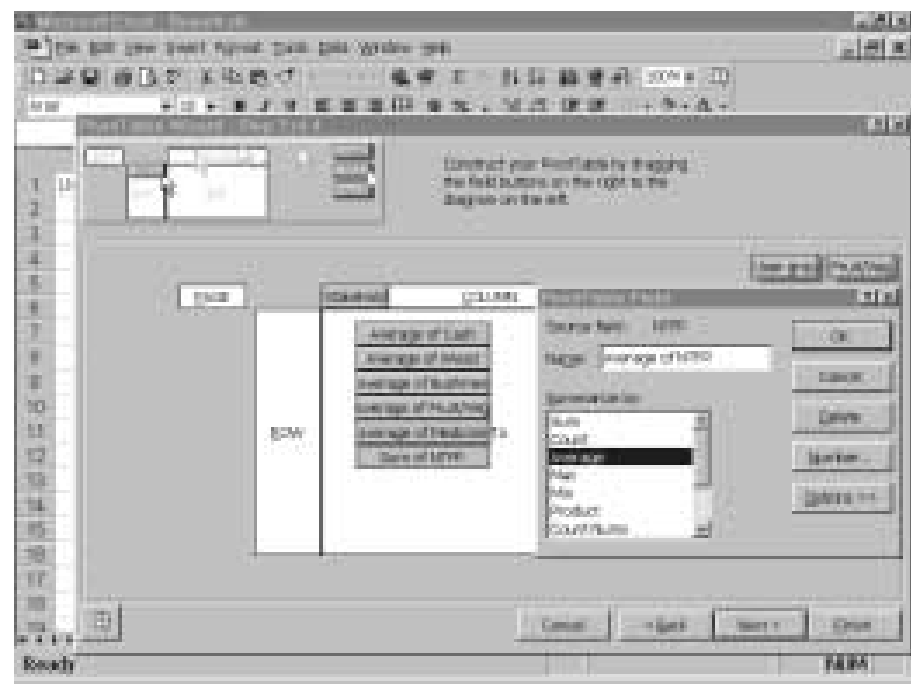

FIGURA 43. Mudando a estatística predefinida nos dados sobre benefícios florestais.

* Após mudar a estatística, você pode clicar no botão Finish para obter a tabela como mostra a Figura 44 . Se preferir um número menor de dígitos, você deve definir a classe decimal. ${ }^{43}$

43 Para definir a classe decimal, vá à opção Format no menu, escolha Cells, e sob a categoria, Numbers. Em seguida, determine a classe decimal que você deseja, aumentando ou reduzindo a classe decimal predefinida (predefinida $=2$ ). 


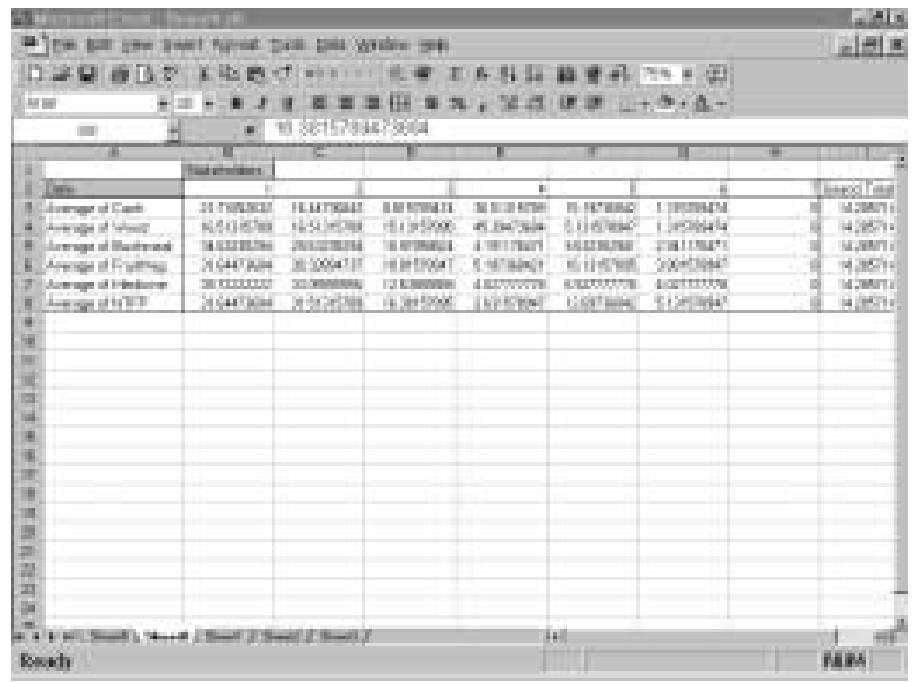

FIGURA 44. Tabela do Excel descrevendo a distribuição dos benefícios florestais de acordo com todos os respondentes.

\section{d. Conduzindo análise avançada dos dados usando o programa SPSS}

- Criando a tabela que descreve a distribuição dos benefícios florestais de acordo com um subgrupo particular

Como no caso do método de classificação de peças para a montagem da Matriz "Acesso aos Recursos ao Longo das Geraçôes”, para a qual descreveu-se a análise anteriormente, pode ser útil comparar subgrupos diferentes dentro de cada elemento demográfico (etnia, gênero, nível educacional etc.), de acordo com suas opiniōes sobre a distribuição de peças entre os atores. Para comparar as opiniōes desses subgrupos, precisamos descrever a distribuição de peças entre os atores de acordo com cada subgrupo. Para obter esses valores, siga nossas instruções abaixo. Imagine que temos um grupo de respondentes com dois níveis educacionais: ensino fundamental e básico do ensino secundário. 
No menu, escolha

Data

Select Cases

Clique na opção if condition is satisfied (Figura 45).

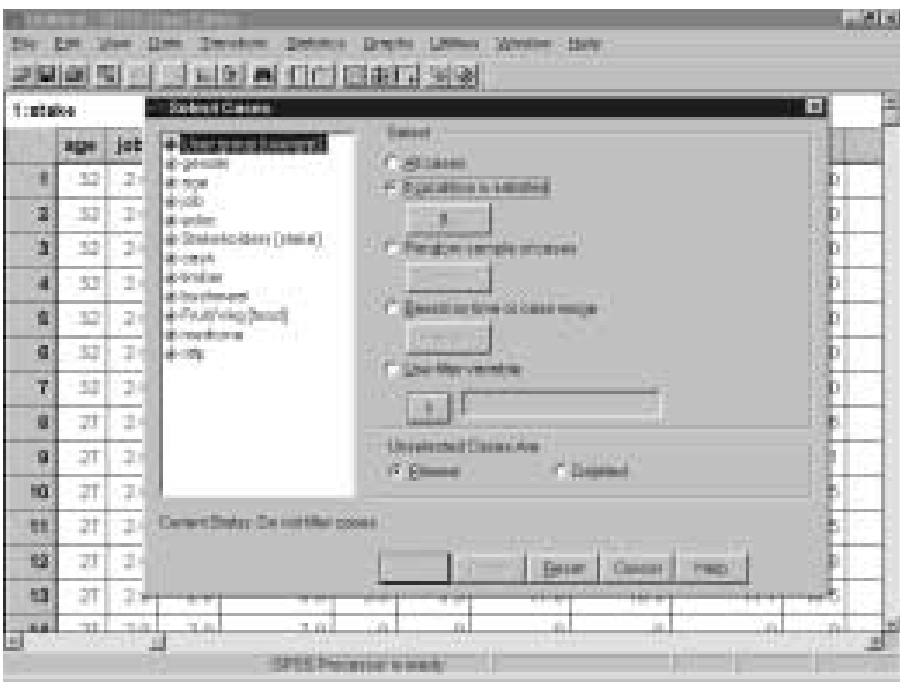

FIGURA 45. Selecionando os casos para o subgrupo específico nos dados sobre benefícios florestais.

Clique no botão If.

* Verifique sua folha de códigos para determinar os códigos para "ensino fundamental" e "básico do ensino secundário" (por exemplo, você pode ter ensino fundamental = 1 e básico do ensino secundário $=2$ ).

* Digite no quadro condicional (Figura 46):

$e d u c=1$ (você filtrará os dados com valor 1 na coluna $e d u c a)$. 
Em seguida, clique em Continue e em $O K$ (Figura 46).

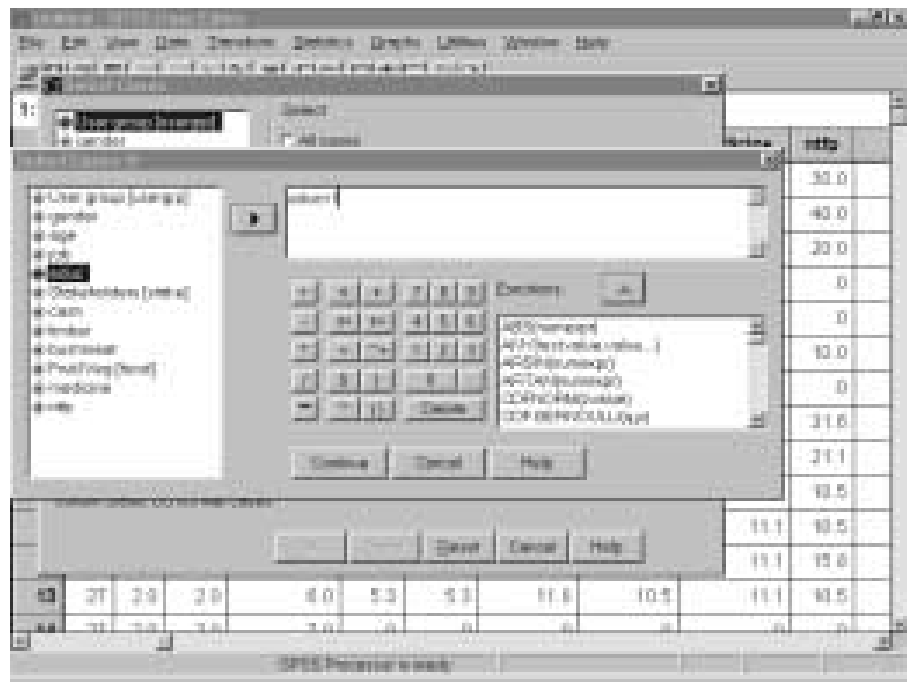

FIGURA 46. Filtrando os respondentes com nível educacional inferior nos dados sobre benefícios florestais.

* Neste momento, se você observar a planilha do SPSS, pode haver fileiras com valores que não são iguais a 1 na coluna educa. Esses valores são respondentes com nível educacional básico do ensino secundário e não estão incluídos na análise, portanto são inativos. A posição de inativo é marcada por uma linha diagonal na numeração da coluna (ver Figura 47). 


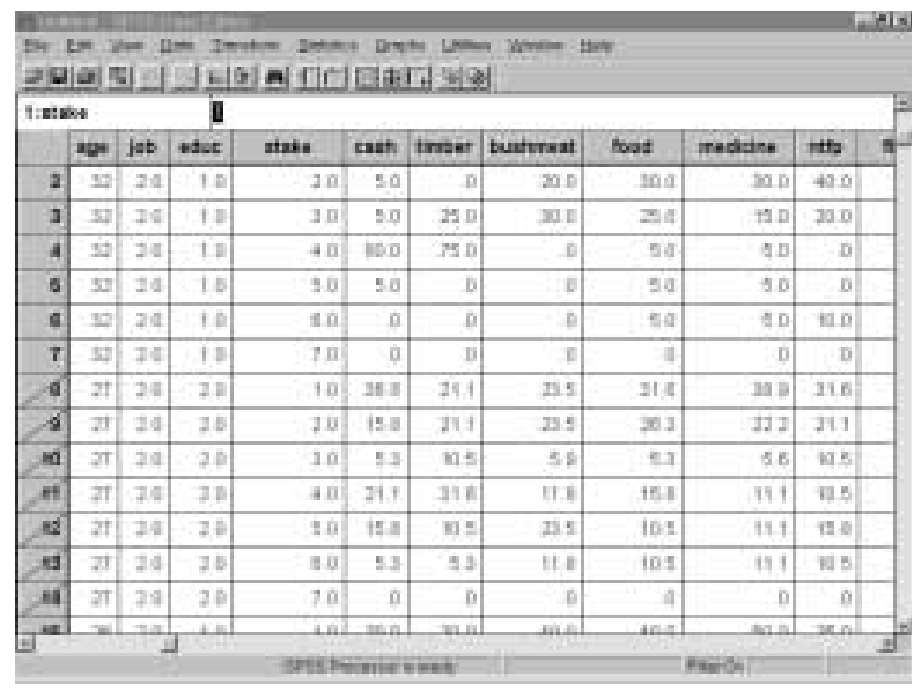

FIGURA 47. Resultado da seleção de casos (dados sobre benefícios florestais).

- Repita o mesmo procedimento da quarta etapa da Parte B desta seção, usado para obter a média da distribuição de peças de acordo com os respondentes com nível educacional fundamental (Figura 48).

Para obter a média da distribuição de peças de acordo com os respondentes com nível educacional básico do ensino secundário, simplesmente mude a expressão condicional para: $e d u c=2$.

Em seguida, siga os mesmos procedimentos da quarta etapa da Parte B desta seção, como acima. 
Neste momento, podemos comparar as diferenças da distribuição dos benefícios florestais entre dois grupos de atores com diferentes níveis educacionais (Figura 49).

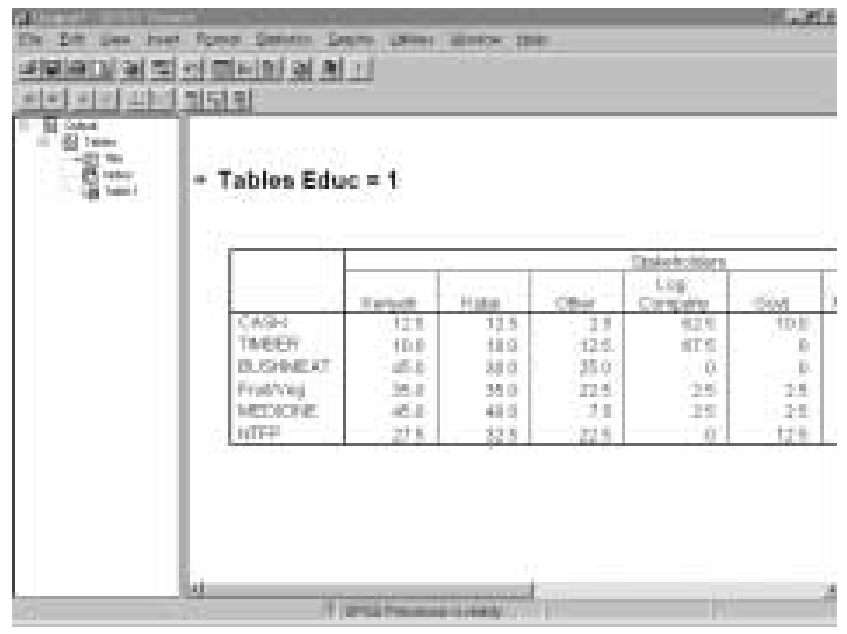

FIGURA 48. Distribuição dos benefícios entre os atores de acordo com os respondentes com nível educacional inferior.

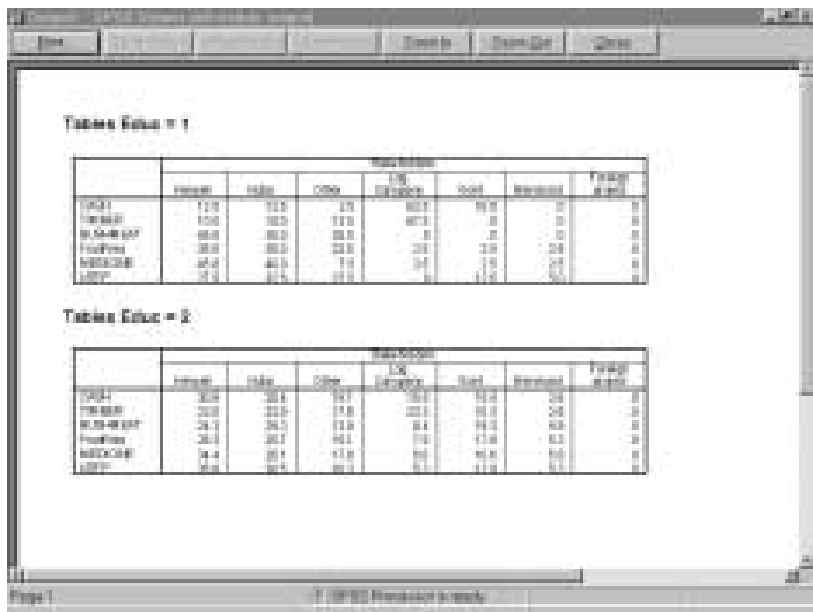

FIGURA 49. Comparação da distribuição dos benefícios florestais entre os atores com base no nível educacional. 
* Se você possui mais de duas categorias em seus dados demográficos (por exemplo, três ou mais níveis educacionais), você pode seguir os mesmos procedimentos para obter a média/mediana da distribuição de peças entre os atores para as outras categorias.

- Testando se há acordo ou desacordo entre os diferentes grupos sobre a distribuição dos benefícios florestais

Você pode verificar se há acordo ou desacordo entre os subgrupos dentro de cada característica demográfica ${ }^{44}$ sobre a quantidade de benefícios florestais atribuída a cada ator. Você pode fazer a análise para cada ator. Filtre os dados até que somente as fileiras para os atores selecionados estejam ativas e as outras fileiras estejam inativas (ver acima, como filtrar subgrupos de dados). $\mathrm{Na}$ Figura 50, filtramos os dados de tal forma que somente as fileiras para Atores = 1 (kenyah) estejam ativas, enquanto as outras estejam inativas.

No menu, escolha:

\author{
Statistics \\ Nonparametric test \\ 2 independent samples ou \\ Kindependent samples ${ }^{45}$
}




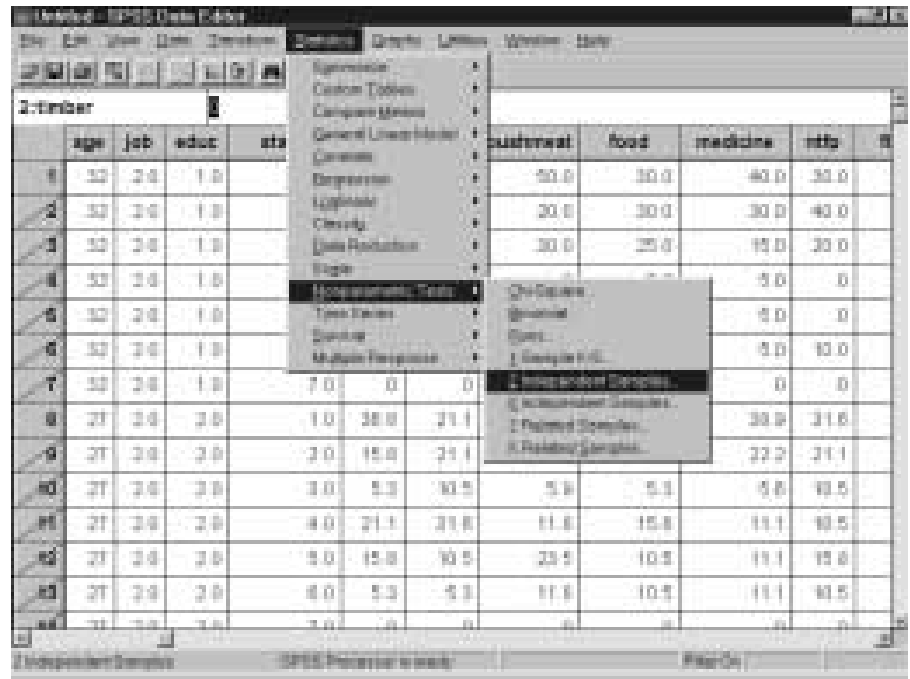

FIGURA 50. Filtrando os dados para o grupo Kenyah e selecionando o teste estatístico (dados sobre benefícios florestais).

Coloque as variáveis de teste ${ }^{46}$ no quadro test variable list e a variável de agrupamento no quadro grouping variable (Figura 51). Em seguida, defina um valor mínimo e um valor máximo da variável de agrupamento (você pode verificar o significado de cada código na sua folha de códigos). Ver Figura 52 para detalhes.

46 As variáveis de teste (test variables) devem ser a coluna que contém o número de peças para cada benefício. A variável de agrupamento (grouping variable) é a coluna que contém informações dos diferentes grupos que você quer comparar. 


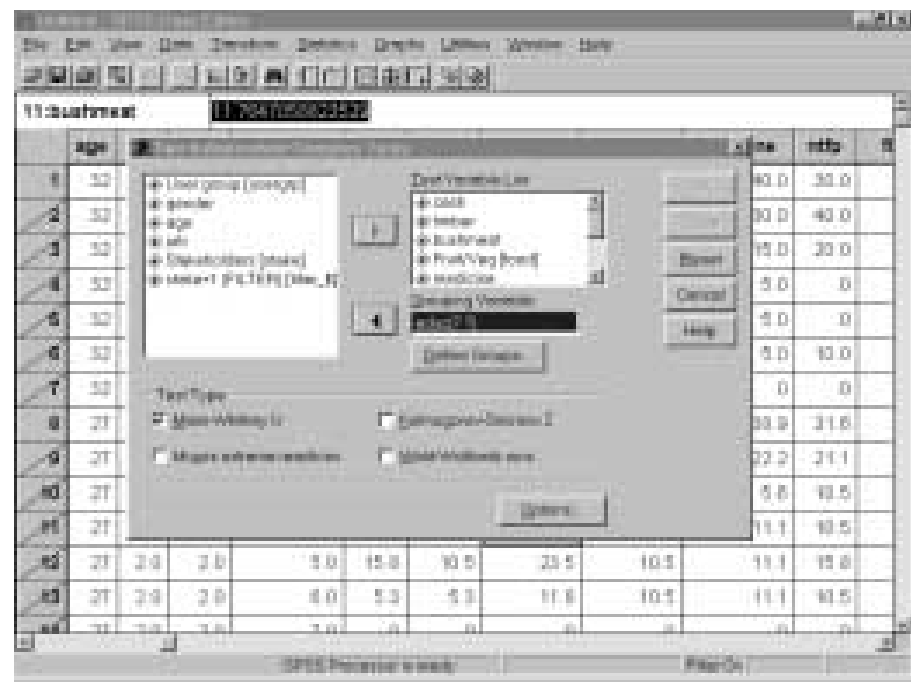

FIGURA 51. Selecionando as variáveis de teste (test variables) e a variável de agrupamento (grouping variable) (dados sobre benefícios florestais).

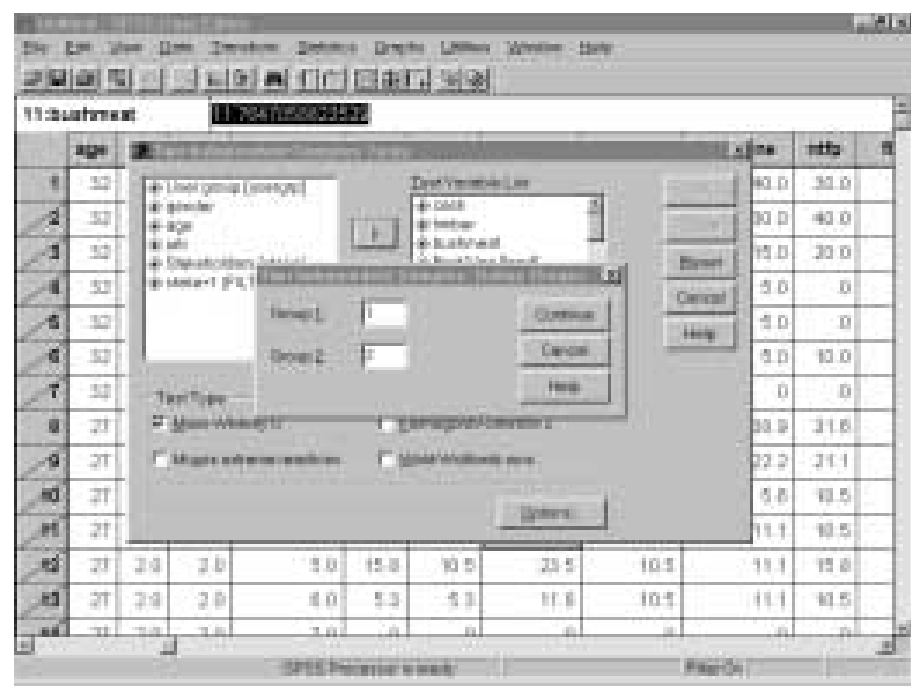

FIGURA 52. Definindo o intervalo para a variável de agrupamento (dados sobre benefícios florestais). 
Clique em Continue e, em seguida, em $O K$.

Você obterá os resultados como mostra a Figura 53. O teste terá de ser realizado para cada geração. Não esqueça de verificar a significância de cada teste.

Verifique o Value- $P$ (indicado pela seta). Se o Value-P for abaixo de 0,05 , rejeitamos a hipótese nula ${ }^{47}$ e concluímos que há desacordo entre os grupos no que se refere à quantidade de peças atribuída aos atores selecionados (o grupo Kenyah, neste caso). Se o Value-P for acima de 0,05 , concluímos que há acordo entre os diferentes grupos.

Proceda da mesma maneira para testar se há acordo ou desacordo sobre a quantidade de benefícios florestais atribuídos aos outros atores. Por exemplo, se você quer verificar se há acordo ou desacordo entre os diferentes grupos sobre a quantidade de peças atribuída aos kutais, você pode filtrar os dados de tal forma que somente as fileiras com ator $=2$ (kutai) estejam ativas, enquanto as outras estejam inativas.

47 Sob cada benefício florestal a hipótese nula é: todos os subgrupos alocaram a mesma quantidade de peças para o ator sendo testado. Em outras palavras, todos os subgrupos concordam sobre a quantidade de benefícios florestais correspondentes atribuída ao ator sendo testado. 


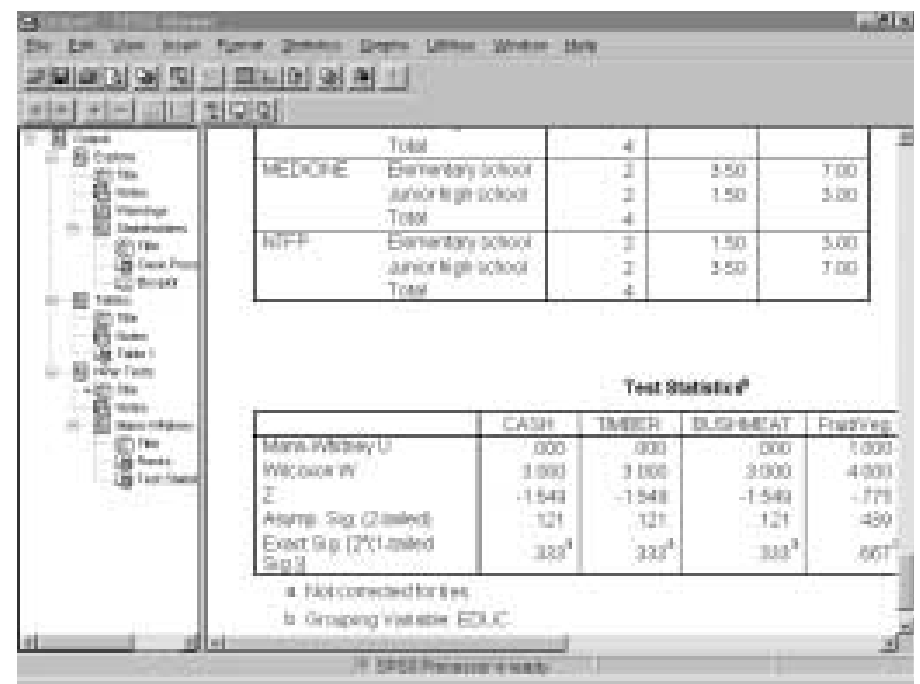

FIGURA 53. Produto do teste estatístico para o grupo Kenyah, com base no nível educacional (dados sobre benefícios florestais).

e. Conduzindo análise avançada dos dados usando o programa Excel

- Criando a tabela que descreve a distribuição dos benefícios florestais, de acordo com um subgrupo particular

Você pode usar um procedimento similar para gerar uma tabela de distribuição dos benefícios florestais de acordo com todos os respondentes (Parte $\mathrm{C}$ desta seção). Porém, para construir a tabela dinâmica (pivot table) o procedimento será diferente. Ao invés de você apenas arrastar todos os benefícios com o mouse para o espaço dos dados e os atores para o espaço da coluna, você também deve mover a coluna onde as características demográficas particulares estão para o espaço da fileira ${ }^{48}$ (Figura 54). Neste exemplo usamos o nível educacional. 


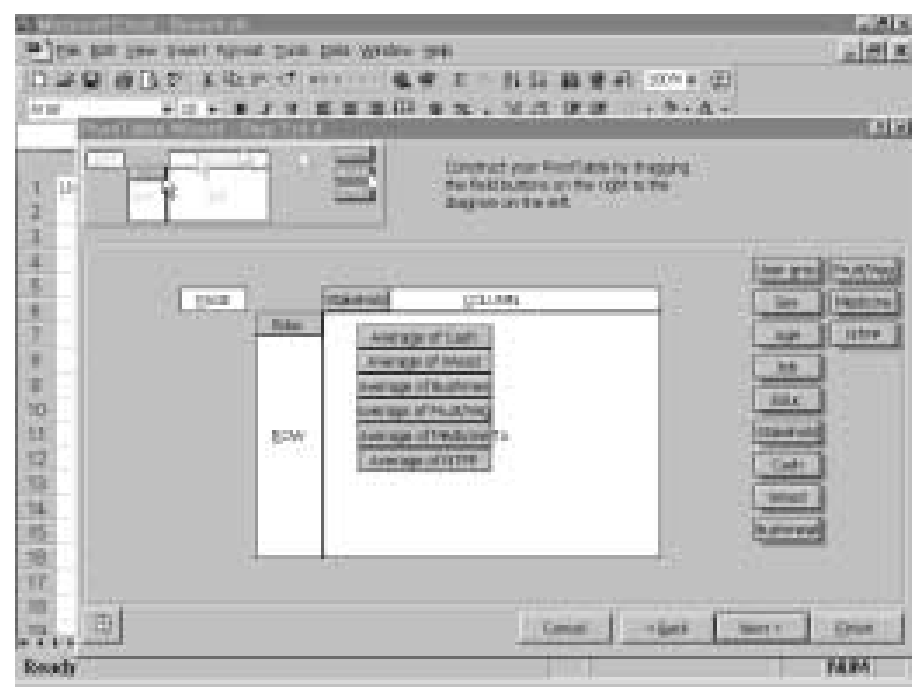

FIGURA 54. Construindo uma tabela dinâmica (pivot table) para análise avançada dos dados sobre benefícios florestais

* Clicando no botão Finish você obterá o resultado (Figura 55). Observe que as duas subtabelas para cada nível educacional (neste exemplo, assim como no anterior, nível educacional1 significa ensino fundamental, enquanto nível educacional 2 significa básico do ensino secundário). 


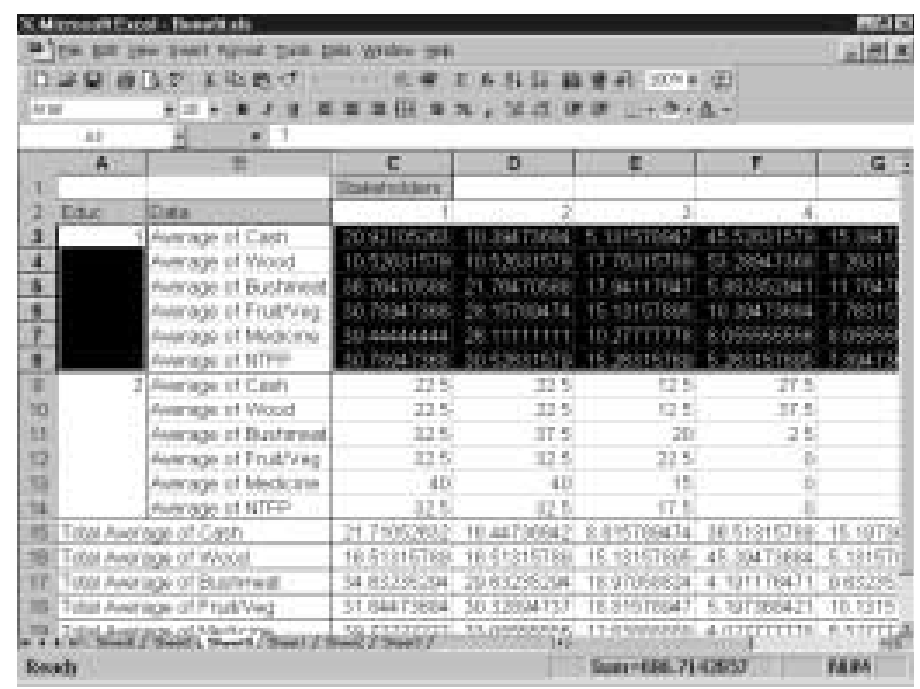

FIGURA 55. Tabela do Excel descrevendo a comparação da distribuição dos benefícios florestais com base no nivel educacional. 


\section{C - ANÁLISE DOS MÉTODOS DE AVALIAÇÃO DOS DIREITOS E MEIOS PARA MANEJAR}

Esta seção contém instruções para análise dos resultados de um método de distribuição de peças, o qual se revelou útil na avaliação dos direitos e meios das pessoas para manejar florestas de forma cooperativa e eqüitativa. Dividimos a apresentação em três partes. Primeiramente, fornecemos informações sobre como montar as planilhas e inserir os dados desse método. Em seguida, explicamos como fazer análises estatísticas simples dos dados, incluindo como examinar a distribuição dos dados e criar tabelas descritivas simples. Aqueles que estão satisfeitos com análises simples não precisam prosseguir. A última parte é direcionada àqueles que desejam fazer análises mais avançadas tais como o teste de significância das diferenças de opinião entre os diferentes grupos dentro de cada característica demográfica (com base na etnia, idade, gênero etc.).

\section{DIREITOS E MEIOS PARA MANEJAR}

a. Introduzindo os dados

- Insira os dados usando um programa de planilha, tal como o Excel ou o Lotus.

- Insira os dados demográficos (grupo de usuários, gênero, idade, nível educacional etc.) nas colunas à esquerda (Figura 56, colunas de A a F). Na medida do possível, insira os dados demográficos usando códigos numéricos. Se você possui dados de categoria como gênero, nível educacional etc., é necessário convertê-los em códigos numéricos (por exemplo, feminino $=0$, masculino $=1$ ). É muito importante manter a folha de códigos, assim você saberá o significado de cada um deles. Você precisará da folha de códigos para conduzir as análises. 


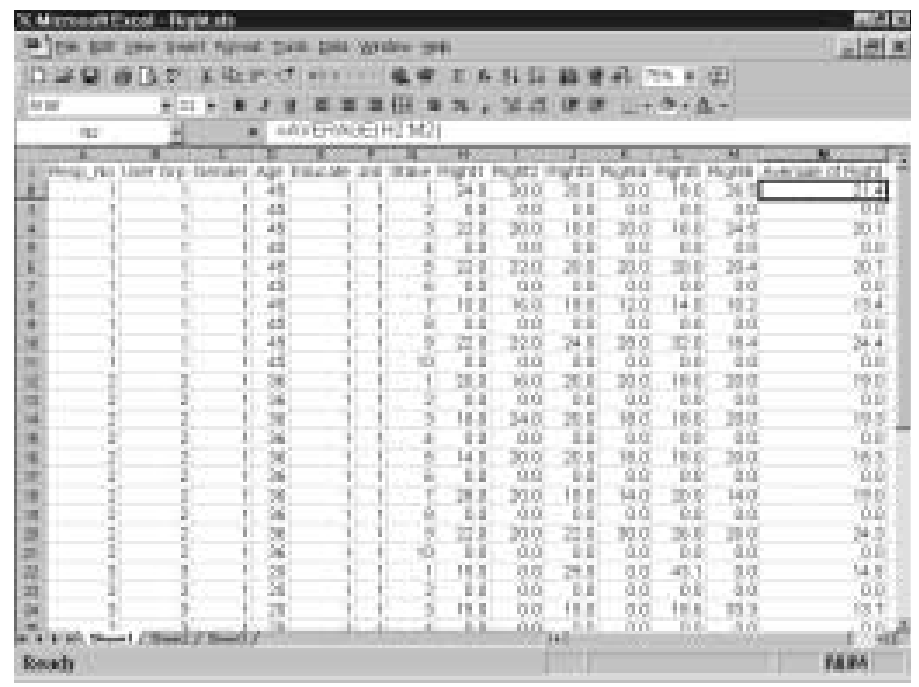

FIGURA 56. Formato das planilhas para os dados sobre direitos para manejar.

- Se você tem um número $(n)$ de atores, você deve usar $n$ fileiras para cada respondente ou, em outras palavras, uma fileira para cada ator. Por exemplo, na Figura 56, usamos um grupo de dados de Bulungan ${ }^{49}$, no qual identificamos dez atores. Usamos as fileiras de 2 a 11 (dez fileiras) para o respondente1; as fileiras de 12 a 21 (dez fileiras) para o respondente2, e assim por diante. Precisamos de uma coluna para inserir os códigos dos atores ${ }^{50}$, indicando quais fileiras pertencem a quais atores. A Coluna $G$ em nosso exemplo acima contém o código dos atores.

- Nas seis colunas seguintes, você pode inserir a quantidade de peças alocada pelos respondentes para cada ator. Coluna $\mathrm{H}$ para Direito1 (Definição/Proteção das Fronteiras), Coluna I para Direito2 (Desenvolvimento/Aplicação Regras/Regulamentos), e assim por diante.

50 Usou-se um número para codificar cada ator. Se temos $n$ atores, assinalamos 1- $n$ para cada ator arbitrariamente. Entretanto, sugerimos que você codifique os atores com códigos de fácil memorização, o qual terá um significado intuitivo para você. Em nossas análises, foram dados números altos para atores com uma relação próxima com o governo e números baixos para pessoas locais que mantêm, em muitos casos, pouca interação com o governo. 
- Use a coluna subseqüente até a última coluna à direita (Direito6) para obter a média dos direitos para cada ator. Para obter a média, simplesmente use a função $A V E R A G E$ do Excel. ${ }^{51}$ Por exemplo, a célula N2 na Figura 56 é uma média do intervalo entre a célula H2 e a M2 (indicado pela seta).

- Quando terminar de inserir os dados para todos os respondentes, não esqueça de salvar o arquivo em formato Lotus 123 (*.wk1).

\section{b. Conduzindo análise simples dos dados usando o programa SPSS ${ }^{52}$}

Usamos o SPSS para analisar os dados.

- Abrindo os dados - Você pode abrir o arquivo do Lotus 123 em uma planilha do programa SPSS. Use a opção read variable name. ${ }^{53}$

- Rotulando os dados - Use a folha de códigos que você elaborou quando codificou os dados demográficos em códigos numéricos para rotular os dados. Coloque o cursor na coluna onde estão os dados demográficos. Aqui, damos um exemplo de rotulação dos dados do nível educacional.

\section{No menu, escolha: \\ $\underline{\text { Data }}$ \\ Define variable (Figura 57).}

Clique no botão Labels (indicado pela seta). O programa pedirá para você inserir seu rótulo (Figura 58).

51 Para usar a função MÉDIA, apenas digite = MÉDIA (Célula Inicial: Célula Final). A média deve ser calculada no intervalo entre a célula inicial e a final. Por exemplo, na Figura 1, a célula N2 é a média do intervalo entre a célula H2 e a M2 (indicado pela seta).

52 Nós também criamos diretrizes para aqueles que querem executar análises simples usando o programa Excel (ver Parte C desta seção).

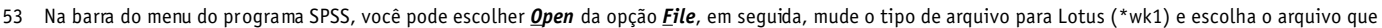
você quer abrir. 0 processador do SPSS automaticamente perguntará se você quer ler o nome da variável ou não. Apenas clique na opção read variable name. 


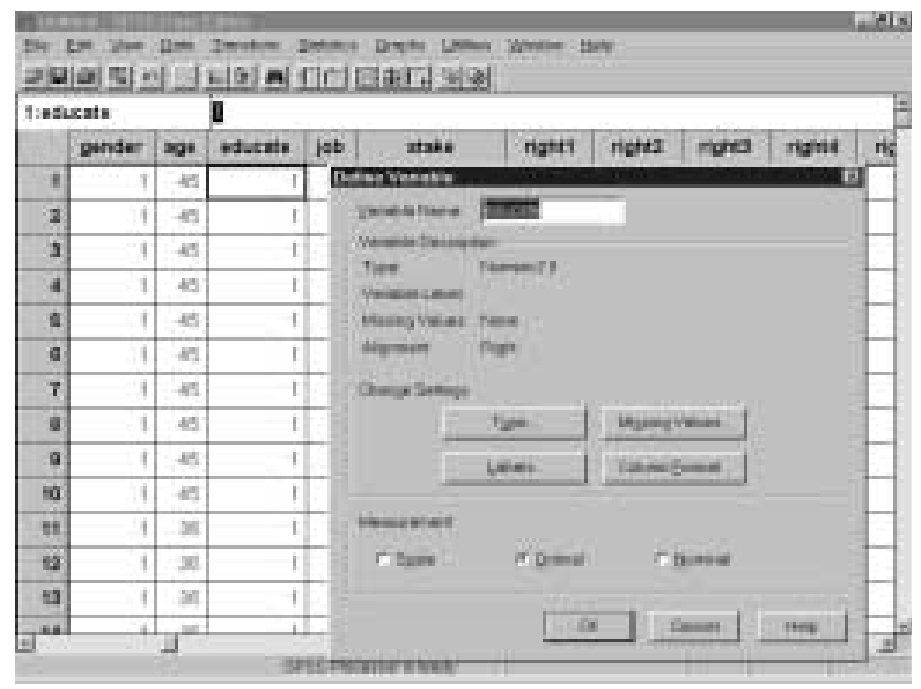

FIGURA 57. Botão Labels (dados sobre direitos para manejar).

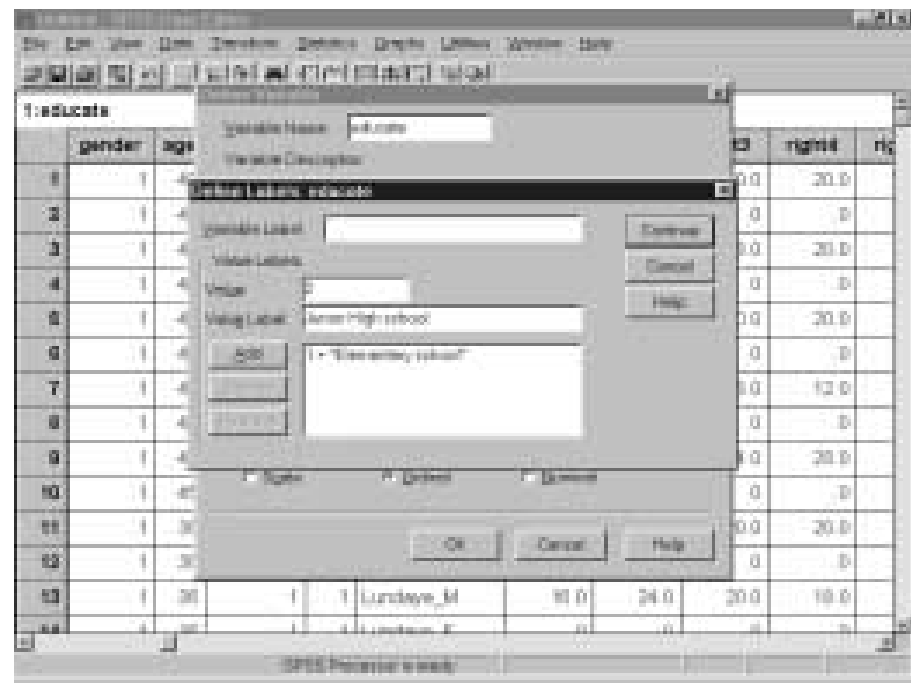

FIGURA 58. Definindo os rótulos para os dados sobre nível educacional (dados sobre direitos para manejar). 
Insira o rótulo demográfico (no exemplo acima, básico do ensino secundário). Quando finalizar, clique em Continue.

Siga os mesmos procedimentos para os outros dados demográficos.

\section{- Verificando a distribuição dos dados}

Geralmente, calculamos a média aritmética para avaliar a distribuição de peças de acordo com os respondentes. Entretanto, há algumas desvantagens no uso da média aritmética quando os dados não estão dispostos simetricamente ou quando há uma ou mais observações discrepantes. Se isso ocorrer, podemos usar o valor mediano. Para verificar se os dados estão dispostos simetricamente ou não, usamos um diagrama de distribuição dos dados (boxplot).

Para obter um diagrama de distribuição dos dados (boxplot) siga as instruções abaixo:

\section{No menu, escolha: $\quad$ Graphs$$
\text { Boxplot }
$$

Escolha simple e summaries para groups of cases (Figura 59).

Clique no botão Define.

Insira a average of rights como variável e ator como eixo da categoria (Figura 60).

Você obterá o diagrama de distribuição dos dados (boxplot), como mostra a Figura 61. A linha em preto dentro da barra mostra a posição mediana. As margens superiores e inferiores da barra mostram a posição dos $3^{\circ}$ e $1^{\circ}$ quartis, respectivamente. Os dados estão distribuídos simetricamente se, e somente se, a mediana estiver localizada no meio da barra, aproximadamente a mesma distância dos $3^{\circ}$ e $1^{\circ}$ quartis. 


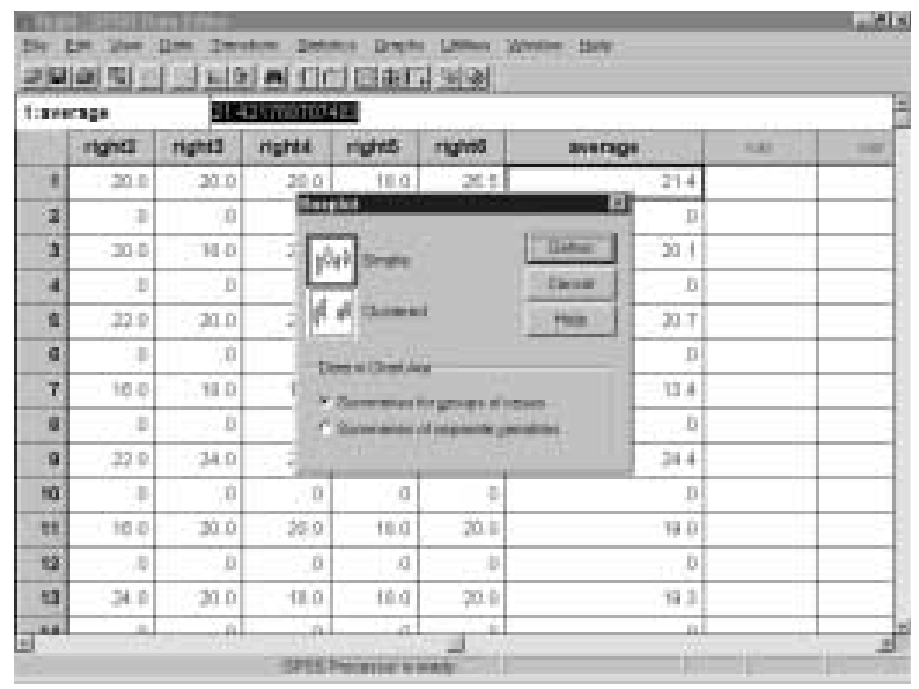

FIGURA 59. Escolhendo o tipo de diagrama de distribuição dos dados (boxplot) sobre direitos para manejar.

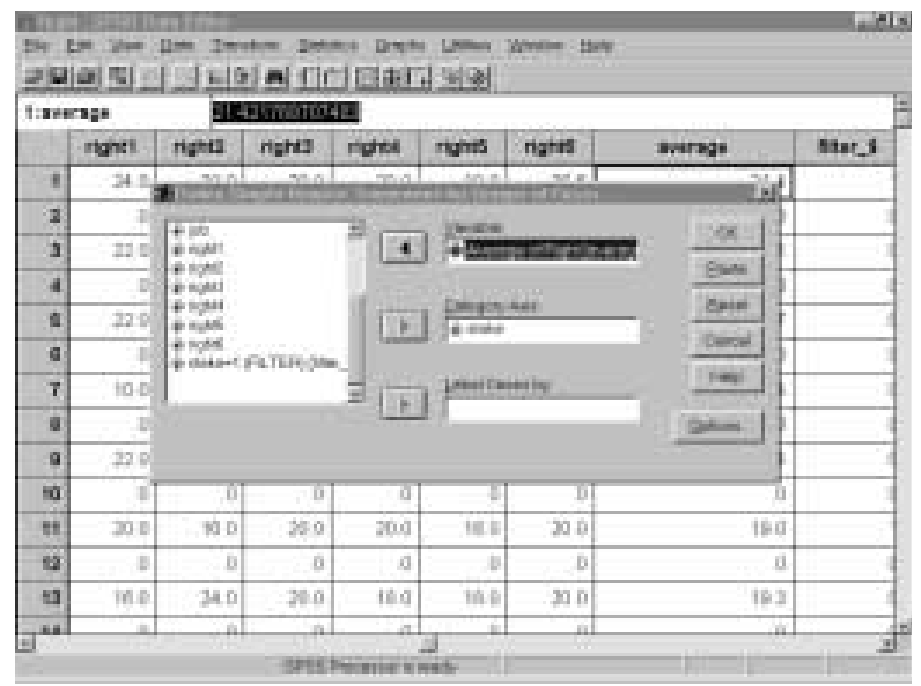

FIGURA 60. Escolhendo as variáveis dos dados sobre direitos para manejar (para verificar a distribuição dos dados). 


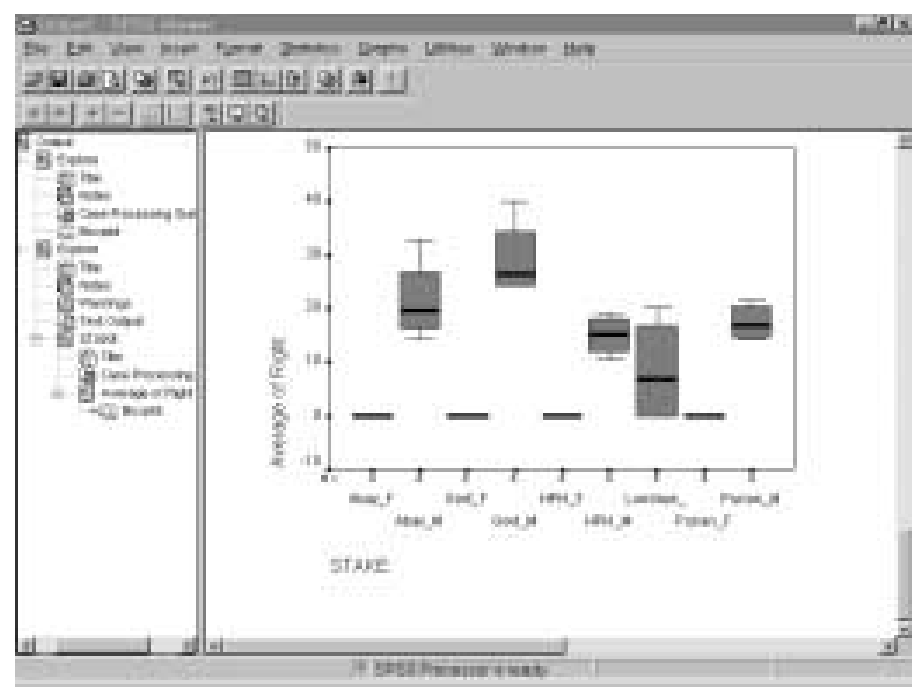

FIGURA 61. Diagrama de distribuição dos dados (boxplot) sobre direitos para manejar.

Se a distribuição dos dados estiver muito assimétrica ou houver algumas observações discrepantes (geralmente indicadas por asteriscos ou círculos), sugerimos que você use o valor mediano.

- Criando a tabela que descreve a distribuição de peças de acordo com todos os respondentes

No menu, escolha:

Statistics

Custom Tables

Basic Tables

Coloque a average of rights no quadro summaries. Você pode fazê-lo clicando no nome da coluna e, em seguida, clicando na seta diante do quadro summaries (Figura 62). 


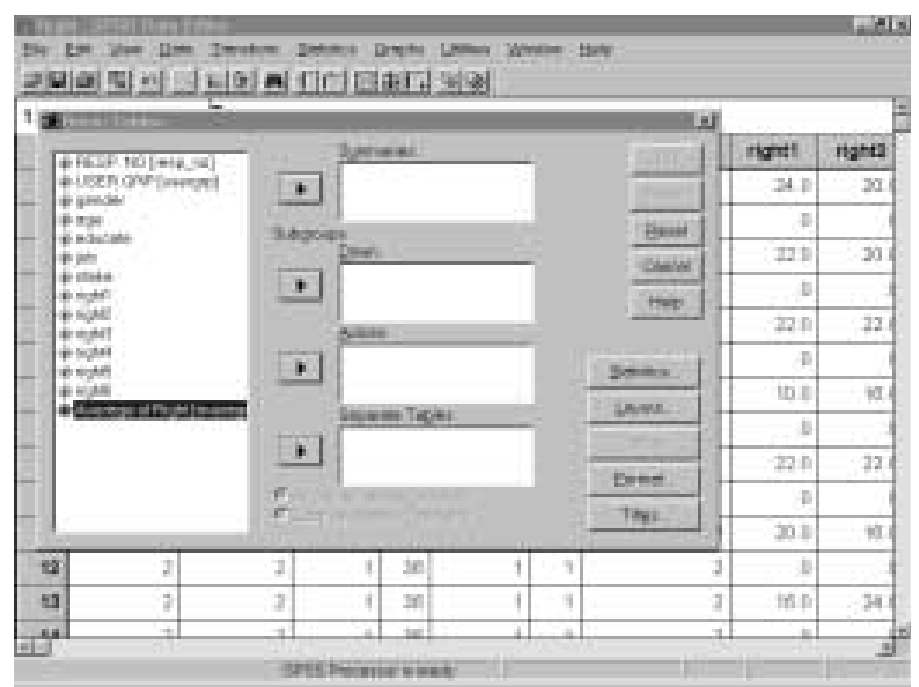

FIGURA 62. Primeira etapa da seleção das variáveis dos dados sobre direitos para manejar (para resumir).

Coloque ator em subgroups - no item down (Figura 63).

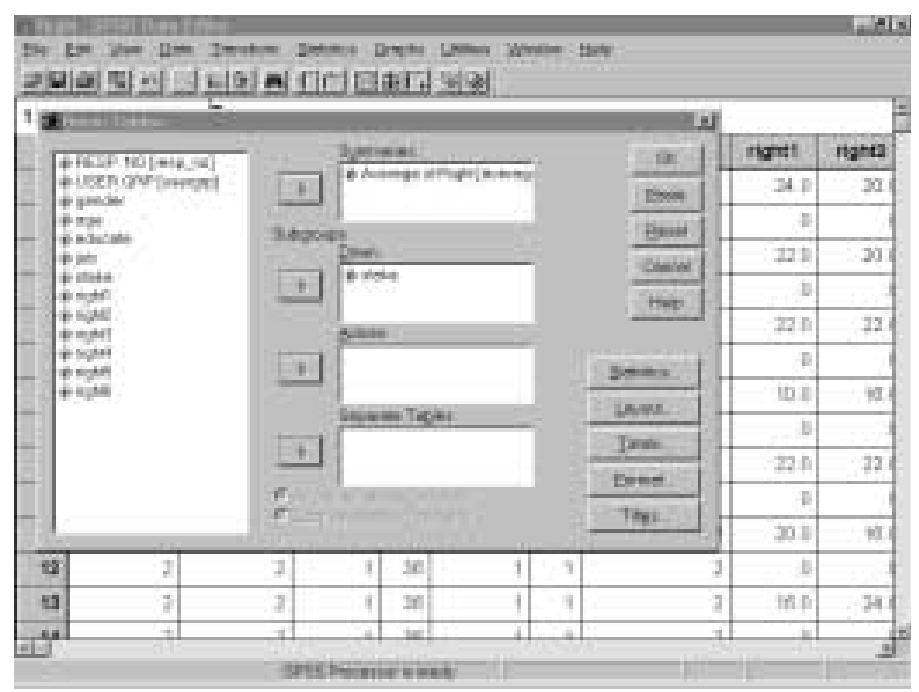

FIGURA 63. Segunda etapa da seleção das variáveis dos dados sobre direitos para manejar (para resumir). 
Clique no botão Statistics e adicione mean ou median (dependendo de qual medida você decidir usar) como a estatística a ser calculada na célula.

* Clicando em $O K$ você obterá os resultados (Figura 64).

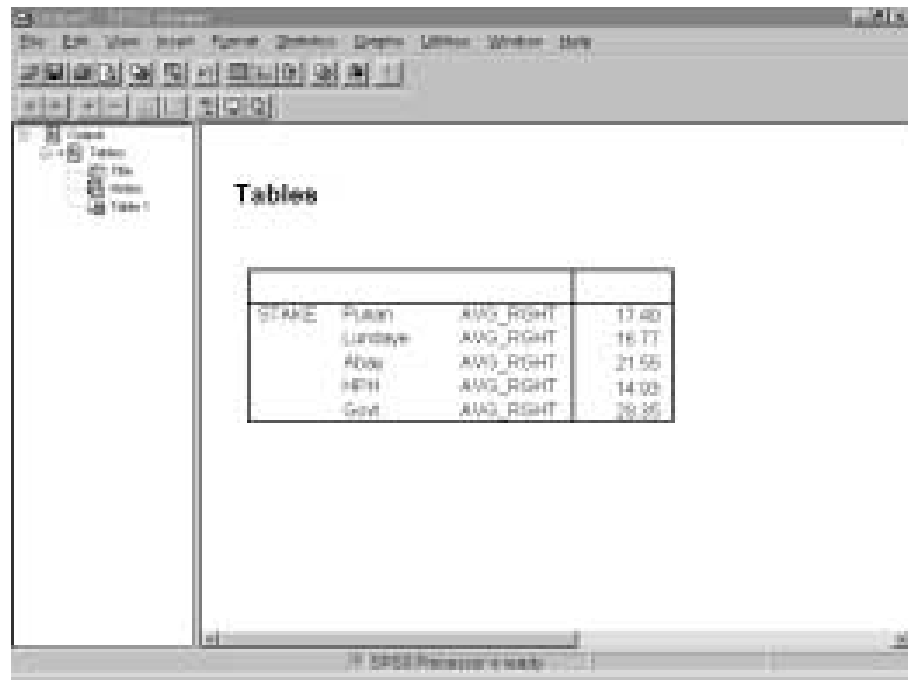

FIGURA 64. Tabela do SPSS descrevendo a distribuição dos direitos para manejar entre os atores de acordo com todos os respondentes. 
c. Conduzindo análise simples usando o programa Excel

- Criando a tabela que descreve a distribuição dos direitos para manejar de acordo com todos os respondentes

* Da opção Data no menu, escolha Pivot Table Report. Você verá a caixa de diálogo como mostra a Figura 65.

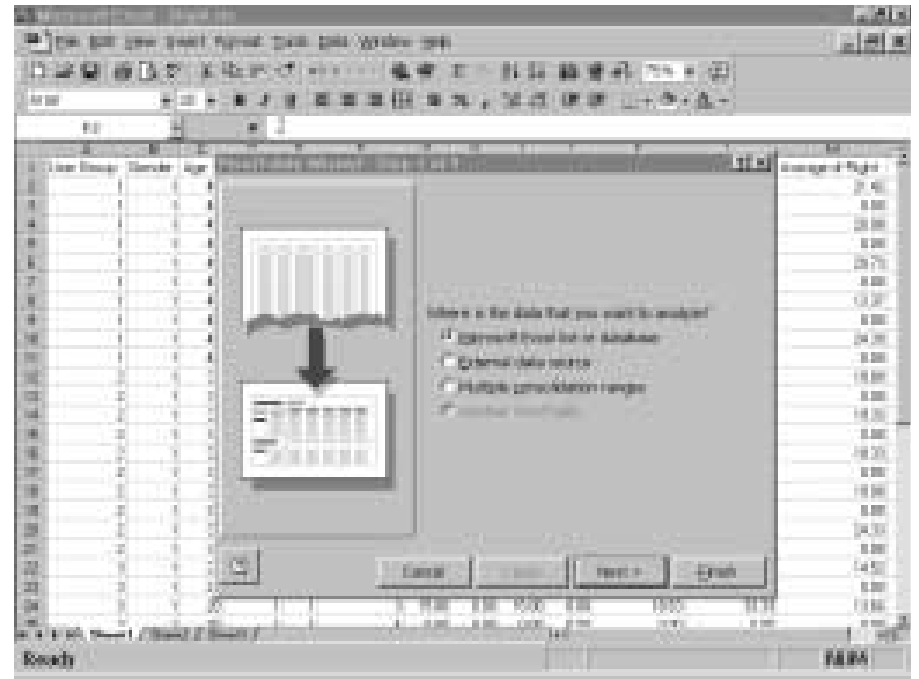

FIGURA 65. Assistente da tabela dinâmica (pivot table wizard) (dados sobre direitos para manejar).

* Clique duas vezes no botão Nexts e você verá uma caixa de diálogo como mostra a Figura 66. 


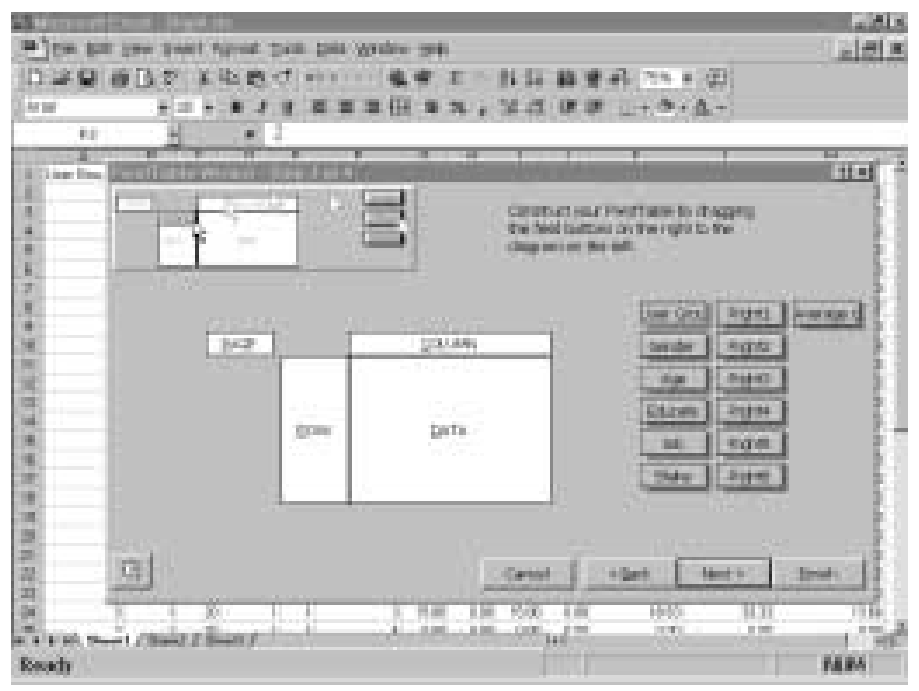

FIGURA 66. Construindo uma tabela dinâmica (pivot table) para análise simples dos dados sobre direitos para manejar ( $1^{\text {a }}$ etapa).

Arraste com o mouse a average of rights para o espaço dos dados e os atores para o espaço da fileira. (Figura 67).

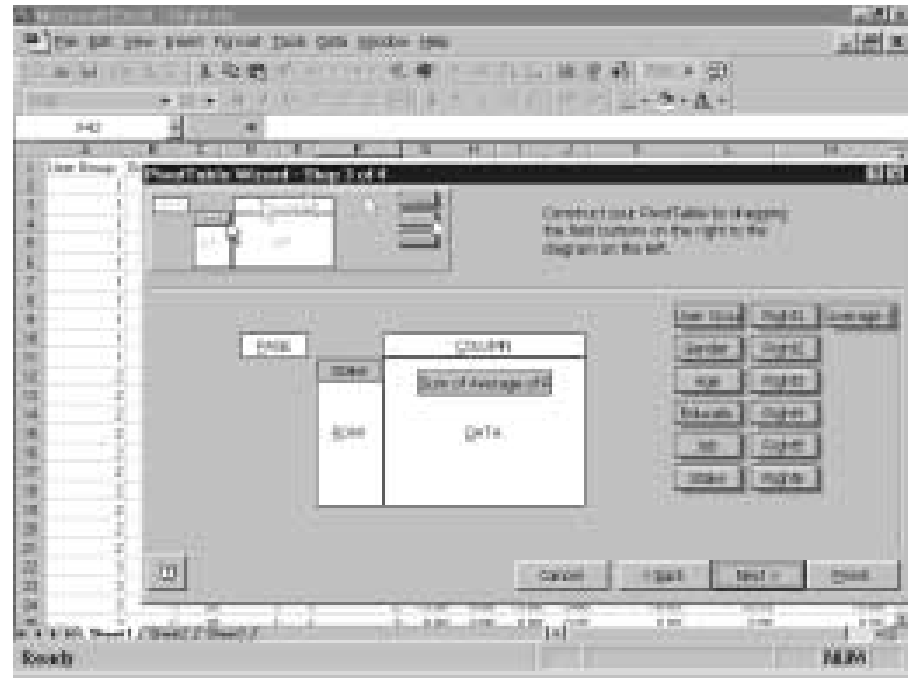

FIGURA 67. Construindo uma tabela dinâmica (pivot table) para análise simples dos dados sobre direitos para manejar ( $2^{\mathrm{a}}$ etapa). 
A soma é a estatística predefinida. Você pode mudar a estatística clicando no botão e escolhendo a estatística que você deseja calcular (Figura 68).

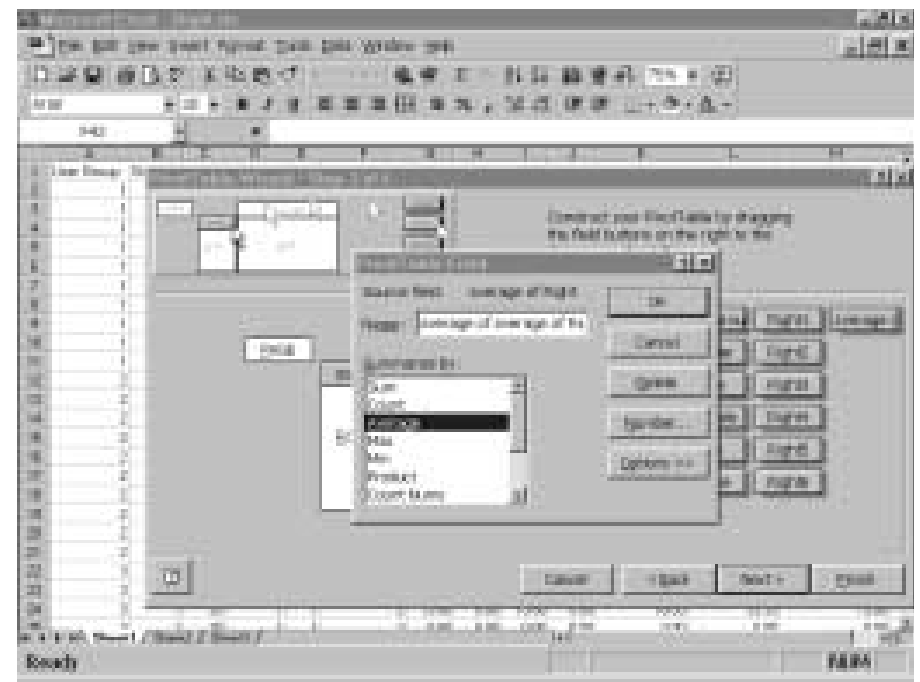

FIGURA 68. Mudando a estatística predefinida nos dados sobre direitos para manejar.

Após mudar a estatística, clique no botão Finish para obter a tabela como mostra a Figura 69. Se preferir um número menor de dígitos, você deve definir a classe decimal. ${ }^{54}$

54 Para definir a classe decimal, escolha a opção Format no menu, escolha Cells, e sob a categoria, Numbers. Em seguida, determine a classe decimal que você deseja, aumentando ou reduzindo a classe decimal predefinida (predefinida $=2$ ). 


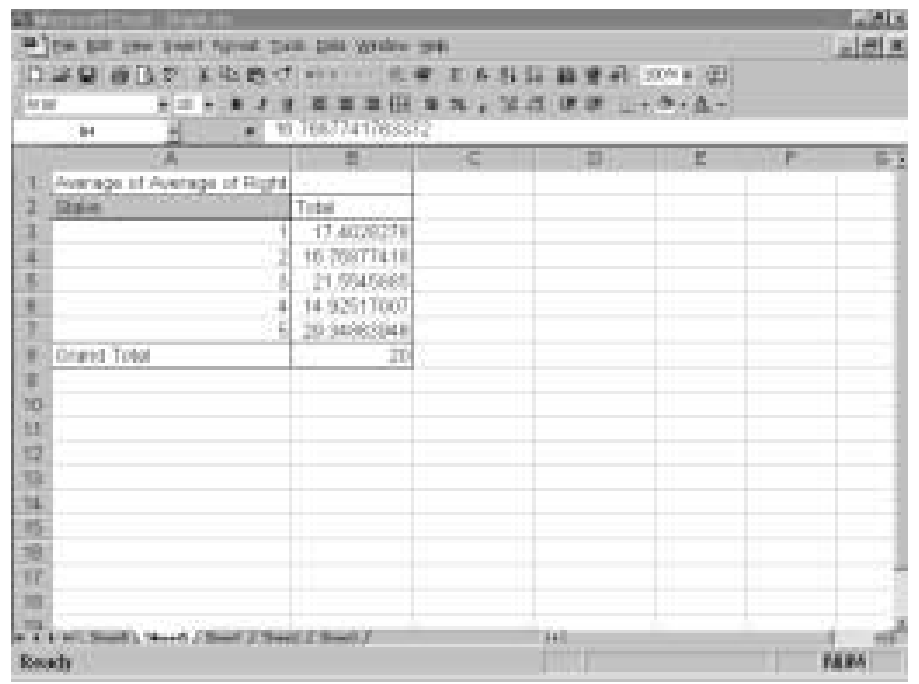

FIGURA 69. Tabela do Excel descrevendo a distribuição dos direitos para manejar entre os atores de acordo com todos os respondentes.

d. Conduzindo análise avançada dos dados usando o programa SPSS

- Criando a tabela que descreve a distribuição dos direitos para manejar de acordo com um subgrupo particular

Em alguns casos, é interessante comparar as opiniōes de subgrupos diferentes dentro de cada característica demográfica (etnia, gênero, nível educacional etc.) sobre a distribuição de peças entre os atores. Para comparar as opiniōes desses subgrupos, precisamos conhecer os valores que descrevem a distribuição dos direitos para manejar entre os atores de acordo com cada subgrupo. Você pode seguir nossas instruções abaixo para obter esses números. Imagine que temos um grupo de respondentes desses três grupos étnicos com dois níveis educacionais, fundamental e básico do nível secundário. 
No menu, escolha

Select Cases

Clique na opção if condition is satisfied (Figura 70).

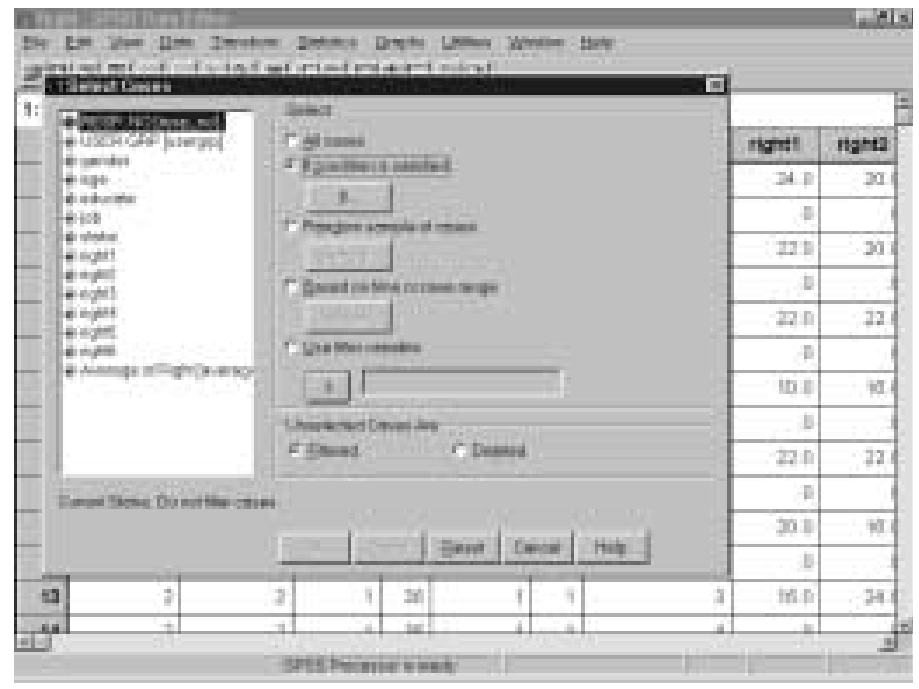

FIGURA 70. Selecionando os casos para o subgrupo específico (dados sobre direitos para manejar).

Clique no botão If.

* Verifique sua folha de códigos para determinar os códigos para o nível "fundamental" e "básico do ensino secundário" (por exemplo, você pode ter nível fundamental $=1$ e básico do ensino secundário $=2$ ).

Digite no quadro condicional: $e d u c=1$ (você filtrará os dados com valor 1 na coluna $e d u c a)$. 
Em seguida, clique em Continue e em $O K$ (Figura 71).

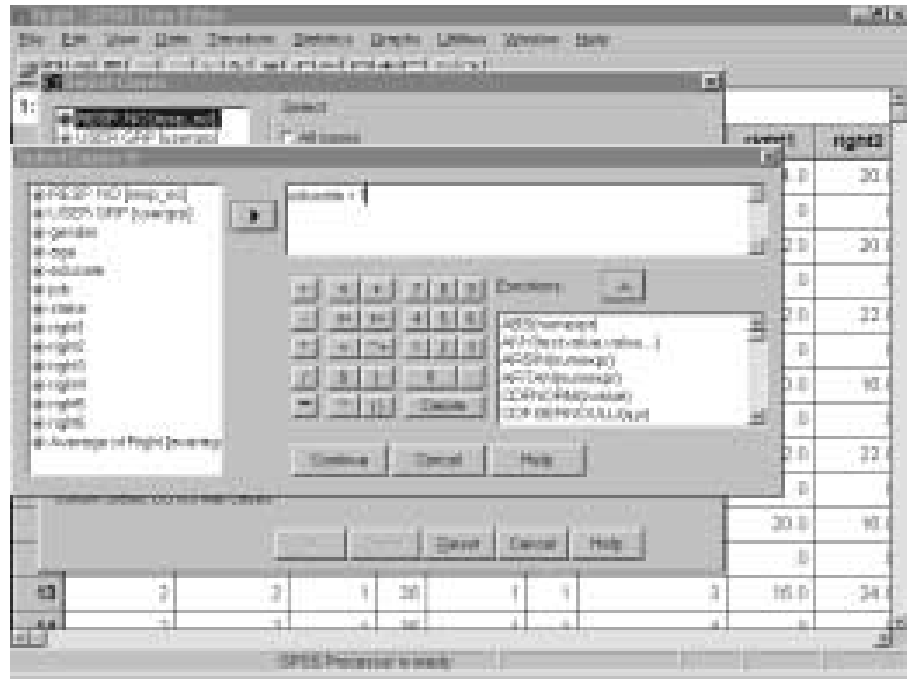

FIGURA 71. Filtrando os respondentes com nível educacional inferior nos dados sobre direitos para manejar.

Neste momento, se você observar na planilha do SPSS pode haver fileiras com valores que não são iguais a 1 na coluna educa. Esses são respondentes com nível educacional mais alto e não estão incluídos na análise, portanto são inativos. Essa posição de inativo é marcada por uma linha diagonal na numeração da fileira (ver Figura 72 para detalhes). 


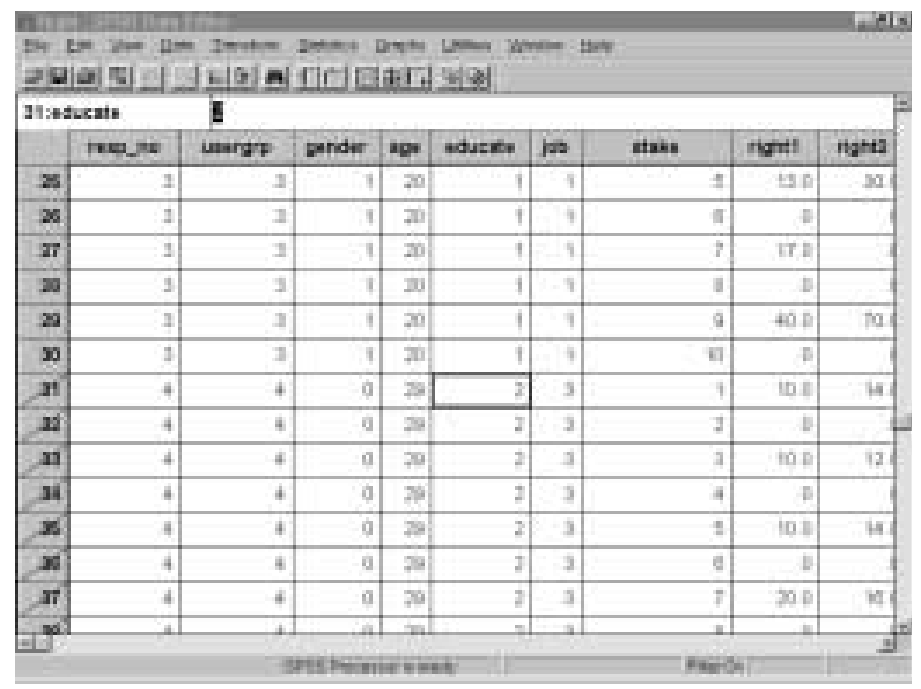

FIGURA 72. Resultado da seleção de casos (dados sobre direitos para manejar)

* Siga o mesmo procedimento da quarta etapa da Parte B desta seção, usado para obter a média da distribuição de peças de acordo com os respondentes com nível educacional fundamental (ver Figura 73).

* Para obter a média da distribuição de peças de acordo com os respondentes com nível educacional básico do ensino secundário, simplesmente mude a expressão condicional para:

educa $=2$.

Em seguida, siga os mesmos procedimentos como na quarta etapa da Parte B desta seção. 
Agora podemos comparar as diferenças na distribuição de peças entre os dois grupos de atores com níveis educacionais diferentes (Figura 74).

Se você tem mais de duas categorias em seus dados demográficos, você pode seguir o mesmo procedimento para obter o valor da média/ mediana da distribuição de peças entre os atores.

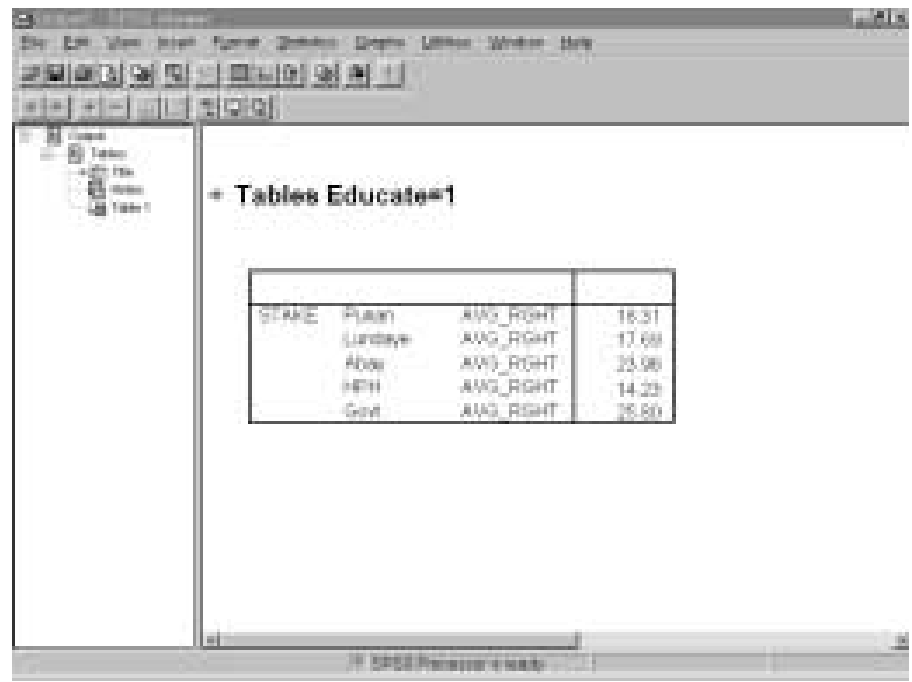

FIGURA 73. Distribuição dos direitos para manejar entre os atores de acordo com os respondentes com nível educacional inferior. 


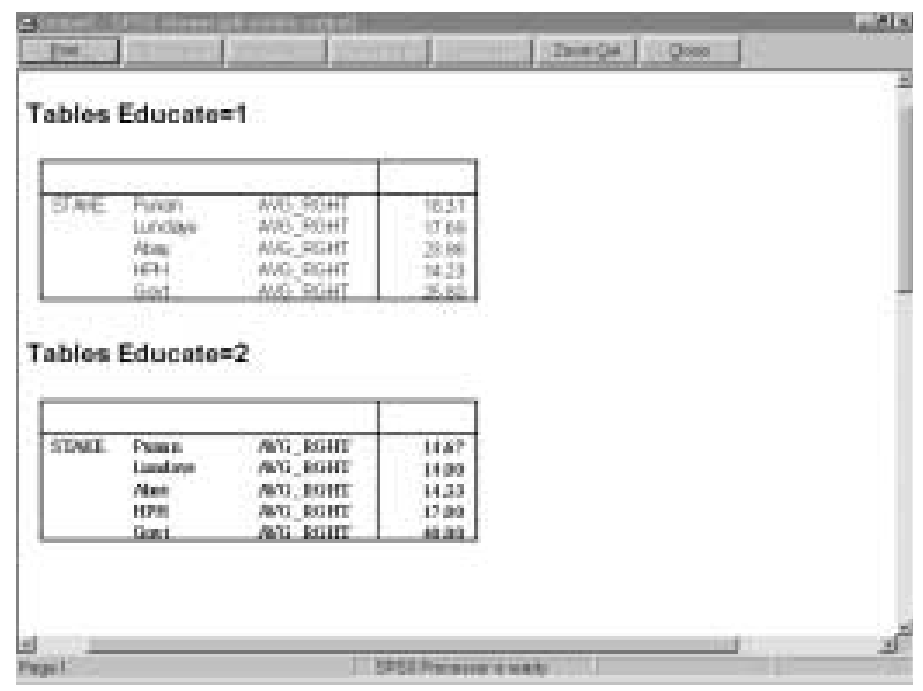

FIGURA 74. Comparação da distribuição dos direitos para manejar entre os atores com base no nível educacional.

- Testando se há acordo ou desacordo entre os diferentes grupos sobre a distribuição dos direitos para manejar

Você pode verificar se há acordo ou desacordo entre os diferentes grupos dentro de cada característica demográfica ${ }^{55}$ relativos à quantidade de direitos atribuída a atores especificados. Você pode fazer a análise para cada ator. O que você deve fazer primeiramente é filtrar os dados até que somente as fileiras para os atores selecionados estejam ativas e as outras fileiras estejam inativas. Neste caso, filtramos somente os dados atribuídos ao grupo Punan $($ Ator $=1)$ (ver Figura 75). Para orientação detalhada sobre como filtrar dados, ver a primeira etapa da Parte D desta seção. 


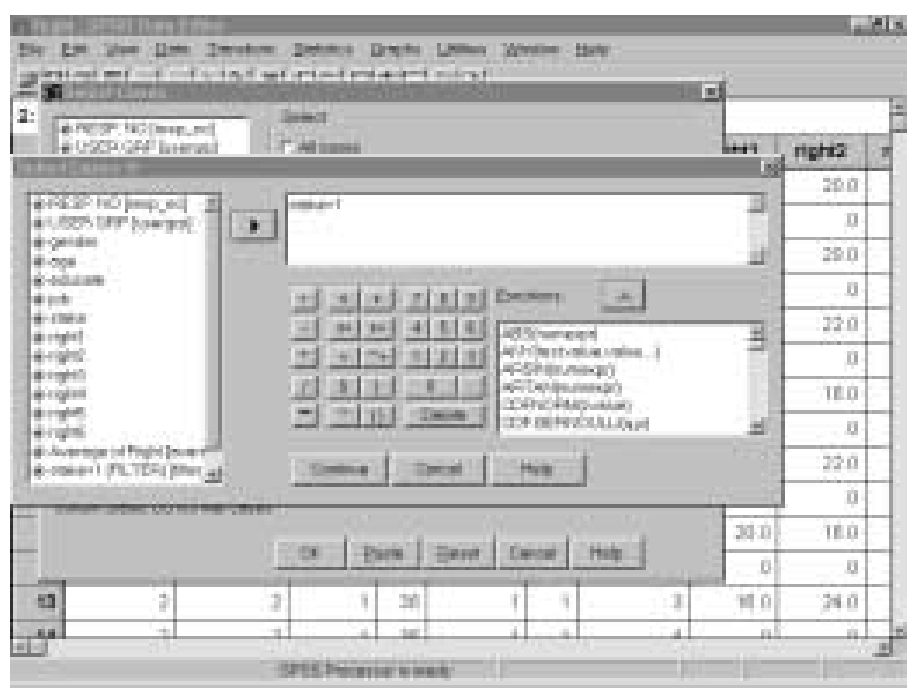

FIGURA 75. Filtrando os dados para o grupo Punan (dados sobre direitos para manejar).

No menu, escolha:

\section{Statistics \\ Nomparametric test $\underline{2}$ independent samples ou \\ $\underline{\text { Kindependent samples }}{ }^{56}$ \\ (Ver Figura 76)}

56 Se você deseja testar os dados com apenas duas categorias ou dois grupos, você deve escolher 2 independent samples e, em seguida, usar o teste de MannWhitney. Se você está lidando com dados em mais de duas categorias, você deve escolher $K$ independent samples e, em seguida, usar o teste de KruskallWallis. 


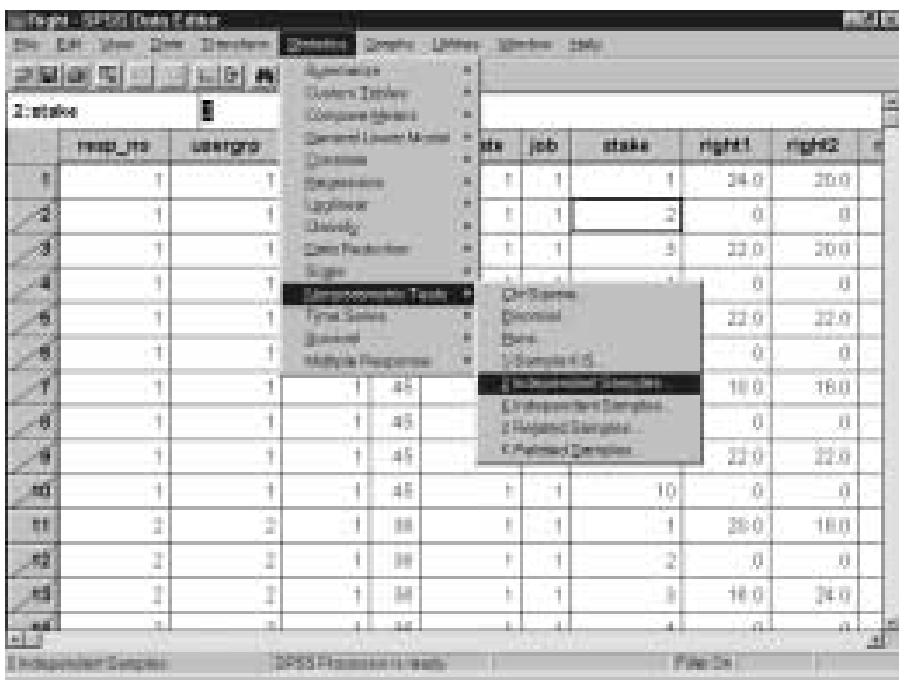

FIGURA 76. Selecionando o teste estatístico para examinar se há acordo nos dados sobre direitos para manejar.

* Coloque as variáveis de teste $\mathrm{e}^{57}$ no quadro test variable list e a variável de agrupamento no quadro grouping variable (Figura 77). Em seguida, defina um valor mínimo e um valor máximo da variável de agrupamento como mostra a Figura 78 (você pode verificar o significado de cada código na sua folha de códigos).

57 As variáveis de teste (test variable) devem ser a coluna que contém a média dos direitos. A variável de agrupamento (grouping variable) é a coluna que contém as características demográficas que queremos comparar. 


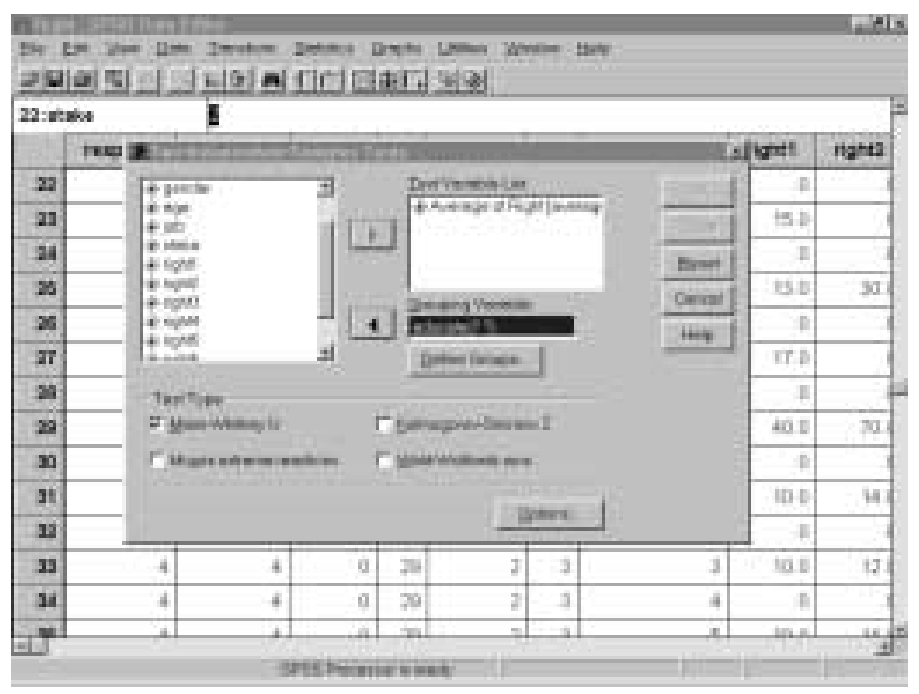

FIGURA 77. Selecionando as variáveis de teste (test variables) e a variável de agrupamento (grouping variable) (dados sobre direitos para manejar).

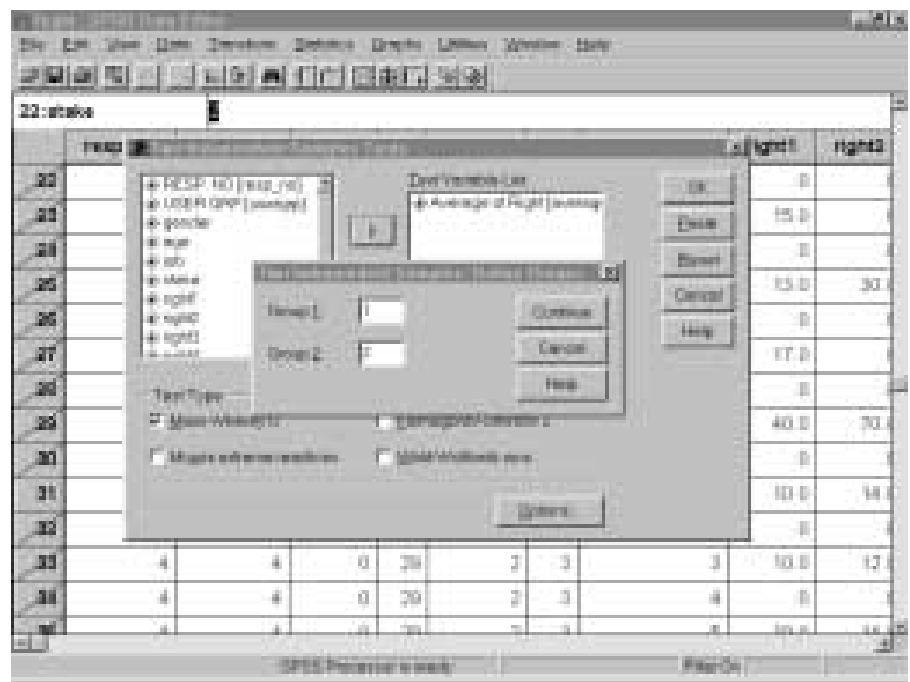

FIGURA 78. Definindo o intervalo para a variável de agrupamento (grouping variable)(dados sobre direitos para manejar). 
* Clique em Continue e em seguida em $O K$.

Você obterá os resultados como mostra a Figura 79.

Verifique o Value-P (indicado pela seta). Se o Value-P for abaixo de 0,05 , rejeitamos a hipótese nula ${ }^{58}$ e concluímos que há desacordo entre os grupos no que se refere à quantidade de peças atribuída ao ator especificado. Se o Value- $\boldsymbol{P}$ for acima de 0,05 , concluímos que há acordo entre os diferentes grupos.

* Você também pode fazer análises para os outros atores, mudando o enunciado de filtração. Por exemplo, se você quer testar a quantidade de peças atribuída aos lundayes ${ }^{59}$ (veja sua folha de códigos e obtenha o código para os lundayes, Ator $=2$ ). Em seguida, mude a condição do filtro na Figura 18 para Ator $=2$ e use o mesmo procedimento para obter o teste estatístico.

58 A hipótese nula é: todos os subgrupos alocaram a mesma quantidade de peças para o ator sendo testado. Em outras palavras, eles concordam sobre a quantidade de peças atribuída ao ator sendo testado.

590 Lundaye é um dos maiores grupos étnicos em Paking, Bulungan, onde realizamos nosso teste de campo. 


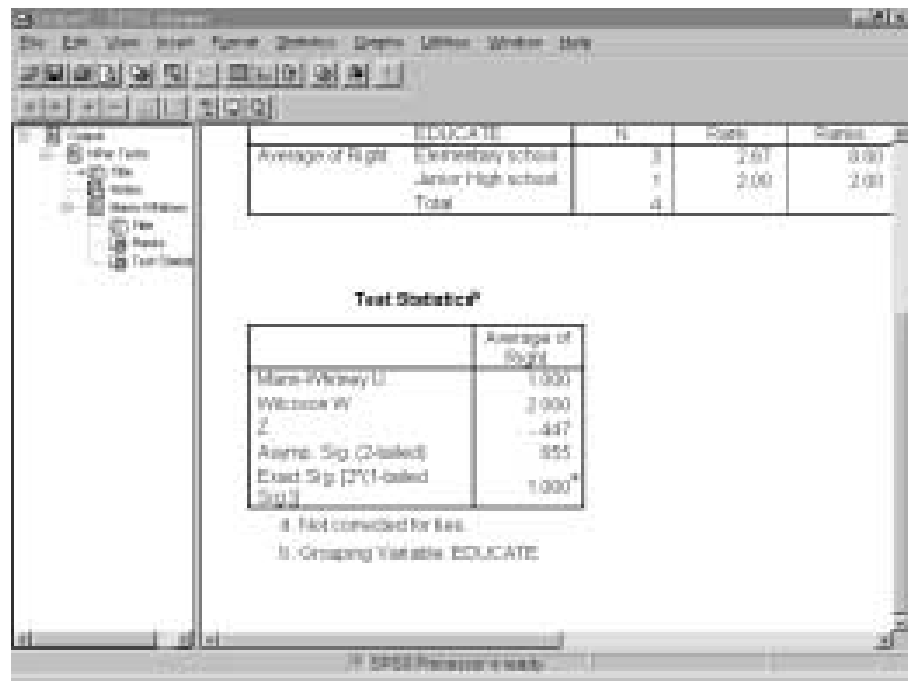

FIGURA 79. Produto do teste estatístico para o grupo Punan com base no nível educacional (dados sobre direitos para manejar).

\section{e. Conduzindo análise avançada dos dados usando o programa Excel}

\section{- Criando a tabela que descreve a distribuição de peças de acordo} com subgrupos particulares

Você pode usar o mesmo procedimento usado para obter uma tabela de distribuição de peças de acordo com todos os respondentes. Porém, para construir a tabela dinâmica, o procedimento será diferente. Ao invés de você apenas arrastar todas as gerações com o mouse para o espaço dos dados, você também deve arrastar a coluna onde os subgrupos particulares estão para o espaço da coluna ${ }^{60}$ (Figura 80). Aqui usamos o nível educacional como exemplo. 


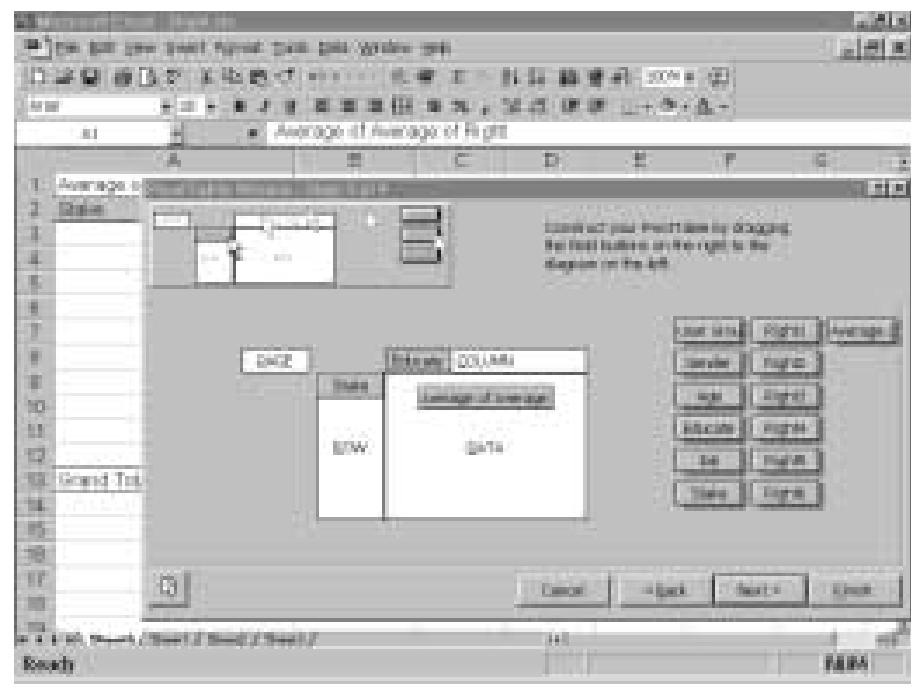

FIGURA 80. Construindo uma tabela dinâmica (pivot table) para análise avançada dos dados sobre direitos para manejar.

Clicando no botão Finish você obterá o resultado (Figura 81). Há duas subtabelas para cada nível educacional (neste exemplo, assim como no anterior, nível educacional = 1 significa ensino fundamental, enquanto nível educacional = 2 significa básico do nível secundário). 


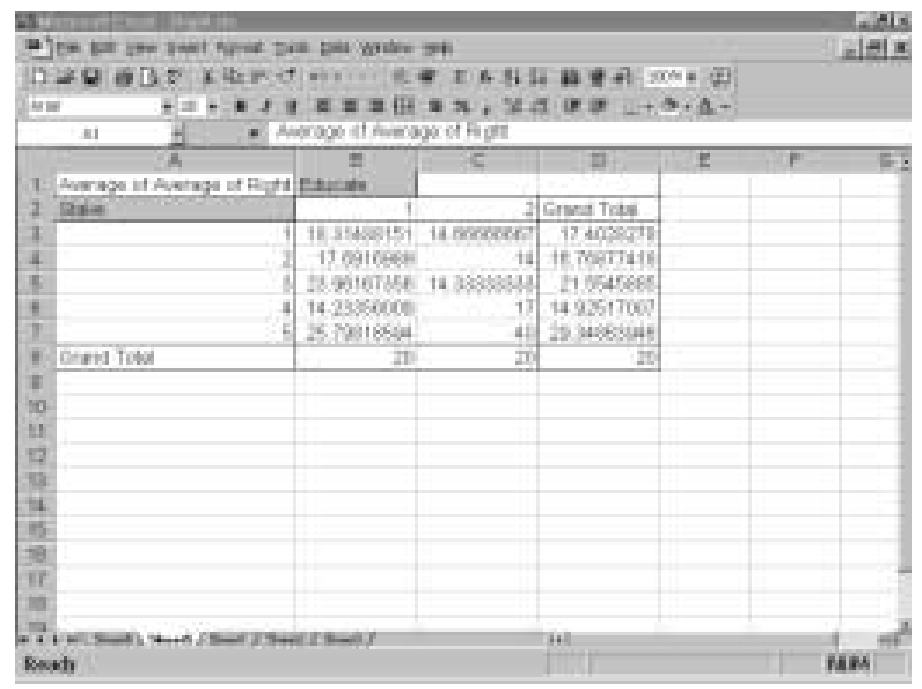

FIGURA 81. Tabela do Excel descrevendo a comparação da distribuição dos direitos para manejar com base no nível educacional. 


\section{D - CONCLUSÃO}

Este manual foi elaborado para complementar outros manuais da série C\&I do Cifor, particularmente o GBA e Os Acessórios. O Guia de Pontuação e Análise trata de três tópicos principais: i) um guia de pontuação; ii) procedimentos para o desenvolvimento de uma planilha principal de C\&I a ser utilizada com o guia de pontuação; e iii) um guia de análise. A primeira (I) seção forneceu ao usuário algumas comparações globais das condições, associadas a pontuações consideradas justas pelos autores e baseadas em consideráveis experiências de campo em testes de C\&I. O objetivo foi ajudar os usuários a avaliarem das condições encontradas no campo, associadas ao bem-estar humano. A segunda (II) seção foi elaborada para usuários com experiência relativa no uso de planilhas eletrônicas. Essa seção explicou o processo de montagem e uso da planilha e forneceu mais detalhes sobre um método de pontuação global proposto. A terceira (III) e mais longa seção, forneceu detalhes consideráveis sobre as formas de analisar os resultados de muitos dos métodos quantitativos descritos no $G B A$ e no Os Acessórios. Este guia é como um documento de referência, no qual os usuários podem consultar diretamente a seção mais relevante para sua necessidade particular.

Temos procurado auxiliar e orientar na difícil tarefa de avaliar, pontuar e analisar dados resultantes de procedimentos de avaliação. Embora tenhamos observado que esses procedimentos são de grande ajuda, reconhecemos que a tarefa de avaliar e a necessidade de julgamentos continuam enormes. Avaliar o bem-estar humano não é uma tarefa fácil.

Continuamos convencidos de que as melhores avaliações dependem de avaliadores experientes e sensíveis que seguem os procedimentos sugeridos neste manual e que ao mesmo tempo são criativos e construtivos. Nós ainda não alcançamos um estado na avaliação do manejo florestal sustentável, incluindo o bem-estar humano, no qual podemos seguir procedimentos 
cegamente e nos aproximarmos de conclusões sensatas. Concluímos encorajando os usuários a manterem-se criativos enquanto examinam as condições das pessoas nas florestas e ao seu redor. 


\section{E - BIBLIOGRAFIA}

Colfer, C.J.P., Brocklesby, M.A., Diaw, C., Etuge, P., Günter, M., Harwell, E., McDougall, C., Porro, N.M.,

Porro, R., Prabhu, R., Salim, A., Sardjono, M.A., Tchikangwa, B.,Tiani, A.M., Wadley, R.L., Woelfel, J. and Wollenberg, E. 1999. The BAG (Basic assessment guide for human well-being). Criteria and Indicators Toolbox Series No. 5. CIFOR, Bogor, Indonesia.

Colfer, C.J.P., Brocklesby, M.A., Diaw, C., Etuge, P., Günter, M., Harwell, E., McDougall, C., Porro, N.M.,

Porro, R., Prabhu, R., Salim, A., Sardjono, M.A., Tchikangwa, B.,Tiani, A.M., Wadley, R.L., Woelfel, J. and Wollenberg, E. 1999. TheGrab Bag: Supplementary methods for assessing human well-being.

Criteria and Indicators Toolbox Series No. 6. CIFOR, Bogor, Indonesia.

Draper, N. and Smith, H. 1981. Applied regression analysis. Wiley, New York.

Makridakis, S., Wheelwright, S.C. and McGee, V.E. 1983. Forecasting: Methods and applications. Wiley, New York.

Sardjono, M.A., Rositah, E., Wijaya, A. and Angie, E.M. 1997. A test of social science assessment methods concerning indicators and criteria for sustainable forest management in East Kalimantan. CIFOR Report. CIFOR, Bogor, Indonesia.

SPSS for Windows, Rel. 8.0.0. 1997. SPSS Inc., Chicago.

Tchikangwa, N.B. with Sikoua, S., Metomo, M. and Adjudo, M.F. 1998. Test des méthodes en sciences sociales de vérification des critères et indicateurs d'aménagement durable des forêts: Périphérie est de la Réserve du Dja (Sud-Cameroun).

CIFOR Report. CIFOR, Bogor, Indonesia.

Woelfel, J.K. 1998. User's Guide CatPac II version 2.0. Rah Press, Amherst, NY. 


\section{APÊNDICE A: VERIFICANDO OS PRESSUPOSTOS DA ANÁLISE DE REGRESSÃO}

\section{HOMOGENEIDADE DAS VARIÂNCIAS DOS RESÍDUOS (HOMOSCEDASTICIDADE)}

Chamamos de homoscedasticidade quando as variâncias dos resíduos são constantes para qualquer valor da variável independente $(\mathrm{X})$. A distribuição dos resíduos em forma de cone em um gráfico onde no outro eixo estão os valores estimados, pode dar o primeiro sinal de que as variâncias dos resíduos não são constantes (ver figuras $82 \mathrm{a}$ e $82 \mathrm{~b}$ ). Um modelo que satisfaz esse pressuposto terá as variâncias dos resíduos constantes, como mostra a Figura 82c.

Se o resíduo indica padrão a ou b, você pode usar "regressão linear ponderada” (Draper e Smith 1981).

Para uma discussão adicional sobre como superar este problema, consulte um estatístico.
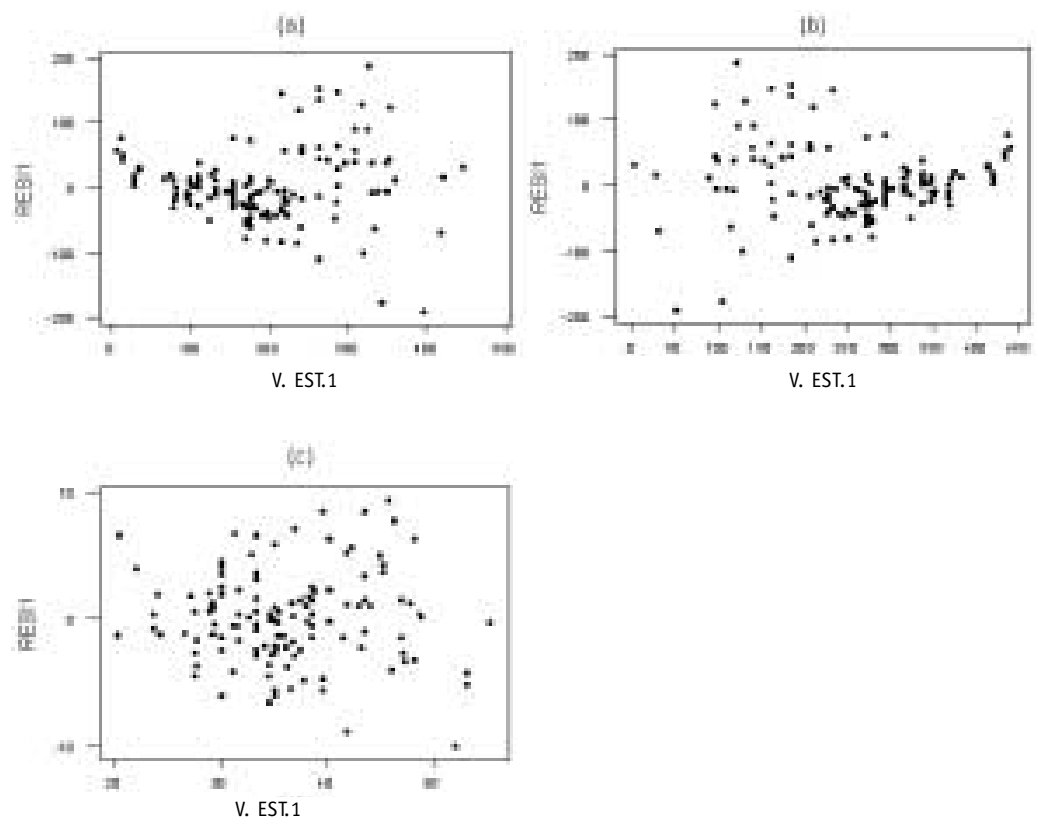

FIGURA 82. Alguns padrões de variâncias dos resíduos. 


\section{NORMALIDADE DO RESÍDUO}

A análise de regressão assume que os resíduos do modelo seguem distribuição normal ${ }^{61}$, com média zero e desvios padrões um. Há muitos testes para verificar a normalidade do pressuposto, incluindo o teste de KolmogorovSmirnov e o teste de Shapiro-Wilk. Esses testes podem ser facilmente realizados usando o programa de computador Minitab. Entretanto, podemos verificar essa hipótese rapidamente usando o diagrama normal Q-Q.

Quando você executar a análise de regressão no Excel, lembre de ter clicado na opção Normal Probability Plot. Essa opção produzirá um diagrama quantil-quantil normal (Q-Q), como mostra a Figura 83.

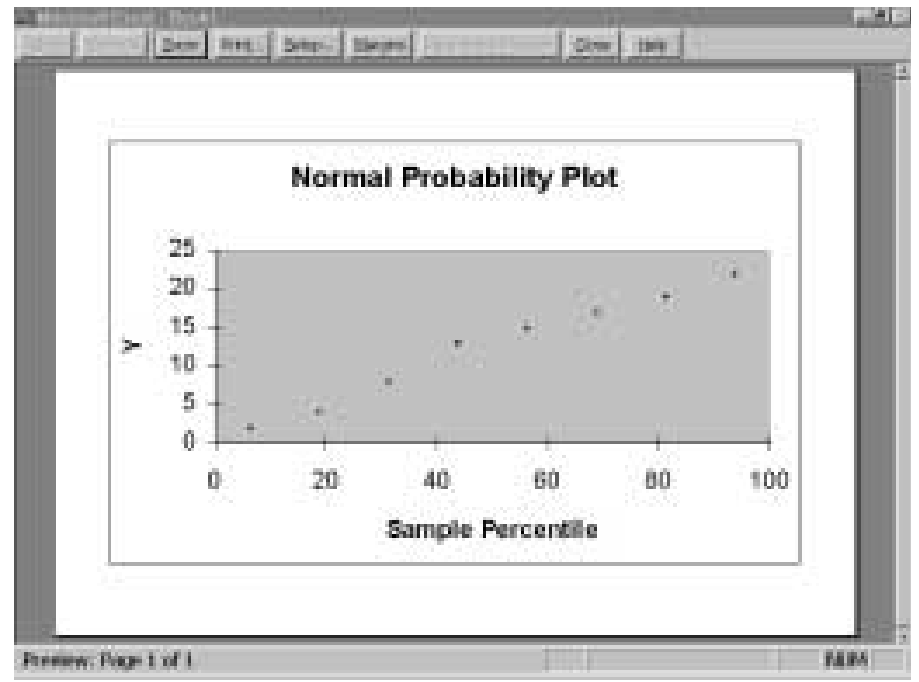

FIGURA 83. Diagrama de Probabilidade Normal (Normal Probability Plot) do Resíduo. 61 X segue uma distribuição normal se sua função de probabilidade, $f(x)$ aproximadamente igual a $\frac{1}{\sqrt{2 \pi \sigma}} e^{-\frac{1(x-\mu)^{2}}{2}}$ onde $\mu$ e $\sigma^{2}$, respectivamente, são a
média e a variância da variável. 
Se os padrões do resíduo seguirem uma linha reta, podemos concluir que o resíduo tem uma distribuição seguindo o pressuposto de distribuição normal. Quanto mais os resíduos se distanciam de um padrão de linha reta, mais provavelmente os resíduos não estão distribuídos seguindo a distribuição normal. Se isso ocorrer, deve-se utilizar testes mais detalhados, tais como aqueles sugeridos acima. Recomenda-se consultar um estatístico sobre como realizar e tirar conclusões do teste.

\section{RESÍDUOS NÃO CORRELACIONADOS}

$\mathrm{Na}$ análise de regressão, assumimos que os erros ou resíduos não são correlacionados. Há, evidentemente, muitos casos em que os resíduos podem ser correlacionados (Draper e Smith 1981). Este tipo de fenômeno freqüentemente ocorre quando lidamos com dados de série temporal. O padrão mais comum que podemos encontrar é quando o resíduo da $i^{\text {ésima }}$ observação (na seqüência temporal) tem relação linear com o resíduo da (i-1) ésima observação. As figuras $84 \mathrm{a}$ e $84 \mathrm{~b}$ mostram dois diagramas que revelam relações funcionais entre os resíduos. A Figura $84 a$ mostra tendência positiva entre o resíduo i e seu anterior (i-1); entretanto, a Figura $84 \mathrm{~b}$ mostra uma tendência negativa entre os resíduos.

A correlação entre a i ${ }^{\text {esima }}$ e (i-1) $)^{\text {ssima }}$ observações foi chamada correlação de série defasada em um período. Para visualizar a existência de correlação de série em defasagens maiores, você pode plotar os resíduos, dois períodos anteriores, três períodos anteriores, e assim por diante. $\mathrm{Na}$ presença do resíduo autocorrelacionado, muitos métodos podem ser usados, incluindo a regressão autogressiva. 
(a)

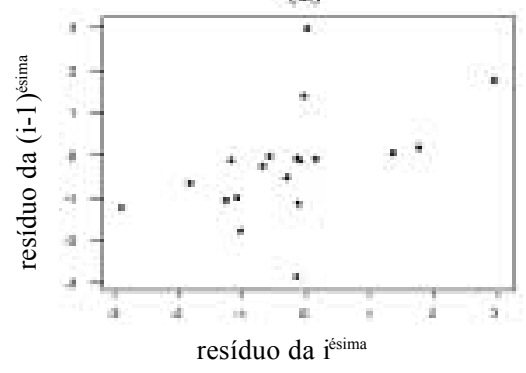

(b)

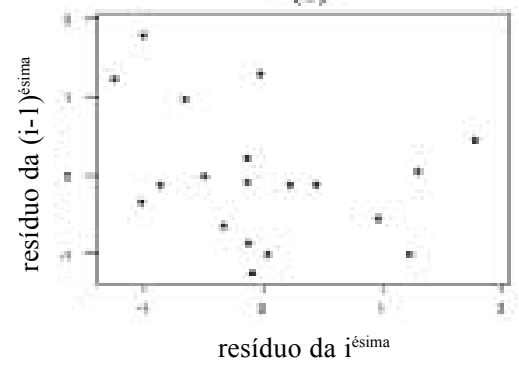

FIGURA 84. Diagramas mostram resíduos autocorrelacionados. 


\section{GLOSSÁRIO}

$\begin{array}{ll}\text { 2independent samples } & 2 \text { amostras independentes } \\ \text { Add-Ins } & \text { Suplementos } \\ \text { Analysis ToolPak } & \text { Ferramentas de análise } \\ \text { Analysis ToolPak-VBA } & \text { Ferramentas de análise-VBA } \\ \text { Analysis tools } & \text { Ferramentas de Análise } \\ \text { Average } & \text { Média } \\ \text { Average of rights } & \text { Média dos direitos } \\ \text { Basic tables } & \text { Tabelas básicas } \\ \text { Boxplot } & \text { Diagrama de distribuição dos dados } \\ \text { Cells } & \text { Células } \\ \text { Clustered } & \text { Agrupado } \\ \text { Continue } & \text { Continue } \\ \text { Copy } & \text { Copiar } \\ \text { Custom tables } & \text { Tabelas personalizadas } \\ \text { Data } & \text { Dados } \\ \text { Data Analysis } & \text { Análise de dados } \\ \text { Define } & \text { Defina } \\ \text { Define variable } & \text { Defina variável } \\ \text { Down } & \text { Abaixo } \\ \text { Edit } & \text { Editar } \\ \text { Enter } & \text { Entrar } \\ \text { Ethnic } & \text { Étnico } \\ \text { Exclude } & \text { Exclui } \\ \text { File } & \text { Arquivo } \\ \text { Finish } & \text { Finalizar } \\ \text { Format } & \text { Formatar } \\ \text { Graphs } & \text { Gráficos } \\ \text { Group of cases } & \text { Grupo de casos } \\ \text { Grouping variable } & \text { Variável de agrupamento } \\ \text { Help } & \text { Ajuda } \\ \text { If condition is satisfied } & \text { Se a condição for satisfeita } \\ \text { If } & \text { Se } \\ \text { Independent samples } & \text { Amostras independentes } \\ \text { Kindependent samples } & \text { K amostras independentes } \\ \text { Labels } & \text { Rótulos } \\ & \\ & \end{array}$


Line Fit Plot

Make dendogram

Mean

Median

Next

Nonparametric Test

Normal Probability Plot

Numbers

Open

Option

Pivot table

Pivot table wizard

PivotTable Report

Print

Read variable name

Regression

Residual Plot

$R$-square

Run

Save As

Select cases

Setup.exe

Simple

Statistics

Subgroup-down

Summaries

Summaries for separate variables

Test variable list

Tools

Value-P

Weight linear regression
Plotagem de ajuste de linha

Criar dendograma

Média aritmética

Mediana ou Mediano

Avançar

Teste não-paramétrico

Plotagem de probabilidade normal, Diagrama de probabilidade normal

Números

Abrir

Opção

Tabela dinâmica

Assistente da tabela diâmica

Relatório da tabela dinâmica

Imprimir

Ler o nome da variável

Regressão

Plotagem de Resíduos

R-quadrado

Executar

Salvar como

Selecionar casos

Executar

Simples

Estatísticas

Subgrupo-abaixo

Resumos

Resumos das variáveis separadas

Lista das variáveis de teste

Ferramentas

Valor-P

Regressão linear ponderada 


\section{O Sistema CGIAR}

0 Grupo Consultivo sobre Pesquisa Agrícola Internacional (CGIAR) é uma associação informal de 41 doadores do setor público e privado que apóiam uma cadeia de 16 institutos de pesquisa agrícola internacional, sendo o Cifor o mais novo deles. 0 grupo foi estabelecido em 1971. Os centros do CGIAR são parte de um sistema de pesquisa agrícola global, o qual se empenha em aplicar a capacidade científica internacional para a resolução dos problemas das populações menos favorecidas do mundo.

\section{Cifor}

0 Cifor foi estabelecido sob o sistema do CGIAR em resposta às preocupações globais sobre as conseqüências econômicas, ambientais e sociais da perda e degradação das florestas. Ele opera através de uma série de parcerias altamente descentralizadas com instituições-chave e ou indivíduos nos países industrializados e em desenvolvimento. A natureza e duração dessas parcerias são determinadas pelos problemas específicos de pesquisa que estão sendo tratados. Esta agenda de pesquisa está sob revisão constante e, desta maneira, sujeita a mudanças quando os parceiros reconhecem novas oportunidades e problemas. 
O Guia de Pontuação e Análise para Avaliâro Bem-Estar Humano foi éláborádo para complementar o GBA e Os Acessórios. Inicialmente, este guia fornece umm método de pontuação que pode ser usado ao lado desses dois manuais. Este método ajuda ovavalíador a decidir sobre os criterios e indicadores específicos em ambientes florestais e humanos particulares. Em séguida, a seção sobre anălise orienta o usuário desde a montagem simples de uma planitha ate análises estatísticas mais complexas que podem ser necessárias em algumas circunstâncias. Equipes diferentes possuem diferentes necessidades por sofisticação quantitativa e estatística em suas análises. Este manual atende a essa variedade de necessidades.
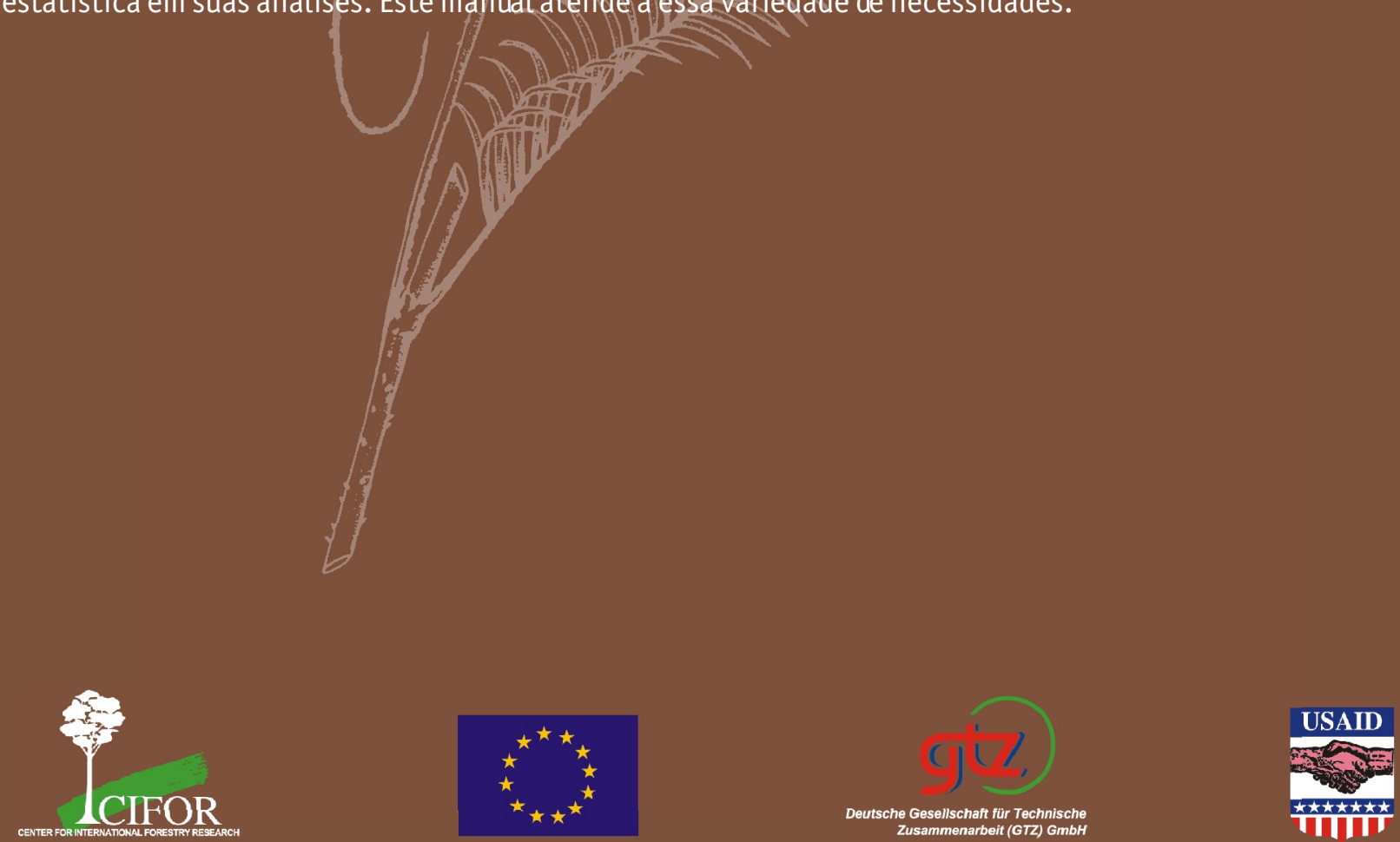